Universidade de São Paulo

Instituto de Física

\title{
EFEITO DE SOLVENTE NO ESPECTRO DE ABSORÇÃO DA 5-FLUOROURACIL. ANÁlISE DE DIFERENTES Procedimentos TEÓRICOS
}

\author{
Carlos Eduardo Bistafa da Silva
}

Dissertação apresentada ao Instituto de Física da USP para a obtenção do título de Mestre em Ciências

Orientador: Prof. Dr. Sylvio Canuto

Banca Examinadora:

Prof. Dr. Sylvio Canuto (IFUSP)

Profa. Dra. Lucy Vitória Credidio Assali (IFUSP)

Prof. Dr. Puspitapallab Chaudhuri (UFAM) 
AUTORIZO A REPRODUÇÃO E DIVULGAÇÃO TOTAL OU PARCIAL DESTE TRABALHO, POR QUALQUER MEIO CONVENCIONAL OU ELETRÔNICO, PARA FINS DE ESTUDO E PESQUISA, DESDE QUE CITADA A FONTE.

\section{FICHA CATALOGRÁFICA \\ Preparada pelo Serviço de Biblioteca e Informação do Instituto de Física da Universidade de São Paulo}

Silva, Carlos Eduardo Bistafa da

Efeito de Solvente no Espectro de Absorção da 5-Fluorouracil.

Análise de Diferentes Procedimentos Teóricos. São Paulo, 2011.

Dissertação (Mestrado) - Universidade de São Paulo.

Instituto de Física - Departamento de Física Geral

Orientador: Prof. Dr. Sylvio Roberto Accioly Canuto

Área de Concentração: Física

Unitermos: 1. Absorção; 2. Polarização; 3. Solvatocromismo;

4. S-QM/MM. 
Aos meus avós, Aparecida e Avelino pois sem seu apoio eu jamais teria chegado até aqui 



\section{Agradecimentos}

$>$ Primeiramente a Deus, pelo dom da vida e da saúde em mais uma encarnação bendita, onde tenho a oportunidade de me aprimorar e evoluir mais na direção de seus caminhos;

$>$ Aos meus pais e aos meus avós pelo apoio e incentivo dados e pelos incontáveis sacrifícios feitos para que eu pudesse estudar: sem eles não teria chegado até aqui;

$>$ Ao meu irmão pelo companheirismo nos momentos de lazer e dos hobbies compartilhados (leia-se vídeo-game, animes e mangás), momentos nos quais eu diminuía o estresse e esquecia as dificuldades;

$>$ Aos familiares, amigos e colegas, juntos nos risos e nas lágrimas;

> À USP, ao IF e mais especificamente ao Departamento de Física Geral e todos seus funcionários e colegas pelo agradável ambiente de trabalho propiciado e pelo suporte concedido;

$>$ Aos colegas das salas 223 e 306 da Ala I, pela ajuda, alegrias, discussões, piadas etc, que permitiram um bom convívio nas atividades diárias;

$>$ A todos os companheiros do Grupo de Física Molecular e Modelagem pelas discussões enriquecedoras, pela ajuda, dicas e pelos momentos alegres que dividimos;

$>$ À FAPESP pelo apoio financeiro em minha IC e no meu Mestrado;

$>$ E por último, mas especialmente, ao Prof. Dr. Sylvio Canuto por, naquele último mês do curso de Física V, ter me convidado para conhecer seu grupo e ter dado a oportunidade de trabalhar nele como seu aluno de IC (oportunidades sem os quais possivelmente eu teria seguido a ideia de desistir da carreira científica), pelos ensinamentos, conselhos e orientação (tanto em coisas acadêmicas como em coisas da vida), pelas discussões (que variavam desde a Mecânica Quântica aos resultados da última rodada do Brasileirão) pelas viagens (para congressos e para Bertioga) e caronas até a estação de trem Cidade Universitária, pelos livros presenteados e pelos livros emprestados (eu devolvi todos!), pelas 5 disciplinas em que interagimos (nas quais $3 \mathrm{eu}$ fui aluno e duas, monitor), pela apostila de Física Molecular (que ainda não acabamos de escrever) e de Mecânica Quântica (que espero um dia começarmos). Obrigado por ter estendido a mão para aquele menino questionador, sempre sentado na primeira carteira da fileira do meio da sala 202 da Ala Central, e ter feito parte do seu sonho de se tornar um cientista, ajudando-o a torná-lo realidade.

A todos meu muitíssimo e sincero obrigado. 

"Quantum Mechanics: The dreams that stuff is made of."

- Stephen Hawking - 



\section{Resumo}

A molécula 5-fluorouracil (5FU) é muito utilizada em tratamentos de câncer. Seu espectro de absorção é caracterizado por duas bandas de diferentes intensidades, as transições $n-\pi^{*}$ e $\pi-\pi^{*}$, e seu estudo em diferentes solventes é de considerável importância para compreender a fotofísica do estado excitado. Este é o primeiro passo essencial para obter a caracterização da dinâmica de emissão. Neste trabalho, nós estudamos teoricamente o espectro de absorção da $5 \mathrm{FU}$ em dois solventes, água e acetonitrila, usando o método Sequential Quantum Mechanics/ Molecular Mechanics (S-QM/MM). Uma etapa importante para uma simulação realista é a polarização do soluto pelo solvente. Neste estudo, esta polarização foi obtida usando dois modelos: Polarizable Continuum Model (PCM), que é uma alternativa simples e um método iterativo usando Average Solvent Electrostatic Configuration (ASEC). Após isso, simulações usando Monte Carlo Metrópolis no ensemble NVT em condições normais de temperatura e pressão foram realizadas e configurações estatisticamente descorrelacionadas separadas para subsequentes cálculos de Mecânica Quântica usando diversos métodos: Configuration Interaction (CI), Time Dependent Density Functional Theory (TD-DFT) e um método semi-empírico (INDO/CIS). Os espectros calculados em ambos os solventes foram obtidos em mais de uma aproximação: contínua, discreta e explícita. Os resultados estão em boa concordância com os valores experimentais e enfatizam a importância da inclusão de moléculas de solvente explícitas nos cálculos. Nós especialmente notamos que em solventes, a transição $n-\pi *$ é deslocada para o azul enquanto a transição $\pi$ - $\pi$ * é deslocada para o vermelho, indicando uma tendência para reversão dessas duas bandas se comparadas à fase gasosa. Isto aponta para diferenças na fotofísica, dependendo da polaridade do solvente. Os resultados também permitem uma avaliação dos diferentes procedimentos teóricos utilizados.

Palavras-chave: 5-fluorouracil, absorção, polarização, solvatocromismo, S-QM/MM. 



\section{Abstract}

The 5-fluorouracil molecule is very used in cancer treatment. Its absorption spectrum is characterized by two broad bands of different intensities, the $n-\pi^{*}$ and $\pi-\pi^{*}$ transitions, and its study in different solvents is of considerable importance for the understanding of the photophysics of the excited state. It is the first essential step for obtaining the characterization of the emission dynamics. In this work we have theoretically studied the absorption spectrum of $5 \mathrm{FU}$ in two solvents, water and acetonitrile, using the Sequential Quantum Mechanics/Molecular Mechanics method (S-QM/MM). An important step for a realistic simulation is the polarization of the solute by the solvent. In this study, this polarization was obtained by using two models: Polarizable Continuum Model (PCM), which is a simple alternative, and an iterative method using the Average Solvent Electrostatic Configuration (ASEC). After this, Monte Carlo Metropolis simulations in the NVT ensemble in normal conditions of temperature and pressure were made and statistically uncorrelated configurations sampled for the subsequent Quantum Mechanics calculations using several methods: Configuration Interaction (CI), Time Dependent Density Functional Theory (TD-DFT) and a semiempirical method (INDO/CIS). The calculated spectra in both solvents were obtained using more than one approach: continuum, discrete and explicit. The results are in good agreement with experimental values and emphasize the importance of explicitly including solvent molecules. We specially note that in solvents, the $n-\pi *$ is blue-shifted and the $\pi-\pi^{*}$ transition is red-shifted leading to a tendency for reversal of these two bands compared to gas phase. This points to differences in the photophysics, depending on the solvent polarity. The results also allow an evaluation of the different theoretical procedures used.

Keywords: 5-fluorouracil, absorption, polarization, solvatochromism, S-QM/MM. 



\section{Lista de Figuras}

Figura 1: Moléculas de 5-fluorouracil, uracil e timina.

pág. 1

Figura 2: Agência Nacional de Vigilância Sanitária (ANVISA) proibiu a utilização de medicamento à base de 5-fluoruracil por causar efeitos colaterais que não estavam indicados na bula. Após regularização, o medicamento voltou a ser liberado. pág. 2

Figura 3: O princípio de Franck-Condon - a absorção e a emissão são "verticais" (adaptada de [19]).

pág. 6

Figura 1.1: Nos modelos contínuos, uma molécula é posta dentro de uma cavidade e o solvente é representado por um contínuo descrito por sua constante dielétrica. pág. 10

Figura 1.2: O modelo PCM.

pág. 11

Figura 1.3: Representação esquemática do método QM/MM. As moléculas no centro são tratadas com Mecânica Quântica enquanto as demais (representadas por pontos roxos) são tratadas classicamente.

pág. 12

Figura 1.4: Representação esquemática do método S-QM/MM. Após uma simulação clássica, algumas configurações estatisticamente descorrelacionadas são separadas e analisadas (esquerda) permitindo assim a escolha a posteriori do que será tratado quanticamente (círculo). A propriedade de interesse é obtida como uma média simples (direita).

pág. 14

Figura 1.5: Caixa de simulação replicada em todas as direções e com condições periódicas de contorno (retirada de [23]). É mostrada replicação no plano xy apenas para melhor visualização, mas ela também é feita no eixo $z$.

pág. 15 
Figura 1.6: O potencial de Lennard-Jones (adaptado de [19]).

Figura 1.7: Organograma do procedimento iterativo usado para polarizar o soluto.

pág. 23

Figura 2.1: Construção da grade tridimensional usada no método CHELPG para ajustar cargas atômicas em moléculas. Como exemplo, utilizamos a molécula de água (extraída de [73]).

pág. 46

Figura 2.2: Grade usada pelo procedimento MK para calcular o potencial eletrostático que é usado para ajustar as cargas atômicas. A molécula de água é usada como exemplo (adaptada de [74]).

pág. 46

Figura 3.1: Tautômeros e rotâmeros da 5FU. Extraído de [77].

pág. 48

Figura 3.2: Energia de ativação dos três tautômeros mais estáveis da 5FU. Extraído de [77].

pág. 49

Figura 3.3: Geometria otimizada da 5FU em vácuo.

pág. 49

Figura 3.4: Função de distribuição radial de pares $G(r)$, considerando a distribuição de mínima distância, obtida simulando 5FU em meio solvente: a) água; b) acetonitrila. A quantidade de moléculas até uma dada distância é obtida integrando-se a curva até essa distância.

pág. 54

Figura 3.5: Ajuste da função de autocorrelação da energia para simulação de uma molécula de 5FU em 499 moléculas de solvente: a) água; b) acetonitrila. pág. 56

Figura 3.6: Uma das configurações utilizadas nos cálculos quânticos. Aqui, temos uma molécula de 5FU e 16 moléculas de água explícitas, com um EE composto por 238 moléculas de água que são representadas pelas cargas pontuais de seus átomos. pág. 58 
Figura 3.7: Médias convergidas para a transição $\pi-\pi^{*}$ de menor energia da $5 \mathrm{FU}$ em água. Apenas alguns níveis de tratamento são mostrados para uma melhor visualização, já que todos apresentam o mesmo comportamento.

pág. 60

Figura 3.8: Orbitais moleculares envolvidos na excitação da 5FU em água. pág. 61

Figura 3.9: Espectro de absorção e emissão da 5FU medido em acetonitrila (linha contínua) e em água (linha tracejada). Extraído de [84].

pág. 62

Figura 3.10: Médias convergidas para a transição $\pi-\pi^{*}$ de menor energia da $5 \mathrm{FU}$ em acetonitrila.

pág. 63

Figura 3.11: Orbitais moleculares envolvidos na excitação da 5FU em acetonitrila.

pág. 64

Figura 3.12: Convergência do momento de dipolo da $5 \mathrm{FU}$ em a) água e b) acetonitrila, obtida usando o procedimento iterativo. "Gás" indica que o dipolo foi obtido usando a geometria otimizada da molécula isolada; "PCM" indica que o dipolo foi calculado considerando o efeito de solvente nessa aproximação em geometria obtida também usando esse modelo; "PCM+MM/QM" significa que o dipolo foi calculado usando para representar o solvente o ASEC obtido após uma simulação de MC que usa os valores obtidos em "PCM" como ponto de partida. O momento de dipolo convergido é obtido ajustando aos dados uma função exponencial.

pág. 72

Figura 3.13: Espectro obtido a partir dos resultados teóricos com nível B3LYP/6$311++\mathrm{G}(\mathrm{d}, \mathrm{p})$ considerando o solvente explicitamente.

pág. 76

Figura 3.14: Orbitais moleculares envolvidos na excitação da 5FU isolada, obtidos com B3LYP. São similares ao obtidos em meio.

pág. 79

Figura 3.15: Diagrama ilustrando o processo de inversão das transições $n-\pi^{*}$ e $\pi$ - $\pi^{*}$ da molécula 5FU, quando em meio solvente, calculado com nível B3LYP. TD-DFT falha ao calcular a transição $\pi-\pi^{*}$ em água: outros métodos como CIS(D) mostram 
comportamento similar ao obtido experimentalmente (linha preta), onde a transição em água é menos energética que a transição em acetonitrila.

pág. 82 


\section{Lista de Tabelas}

Tabela 3.1: Parâmetros OPLS para os átomos da 5FU.

pág. 50

Tabela 3.2: Cargas (em Coulomb) e momentos de dipolo (em Debye) da 5FU otimizada em vácuo e em meio, obtidos usando CHELPG e MK.

pág. 51

Tabela 3.3: Modelo SPC para a água. Extraído de [25].

pág. 53

Tabela 3.4: Modelo para a acetonitrila. Extraído de [83].

pág. 53

Tabela 3.5: Transições de mais baixa energia da 5FU em água, considerando diferentes tratamentos para o solvente, obtidas com nível B3LYP/6-311++G(d,p). O resultado é a média convergida de 100 configurações que possuem uma correlação estatística de $8 \%$. Também são apresentados os resultados obtidos com PCM, ASEC e o valor experimental. Apesar de não mostrada, a terceira transição também foi calculada e sua energia é cerca de 0.2 a $1 \mathrm{eV}$ maior que a segunda, dependendo do modelo de solvente utilizado. A incerteza estatística não é apresentada por ser inferior a casa decimal exibida.

pág. 59

Tabela 3.6: Transições de mais baixa energia da 5FU em acetonitrila, considerando diferentes tratamentos para o solvente, obtidas com nível B3LYP/6-311++G(d,p). O resultado é a média convergida de 100 configurações que possuem uma correlação estatística de 4\%. Também são apresentados os resultados obtidos com PCM, ASEC e o valor experimental. Apesar de não mostrada, a terceira transição também foi calculada e sua energia é cerca de 0.7 a $1 \mathrm{eV}$ maior que a segunda, dependendo do modelo de solvente utilizado. A incerteza estatística não é apresentada por ser inferior a casa decimal exibida.

pág. 63 
Tabela 3.7: Variação da transição $\pi-\pi^{*}$ de menor energia da 5FU em acetonitrila com relação à transição em água. As incertezas são provenientes dos erros estatísticos. A incerteza no resultado experimental é inferior a casa decimal mostrada na tabela.

pág. 65

Tabela 3.8: Transições de mais baixa energia da 5FU em água e em acetonitrila, obtidas com nível B3LYP/6-311++G(2d,2p), tratando o solvente de maneira discreta e usando ASEC.

pág. 66

Tabela 3.9: Transições de mais baixa energia da $5 F U$ em água e em acetonitrila, obtidas com os funcionais PBE0, O3LYP e BHandHLYP, todos com a base 6$311++\mathrm{G}(\mathrm{d}, \mathrm{p})$, tratando o solvente de maneira discreta (para os dois primeiros) e usando ASEC (todos).

pág. 67

Tabela 3.10: Transições de mais baixa energia da $5 F U$ em água e em acetonitrila, obtidas usando CIS e CIS(D) com a base 6-311++G(d,p), tratando o solvente de maneira discreta e usando ASEC e com o método INDO/CIS, considerando o solvente explicitamente até uma distância de $8 \AA$.

pág. 69

Tabela 3.11: Transições de mais baixa energia da 5FU em água e em acetonitrila, cuja polarização foi obtida iterativamente. Os resultados foram obtidos usando B3LYP, representando o solvente por ASEC e moléculas explícitas, e BHandHLYP, CIS e CIS(D), representando o solvente por ASEC, todos com a base 6-311++G(d,p). pág. 73

Tabela 3.12: Transições de mais baixa energia da 5FU (otimizada com nível MP2/augcc-pVDZ) em água e em acetonitrila, obtidas usando B3LYP, representando o solvente por cargas pontuais, ASEC e moléculas explícitas, e CIS e CIS(D), representando o solvente por ASEC, todos com a base 6-311++G(d,p).

pág. 75

Tabela 3.13: Deslocamento da transição $\pi-\pi^{*}$ obtido da convolução dos resultados teóricos e comparação com os valores obtidos a partir das médias. Exceto quando indicado, a base utilizada foi 6-311++G(d,p).

pág. 77

Tabela 3.14: Transições de mais baixa energia da molécula 5FU isolada.

pág. 79

xviii 
Tabela 3.15: Dependência das transições $n-\pi^{*}$ e $\pi-\pi^{*}$ com interações nãoeletrostáticas; esta última é mais sensível a este tipo de interação. Apenas uma configuração escolhida ao acaso foi utilizada devido à alta demanda computacional para o método CIS(D)*. A base usada foi $6-311++G(d, p)$.

pág. 81 



\section{Lista de Siglas, Abreviaturas e Acrônimos}

\begin{tabular}{|c|c|}
\hline $5 \mathrm{FU}$ & 5-fluorouracil \\
\hline ANVISA & Agência Nacional de Vigilância Sanitária \\
\hline ASEC & Average Solvent Electrostatic Configuration \\
\hline a.u. & Atomic Units \\
\hline aug-cc-pVDZ & $\begin{array}{l}\text { Conjunto de bases do tipo correlation consistent com funções difusas } \\
\text { e polarizáveis }\end{array}$ \\
\hline B3LYP & $\begin{array}{l}\text { Funcional da densidade híbrido, com termo de troca de Becke com } 3 \\
\text { parâmetros e correlação de Lee, Yang e Parr }\end{array}$ \\
\hline $\mathrm{BO}$ & Born-Oppenheimer \\
\hline CHELPG & Charges from electrostatic potentials using a grid based method \\
\hline CI & Configuration Interaction \\
\hline CIS & CI considerando apenas excitações simples \\
\hline CIS(D) & CI considerando excitações simples, e duplas perturbativas \\
\hline c.p. & Cargas pontuais \\
\hline DFT & Density Functional Theory \\
\hline DH & Dunning e Huzinaga \\
\hline $\mathrm{DM}$ & Dinâmica Molecular \\
\hline DNA & Sigla em inglês para Ácido Desoxirribonucléico \\
\hline $\mathrm{EE}$ & Electrostatic Embedding \\
\hline $\mathrm{FC}$ & Franck-Condon \\
\hline GGA & Generalized Gradient Approximation \\
\hline GTO & Gaussian Type Orbital \\
\hline $\mathrm{HF}$ & Hartree-Fock \\
\hline HK & Hohenberg e Kohn \\
\hline HOMO & Highest Occupied Molecular Orbital \\
\hline IARC & International Agency for Research on Cancer \\
\hline INDO & Intermediate Neglect of Differential Overlap \\
\hline KS & Kohn e Sham \\
\hline LCAO & Linear Combination of Atomic Orbitals \\
\hline LDA & Local Density Approximation \\
\hline LSDA & Local Spin Density Approximation \\
\hline LJ & Lennard-Jones \\
\hline $\mathrm{LJ}+\mathrm{C}$ & Lennard-Jones + Coulomb \\
\hline LUMO & Lowest Unoccupied Molecular Orbital \\
\hline $\mathrm{MC}$ & Monte Carlo \\
\hline MDDF & Minimum Distance Distribution Function \\
\hline MK & Merz-Singh-Kollman \\
\hline MP2 & Teoria de Perturbação de Møller-Plesset de $2^{\mathrm{a}}$ ordem \\
\hline NPT & $\begin{array}{l}\text { Ensemble onde o número de partículas, a pressão e a temperatura são } \\
\text { constantes }\end{array}$ \\
\hline
\end{tabular}


Ensemble onde o número de partículas, a pressão e o volume são constantes

O3LYP Funcional da densidade híbrido, que é uma modificação do B3LYP feita por Handy

OMS Organização Mundial da Saúde

OPLS-AA Optimized Potentials for Liquid Simulations - All Atom.

PBE

PBE0

Funcional da densidade híbrido proposto por Perdew, Burke and Ernzerhof em 1997

Funcional da densidade híbrido que possui energia de troca proveniente de PBE e HF e correlação de PBE. Também chamado PBE1PBE

PCM Polarizable Continuum Model

PEM Potencial Eletrostático Molecular

QM Mecânica Quântica

QM/MM Quantum Mechanics/ Molecular Mechanics

RG Runge e Gross

RNA Sigla em inglês para Ácido Ribonucléico

RS

SCF

SEP

SCRF

Teoria de Perturbação de Rayleigh-Schrödinger

Self-Consistent Field

S-QM/MM Sequential Quantum Mechanics/ Molecular Mechanics

STO

Superfície de Energia Potencial

Self-Consistent Reaction Field

STO-XG

$\mathrm{T}$

Slater Type Orbital

Slater Type Orbitals approximated by X Gaussians

TD-DFT

TD-HF

TS

$\mathrm{U}$

UV-Vis

Timina

Time Dependent Density Functional Theory

Time Dependent Hartree-Fock

Thymidylate Synthetase, enzima responsável pelo equilíbrio entre

Timina e Uracil no organismo

Uracil

VWN

Região do Espectro Ultravioleta e Visível

Terceiro funcional para correlação local proposto por Vosko, Wilk e Nusair

VWN5 Quinto funcional para correlação local proposto por Vosko, Wilk e Nusair

ZDO Zero Differential Overlap 


\section{Sumário}

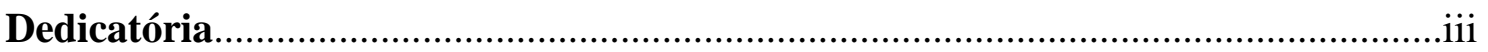

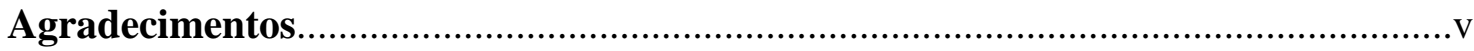

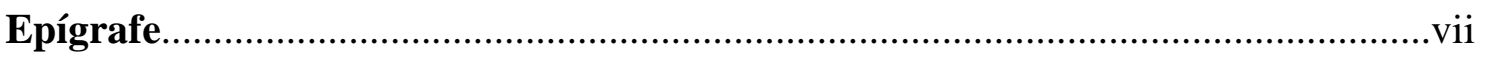

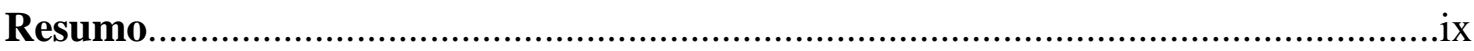

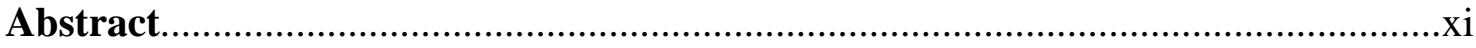

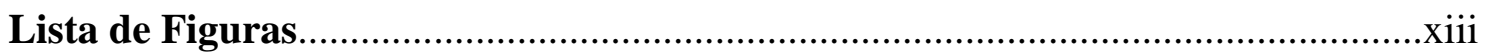

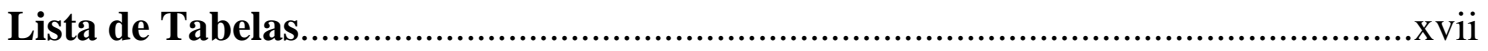

Lista de Siglas, Abreviações e Acrônimos.............................................................xi

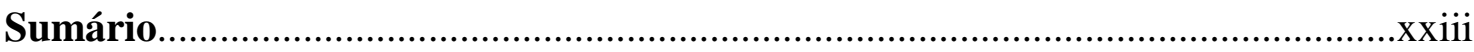

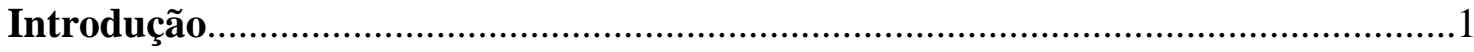

Absorção e Solvatocromismo............................................................................

Capítulo 1 - O método Sequential - Quantum Mechanics/ Molecular Mechanics.....9

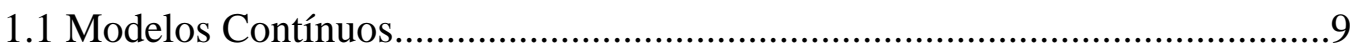

1.2 Métodos Quantum Mechanics / Molecular Mechanics.................................11

1.3 Método Sequential-QM/MM.............................................................13

1.3.1 A Simulação.............................................................................14

1.3.2 O Algoritmo de Monte Carlo Metrópolis......................................16

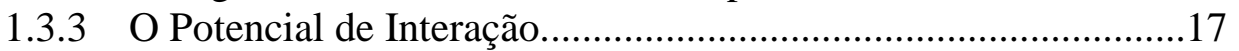

1.3.4 Análise da Simulação..............................................................20

1.3.5 Melhorando a descrição: Introduzindo polarização do soluto.....22

1.3.6 O futuro...............................................................................24 
2.1 Aproximação de Born-Oppenheimer...........................................................25

$2.2 \mathrm{O}$ método de Hartree-Fock......................................................................2.

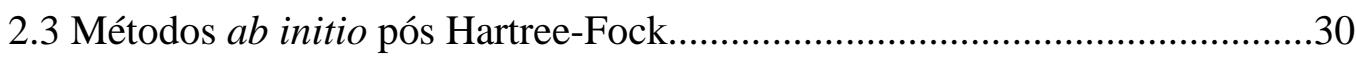

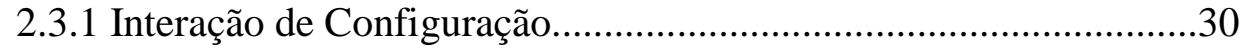

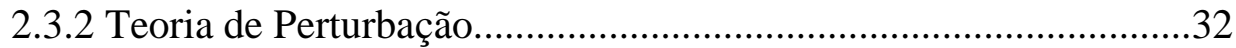

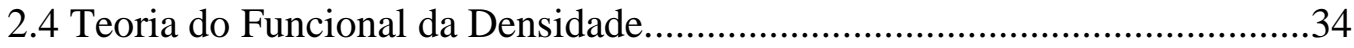

2.4.1 Teoria do Funcional da Densidade Dependente do Tempo.............36

2.4.2 Funcionais de Troca e Correlação.....................................................37

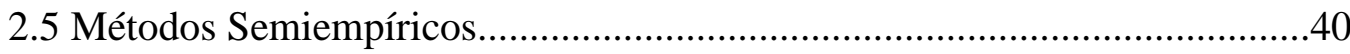

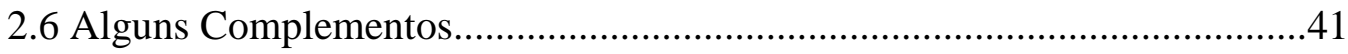

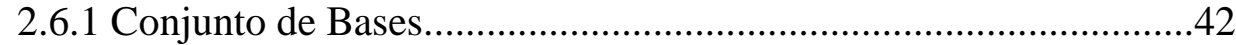

2.6.2 Métodos para calcular cargas atômicas parciais..............................45

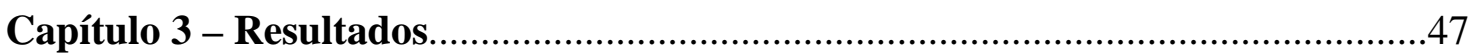

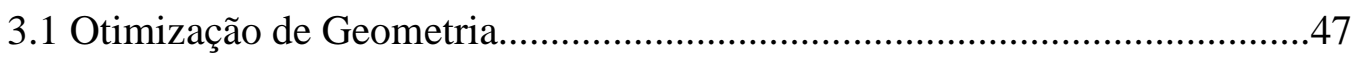

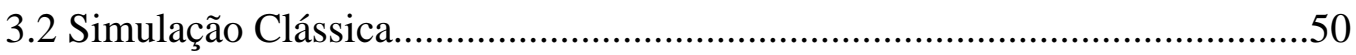

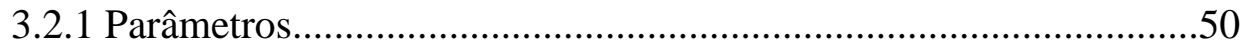

3.2.2 Simulação e Análise....................................................................53

3.3 Cálculos Quânticos e Resultados Obtidos..................................................57

3.3.1 Determinação do deslocamento espectral da transição de maior intensidade da 5FU em água e em acetonitrila..............................57

3.3.2 Inversão dos estados $n-\pi^{*}$ e $\pi$ - $\pi^{*}$ quando em meio solvente..........78

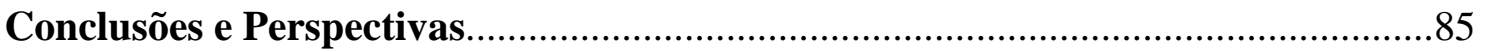

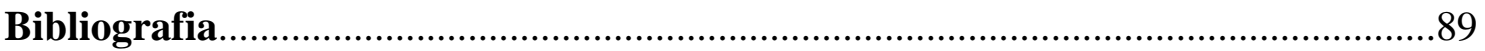




\section{Introdução}

Segundo os dados mais recentes da Agência Internacional de Pesquisa em Câncer (IARC) ${ }^{1}$, órgão ligado à Organização Mundial da Saúde (OMS), cerca de 12.7 milhões ${ }^{2}$ de casos de câncer foram registrados só no ano de 2008 [1], sendo essa a terceira principal causa de morte da população mundial $(12.6 \%)$, atrás somente de doenças cardiovasculares $(29.1 \%)$ e doenças infecciosas e/ou parasitárias (16.2\%). Nos últimos 40 anos, muitos esforços foram feitos para tornar mais eficientes os tratamentos, aumentando as chances de cura. Entre as muitas substâncias usadas, 5-fluorouracil (5FU) têm ganhado destaque, principalmente para os tratamentos de câncer de mamas ( $2^{\circ}$ em número de ocorrências e $5^{\circ}$ em mortalidade), cólon ( $3^{\circ}$ em ocorrência e $4^{\underline{0}}$ em mortalidade) e do trato aerodigestivo ${ }^{3}$.

A 5FU é um derivado da Uracil (U) e um análogo da Timina (T) (figura 1). Sua grande eficiência em reduzir tumores se dá principalmente por dois efeitos citotóxicos: falsificação do RNA e inibição da enzima thymidylate synthetase (TS) [2].<smiles>[R]c1c[nH]c(=O)[nH]c1=O</smiles>

$$
\mathrm{R}= \begin{cases}\mathrm{F}: & 5-\text { fluorouracil } \\ \mathrm{H}: & \text { Uracil } \\ \mathrm{CH}_{3}: & \text { Timina }\end{cases}
$$

Figura 1: Moléculas de 5-fluorouracil, uracil e timina.

$\mathrm{O}$ primeiro é de certa maneira intuitivo: injeta-se 5FU nas proximidades do tumor, que nada mais é do que um aglomerado de células se reproduzindo

\footnotetext{
${ }^{1}$ Todas as siglas e acrônimos utilizados neste trabalho estão definidos nas páginas xxi e xxii.

${ }^{2}$ Contrariando o padrão nacional, usaremos ponto como separador decimal.

${ }^{3}$ Órgãos e tecidos comuns aos sistemas digestivo e respiratório, como boca e traquéia.
} 
descontroladamente. A produção de novas células depende da replicação do RNA e do DNA. Com a alta demanda por bases nitrogenadas e devido a abundância de 5FU e sua similaridade com $\mathrm{U}$, a probabilidade de um ribossomo processar aquela no lugar dessa é muito grande. Quando esse RNA “falso" é usado para gerar um novo DNA, o ribossomo não é capaz de interpretar essa informação, e a célula morre antes de se reproduzir. Isso acarreta na autodestruição do tumor.

O segundo efeito, bem menos intuitivo está relacionado com o equilíbrio entre U e T. Como as células precisam de ambos para se reproduzir e em mesmo número, é natural que haja um equilíbrio entre ambas. Quando isso não ocorre a TS entra em ação, convertendo $\mathrm{T}$ em U. Porém 5FU é capaz de ligar-se ao sítio ativo dessa enzima, inibindo-a.

Essa dupla eficiência fez da 5FU um dos medicamentos mais utilizados para o tratamento de câncer. Entretanto, nem tudo é perfeito. A alta demanda de produção pode levar a erros graves como mostrado abaixo:

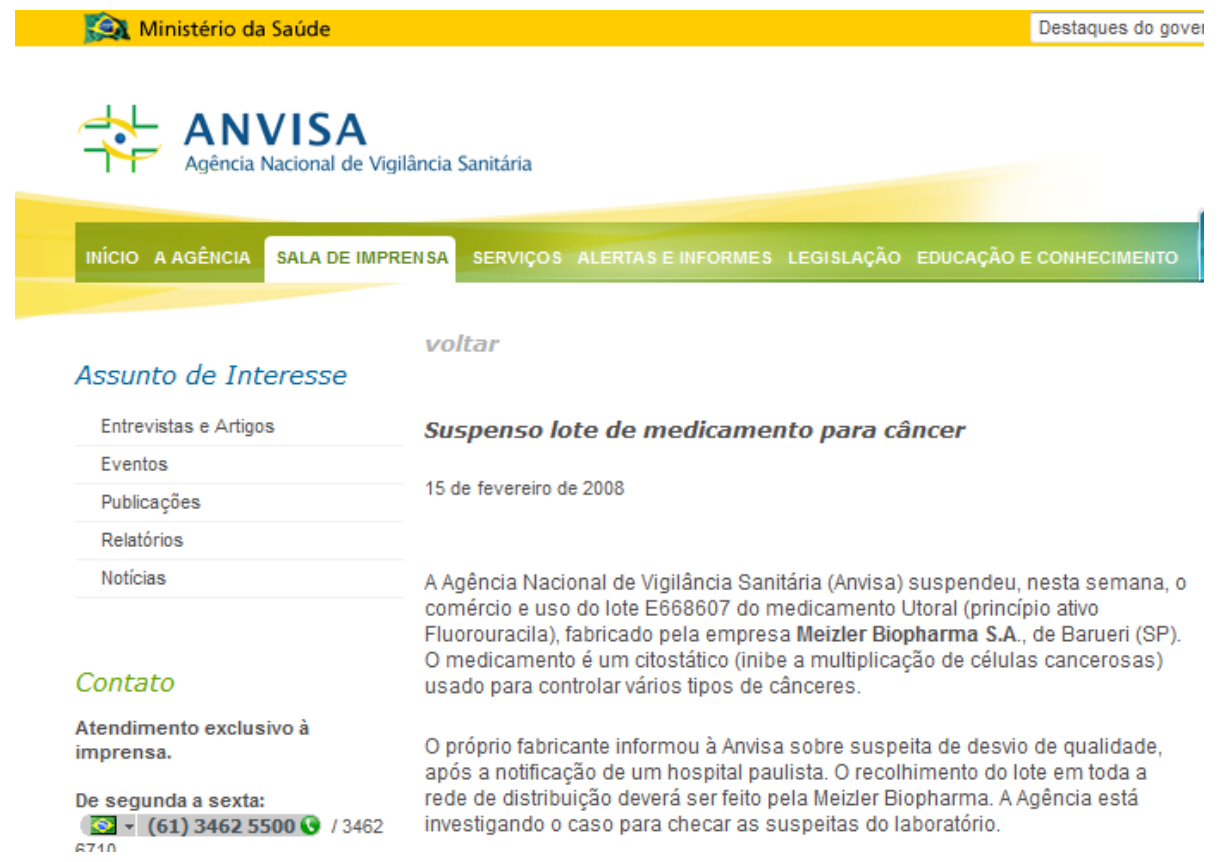

Figura 2: Agência Nacional de Vigilância Sanitária (ANVISA) proibiu a utilização de medicamento à base de 5-fluoruracil por causar efeitos colaterais que não estavam indicados na bula. Após regularização, o medicamento voltou a ser liberado.

Apesar de todos os avanços, grande parte dos fenômenos que ocorrem com a 5FU dentro do organismo ainda não é compreendida. O maior exemplo disso é a baixa 
resposta que 5FU apresenta em casos avançados de câncer de cólon, justamente aquele em que, no estágio inicial, ela apresenta a maior eficiência [2]. Muitos trabalhos e testes estão sendo realizados não só para solucionar questões em aberto como essa, como também propor novos métodos e medicamentos que, aliados à 5FU, melhorem a resposta do tratamento e diminuam o sofrimento dos pacientes.

Enquanto muitos estudos experimentais são feitos para compreender as reações biológicas nas quais a 5FU está envolvida, estudos teóricos a nível de Mecânica Quântica, principalmente usando métodos $a b$ initio, que possibilitariam um profundo entendimento teórico dessas reações, fazem-se impeditivos devido às limitações computacionais atuais.

Isso não impede, porém, que alguns avanços teóricos sejam feitos. Dentre eles, talvez o mais importante seja o estudo do comportamento deste tipo de molécula em meio solvente, principalmente água, uma vez que grande parte das reações de interesse biológico ocorre nesse meio [3-5].

De fato, muitos esforços têm sido feitos para entender a interação solutosolvente desde a década de 70, com a proposta do Campo de Reação Autoconsistente SCRF) por Tapia e Goscinski [6], inspirado nas idéias de Onsager [7] e Kirkwood [8]. Esse método foi a base para o que conhecemos hoje como modelos contínuos, dentre os quais se destaca o Modelo Contínuo Polarizável (PCM) [9] . Nesse tipo de abordagem, constrói-se uma cavidade contendo a molécula do soluto, que é tratada explicitamente, enquanto que o solvente é a região fora da cavidade, caracterizado por uma quantidade limitada de grandezas físicas como a constante dielétrica ou índice de refração. Os multipolos da molécula polarizam esse meio contínuo, gerando um campo que atua na molécula, rearranjando seus multipolos, levando ao procedimento iterativo SCRF. Obviamente um modelo simplificado como esse tem a vantagem de ser computacionalmente barato, mas traz consigo uma série de limitações, dentre as quais podemos destacar a dependência com o tamanho e forma da cavidade, a dificuldade de estudar solventes apolares e as falhas em descrever propriedades que tenham forte dependência de interações específicas como pontes de hidrogênio. Essas limitações levaram a busca de métodos mais sofisticados, mas que continuassem sendo computacionalmente viáveis.

Surgiram então métodos que tratavam o solvente de maneira discreta. Obviamente o custo computacional nesse caso é muito mais elevado, devido a grande quantidade de moléculas necessárias para se obter uma situação que descreva de 
maneira realística um líquido, o que torna cálculos inteiramente quânticos infactíveis até hoje, mesmo com o avanço e desenvolvimento dos computadores sendo cada vez maiores. Dessa forma, esses métodos envolvem aproximações para não incluir todas as moléculas nos cálculos quânticos, tratando uma parte classicamente e a outra quanticamente, ou seja, são métodos híbridos conhecidos como Quantum Mechanics/ Molecular Mechanics (QM/MM).

Usar QM/MM abre caminho para estudar as interações específicas solutosolvente e, aliado a sábias escolhas no nível quântico de tratamento, permite uma gama de possibilidades e estudos que os métodos contínuos não permitem. Entretanto uma nova questão se torna crucial: além da preocupação com a maneira que as partes clássica e quântica interagem, surge o problema da escolha de onde a separação deve ser feita. Em alguns casos isso pode ser imediato, como em uma enzima, onda a parte mais importante a ser considerada em um cálculo quântico é o seu sítio ativo. Mas quais ligações químicas devem ser cortadas? Isso é realista? E no caso de efeitos de solvente, o que é suficiente: as moléculas que fazem pontes de hidrogênio com o soluto? A primeira camada de solvatação? Há de se frisar que essa abordagem pode ser deveras cara, principalmente em sistemas líquidos, pois será necessário fazer grandes quantidades de cálculos clássicos seguidos de cálculos quânticos para se ter uma amostragem significativa do espaço de configurações.

Evitar esse tipo de problemas foi uma das motivações que levou à criação do Sequential - Quantum Mechanics/Molecular Mechanics (S-QM/MM), desenvolvido por Coutinho e Canuto há cerca de 10 anos [10,11]. Esse método consiste em fazer simulações clássicas usando o método de Monte Carlo (MC) e separar algumas poucas configurações mais relevantes e estatisticamente descorrelacionadas para posteriores cálculos usando Mecânica Quântica. As vantagens residem no baixo tempo computacional, na eliminação das dificuldades de tratamento entre as fronteiras clássica e quântica e no fato que a mesma simulação pode ser usada para o cálculo de mais de uma propriedade. Obviamente há desvantagens: só é possível obter valores médios, uma vez que o método MC não permite acompanhar a evolução temporal do sistema; usar MC também exige que o tratamento clássico seja feito na aproximação de molécula rígida, ou a taxa de aceitação de configurações seria muito baixa, tornando os cálculos muito longos.

O S-QM/MM tem se mostrado muito eficaz para se estudar o efeito de solvente e as alterações por ele causado no espectro de moléculas [10-18]. Assim, nesse 
trabalho, nós o utilizamos para estudar o espectro de absorção da 5FU em dois solventes, água e acetonitrila. A escolha desses solventes não é fortuita: ambos são polares, porém com constantes dielétricas bem distintas $\left(\varepsilon_{\text {agua }}=78.39 \mathrm{e}\right.$ $\varepsilon_{\text {acetonitrila }}=36.64$ ), além de acetonitrila ser aprótica, dando-nos possibilidade de entender as variações de seu espectro em ambientes diferentes. Como essa variação é muito pequena, nós a utilizamos para avaliar o comportamento e a precisão de alguns procedimentos teóricos de grande uso atualmente. Além disso, comparamos os resultados obtidos em meio solvente com a molécula isolada para entender alguns efeitos já observados com outras moléculas similares a 5FU, como as bases nitrogenadas.

\section{Absorção e Solvatocromismo}

As moléculas são compostas de núcleos, portadores de carga positiva, e elétrons, portadores de cargas negativas, o que permite que elas interajam com a radiação eletromagnética. Diferentes comprimentos de onda ocasionam diferentes fenômenos: micro-ondas leva às excitações rotacionais; infravermelho altera as vibrações; ultravioleta e visível (UV-Vis) excitam os elétrons. É nesse último fenômeno que vamos nos focar.

Quando uma molécula absorve luz UV-Vis (mais exatamente um fóton), a nova quantidade de energia precisa ser "acomodada" de alguma maneira. Isso ocorre com a promoção de um elétron para um orbital virtual, fazendo com que a molécula passe para o que chamamos de estado excitado. Essa promoção desencadeia um efeito cascata: os outros elétrons passam a sentir um campo diferente e necessitam se adaptar a essa nova conformação. Por último vêm os núcleos, que por serem muito mais pesados ${ }^{4}$, levam mais tempo para se adaptarem.

Nós acabamos de descrever (de modo informal) o princípio de Franck-Condon (FC): a absorção ocorre na molécula em sua geometria de mínima energia para o estado fundamental, que não é a geometria de mínima energia do estado excitado. A molécula necessita de um certo tempo para que sua geometria relaxe para o novo mínimo. Dessa

\footnotetext{
${ }^{4}$ Prótons e Nêutrons têm uma massa de $\approx 1.67 \times 10^{-27} \mathrm{Kg}$ enquanto os elétrons têm uma massa de $\approx 9.1 \times 10^{-31} \mathrm{Kg}$, ou seja, elétrons são cerca de 1830 vezes mais leves!
} 
forma, na absorção, a molécula passa de um ponto de mínimo em sua superfície de energia potencial (SEP) do estado fundamental para o ponto verticalmente correspondente em sua SEP do estado excitado (figura 3). Dizemos, por simplicidade, que a absorção é "reta" ou "vertical".

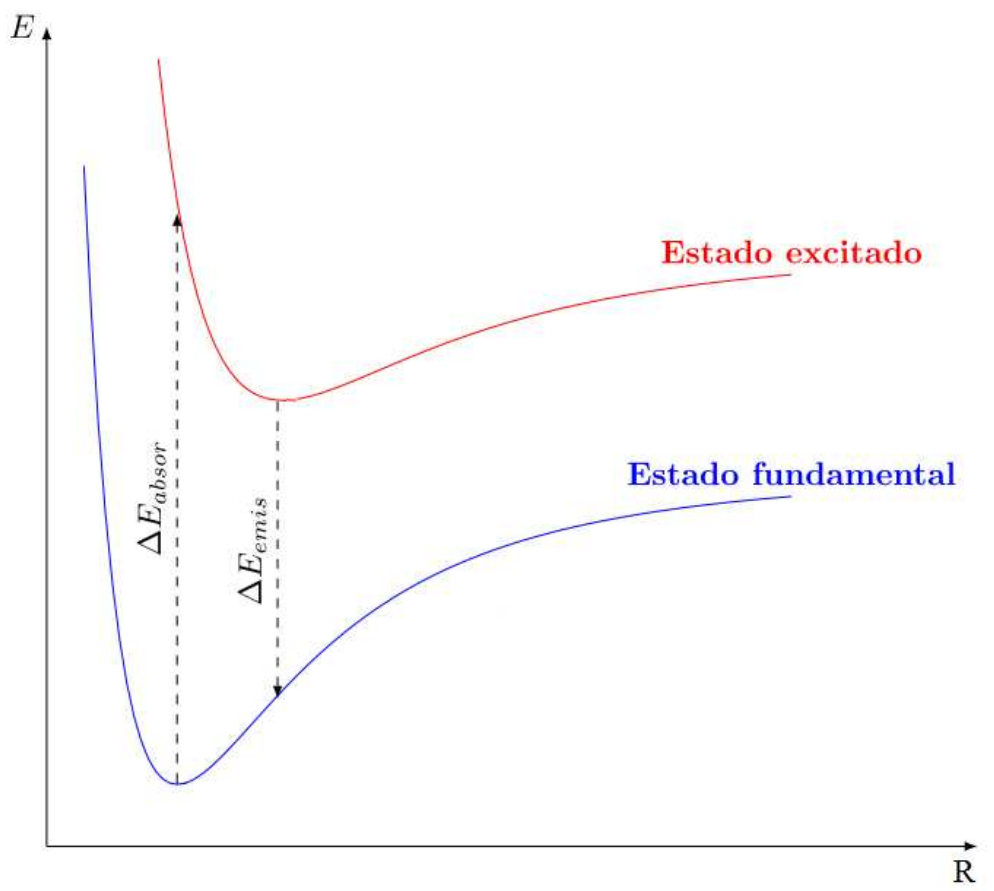

Figura 3: O princípio de Franck-Condon - a absorção e a emissão são "verticais" (adaptada de [19]).

O mesmo é verdade para a emissão: ela ocorre do mínimo da SEP do estado excitado para o ponto verticalmente correspondente da SEP do estado fundamental. A diferença entre os comprimentos de onda em que ocorrem a absorção e a emissão é dita deslocamento de Stokes.

$\mathrm{Na}$ linguagem da Mecânica Quântica, a transição de um estado vibrônico (vibracional $v+$ eletrônico $\varepsilon$ ) $|v \varepsilon\rangle$ para um estado $\left|v^{\prime} \varepsilon^{\prime}\right\rangle$ (é comum usar apostrofo para designar o estado final), após interagir com a radiação eletromagnética é descrita como [20]:

$$
\left\langle v^{\prime} \varepsilon^{\prime}|\mu| v \varepsilon\right\rangle=\int \psi_{v^{\prime}}^{*} \psi_{v} d^{3} R \int \psi_{\varepsilon^{\prime}}^{*} \mu_{\varepsilon} \psi_{\varepsilon} d^{3} r=S\left(v^{\prime}, v\right) \mu_{\varepsilon^{\prime} \varepsilon}
$$


onde $\mu$ é o momento de dipolo total (nuclear + eletrônico) da molécula, $\mu_{e}$ é o momento de dipolo eletrônico, $R$ são as coordenadas nucleares, $r$ as coordenadas eletrônicas, $\psi_{v}$ é a função de onda nuclear, $\psi_{e}$ é a função de onda eletrônica e estamos assumindo a aproximação de Born-Oppenheimer (vide seção 2.1). $S\left(v^{\prime}, v\right)$ é a integral de sobreposição de dois estados vibracionais, conhecida como Fator de Franck-Condon; o termo $\mu_{\varepsilon^{\prime} \varepsilon}$ indica que as transições não podem ocorrer entre dois estados quaisquer: dizemos então que há uma regra de seleção para as transições.

Cada transição é definida por duas características:

- O comprimento de onda $\lambda$ para o qual a transição ocorre, que pode ser calculado por

$$
\lambda=\frac{h c}{\Delta E},
$$

com $h\left(\cong 6.62 \times 10^{-34} \mathrm{Js}\right)$ a constante de Planck, $c\left(\cong 3 \times 10^{8} \mathrm{~m} / \mathrm{s}\right)$ a velocidade da luz no vácuo e $\Delta E$ a diferença de energia entre os estados inicial e final.

Note que como existem vários estados vibracionais associados a uma transição eletrônica, o que se observa não é uma única transição, mas sim uma larga distribuição ao redor de um pico;

- A intensidade, teoricamente representada pela grandeza adimensional

$$
f=\frac{2}{3}\left|\mu_{\varepsilon^{\prime} \varepsilon}\right|^{2} \Delta E_{\varepsilon^{\prime} \varepsilon}
$$

que é conhecida como força de oscilador e varia entre 0 e 1 (quanto mais próxima da unidade, mais intensa é a transição); experimentalmente a intensidade é obtida como a área sob o pico.

Solvatocromismo é um fenômeno intimamente relacionado com a absorção. Nós consideramos até agora que a molécula que está absorvendo está isolada. O que ocorrerá se a colocarmos em um meio? Primeiramente, a geometria sofrerá mudanças que acarretarão numa alteração do valor da energia. O mesmo ocorrerá com a energia 
necessária para excitá-la. Dessa forma a diferença de energia do estado fundamental para o estado excitado poderá ser maior ou menor que a diferença quando a molécula estava isolada. Se for maior, diremos que houve um deslocamento para o azul; caso contrário, temos um deslocamento para o vermelho. $\mathrm{O}$ aumento ou a diminuição na diferença de energia e o quão expressiva é essa variação vão depender da molécula e do meio em questão.

Esse fenômeno nós chamamos de solvatocromismo, uma palavra derivada do grego e que significa "ação do solvente na cor",

Dessa forma, o espectro de absorção de uma molécula em diferentes meios fornece informações sobre sua estrutura eletrônica e seu comportamento. Por isso nós o elegemos como propriedade a ser estudada, no intuito de melhor compreender a molécula 5FU.

\footnotetext{
${ }^{5}$ Solvato $=$ solvente chrômas $=$ cor $;$ ismos $=$ ação, efeito.
} 


\section{Capítulo 1}

\section{O método Sequential-QM/MM}

Como vimos brevemente, muitos métodos foram criados e têm sido aprimorados para se estudar teoricamente as alterações em propriedades de moléculas devido aos efeitos causados pela presença de solvente. Neste capítulo nós resumiremos algumas das principais abordagens e depois detalharemos o método Sequential - Quantum Mechanics / Molecular Mechanics (S-QM/MM), que foi por nós utilizado para descrever o espectro de absorção da molécula 5FU em meio solvente.

\subsection{Modelos Contínuos}

Com o desenvolvimento da Mecânica Quântica e o surgimento de métodos para tratar a repulsão eletrônica, o interesse e o número de estudos teóricos sobre moléculas cresceram, impulsionados também pelo advento dos computadores. Os estudos visavam o entendimento de propriedades estruturais, eletrônicas e espectroscópicas de moléculas isoladas. Entretanto, a quase totalidade das reações químicas de interesse acontece em solução. Para representar significativamente um sistema líquido, um grande número de moléculas é necessário a as limitações computacionais impediam (e impedem até hoje) o tratamento de um sistema quântico com um grande número de moléculas. Tornou-se necessário então o desenvolvimento de métodos, técnicas e aproximações para reduzir o número de cálculos de modo a possibilitar que os estudos se tornassem factíveis.

É difícil conceber uma teoria microscópica sobre a fase líquida da matéria pois, diferentemente do gás, em um líquido as moléculas não estão afastadas o suficiente para que seja possível desprezar suas interações, ao mesmo tempo que não estão próximas o suficiente para dar origem a ordenamentos e simetrias como na fase sólida. Resumindo, 
um líquido é um sistema denso e desordenado e é a combinação dessas características que tornam seu tratamento teórico mais complexo.

Como dissemos, o primeiro tratamento de interações de moléculas com solvente surgiu com os trabalhos de Tapia e Gocinski na década de 1970 [6] que, baseados nas idéias clássicas e semiclássicas de Onsager [7] e Kirkwood [8], desenvolveram o método campo de reação autoconsistente (SCRF). Nessa abordagem, a molécula é posta em uma cavidade cercada por um meio contínuo representado pela constante dielétrica (figura 1.1). O dipolo da molécula induz um dipolo nesse contínuo que por sua vez altera o dipolo da molécula, levando a um processo de autoconsistência, o que justifica o nome do método. A cavidade em geral é esférica ou elipsoidal, para facilitar a resolução.

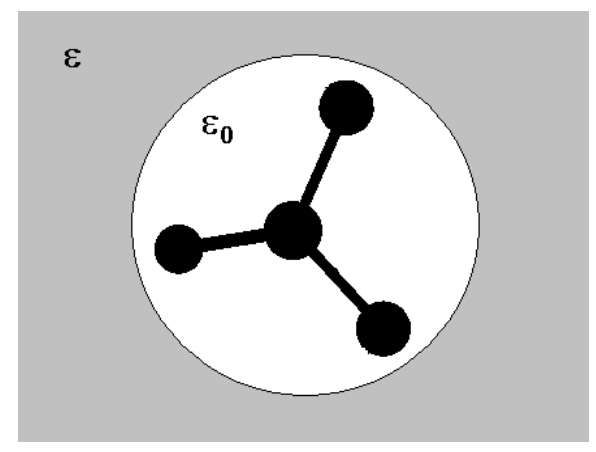

Figura 1.1: Nos modelos contínuos, uma molécula é posta dentro de uma cavidade e o solvente é representado por um contínuo descrito por sua constante dielétrica.

Esse modelo deu origem a muitos outros que apresentam melhores aproximações a fim de representar o solvente mais realisticamente (para uma excelente revisão de modelos contínuos vide [9]). Entre todos eles, o que mais se destaca é o Modelo Contínuo Polarizável (PCM). O PCM apresenta algumas melhorias em relação ao modelo original: a cavidade não é mais esférica, sendo formada pela união de esferas centradas nos átomos da molécula, cujo raio é tipicamente $20 \%$ maior que o raio de van der Waals do respectivo átomo, gerando assim uma superfície que possui a mesma forma da molécula. O PCM também tem um tratamento mais exato para a interação eletrostática com o meio envolvente, considerando, por exemplo, como o soluto gera uma densidade superficial de cargas aparente na superfície da cavidade (figura 1.2). A corrente implementação utiliza um formalismo de equações integrais, que torna o método muito eficiente computacionalmente [21]. 


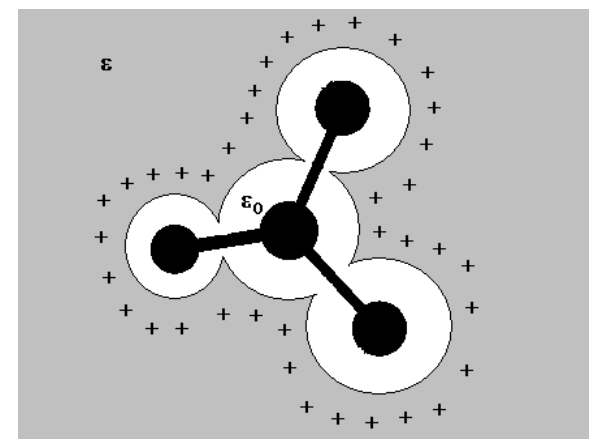

Figura 1.2: $\mathrm{O}$ modelo PCM.

Com a introdução dessas melhorias, o PCM se torna um método poderoso, permitindo o estudo de muitas propriedades de moléculas em meio solvente. Porém o método possui suas limitações. Desde seu surgimento, os autores ressaltam que o método é uma boa aproximação para moléculas com grande momento de dipolo e cuja interação com o meio seja predominantemente eletrostática. Sistemas onde interações específicas, como pontes de hidrogênio, desempenhem papel crucial tendem a ser mal descritos. Transferência de carga do soluto para o solvente, e vice-versa, também não é considerada, uma vez que não há elétrons no solvente.

\subsection{Métodos Quantum Mechanics / Molecular Mechanics}

Diante das limitações apresentadas pelo modelo contínuo, um tratamento explícito por vezes se faz necessário. Devido ao alto custo computacional exigido para tratar grandes quantidades de moléculas, vários métodos e aproximações surgiram como alternativa para reduzir o número de moléculas explícitas, sem prejudicar significativamente os resultados.

Uma abordagem que tem se tornado cada vez mais frequente é a combinação de cálculos quânticos e simulações clássicas. Por combinarem mecânica clássica e quântica esses métodos são ditos híbridos e são conhecidos pela sigla QM/MM: Quantum Mechanics / Molecular Mechanics.

De um modo geral, num procedimento QM/MM inicialmente escolhe-se uma parte pequena para tratar quanticamente, deixando o restante para ser tratado através da Mecânica Clássica (figura 1.3). Essa é a primeira dificuldade do método: como escolher a parte crucial que deve ser tratada com os métodos de Mecânica Quântica. O que é suficiente ou (estritamente necessário) para calcular certa propriedade de uma molécula 
em solução: as moléculas de solvente que fazem pontes de hidrogênio com o soluto? A primeira camada de solvatação? E se a escolha não envolver o número de moléculas e sim a parte de uma delas, por exemplo, se o soluto for grande, uma enzima talvez: tratar seu sítio ativo é o suficiente? E que ligações químicas cortar? Isso é realista?

Depois de definido o subsistema que será tratado quanticamente, o segundo passo, tão importante quanto e intimamente relacionado com o primeiro, diz respeito à maneira como acoplar as interações das partes clássica e quântica. É essa parte do tratamento que difere os vários métodos QM/MM.

Uma vez definidos esses passos básicos, alguns problemas persistem: os cálculos ainda podem ser caros, pois a parte clássica é tratada através de simulações usando o método de Monte Carlo ou Dinâmica Molecular, e essas simulações exigem um grande número de passos para serem representativas. Como um cálculo quântico é feito a cada passo clássico, a exigência computacional total pode ser equiparada a de um cálculo puramente quântico de um sistema grande. Mais que isso, como os cálculos são feitos durante a simulação (on-the-fly), não há garantias da convergência da mesma, o que representa um sério risco (um vôo cego...).

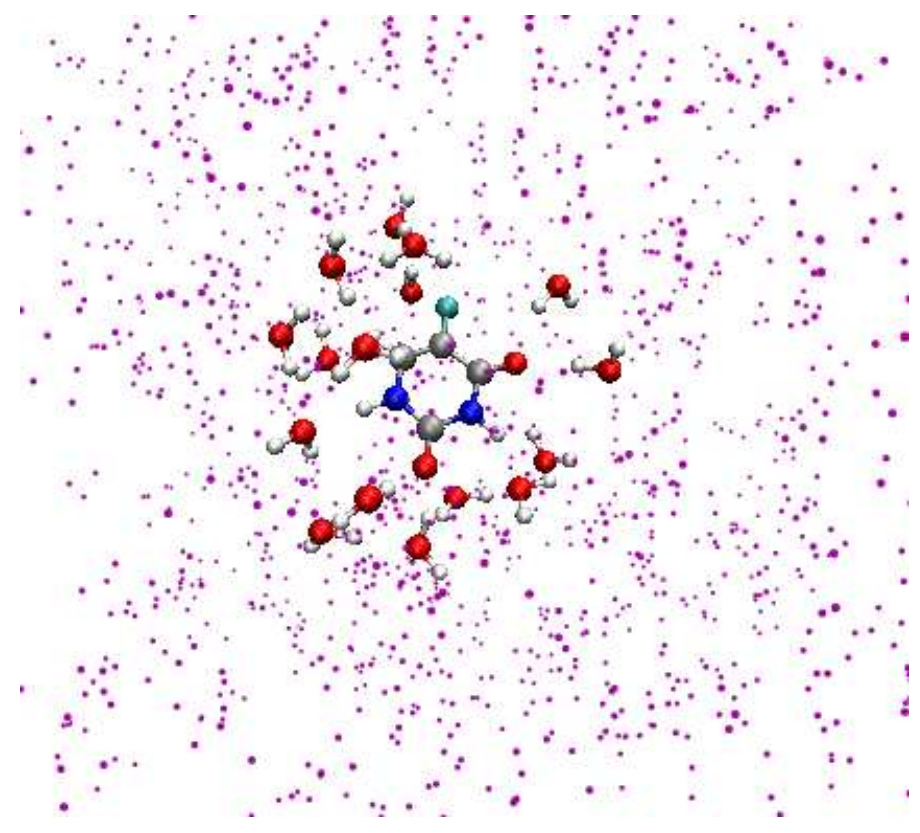

Figura 1.3: Representação esquemática do método QM/MM. As moléculas no centro são tratadas com Mecânica Quântica enquanto as demais (representadas por pontos roxos) são tratadas classicamente. 


\subsection{Método Sequential - QM/MM}

Para evitar estes problemas e tornar os cálculos mais eficientes, Canuto e Coutinho desenvolveram o Sequential - Quantum Mechanics / Molecular Mechanics (S-QM/MM) [10,11], como uma alternativa ao QM/MM convencional.

Como o nome sugere, no S-QM/MM as partes clássica e quântica são calculadas de modo desacoplado e em sequência: somente após a conclusão das simulações clássicas é que os cálculos quânticos são realizados. Isto traz várias vantagens:

- Garante que os cálculos quânticos serão feitos a partir de uma simulação clássica convergida;

- Permite a escolha de apenas uma pequena amostra das configurações geradas pela simulação clássica, baseando-se no fato que de um passo para outro, as configurações mudam muito pouco e, portanto, os valores quânticos obtidos assim são pouco significativos para a média. Isso reduz os cálculos quânticos de centenas de milhares para apenas algumas poucas dezenas (geralmente algo entre 60 e 150 cálculos);

- Uma mesma simulação pode ser usada para a determinação de mais de uma propriedade quântica;

- O recorte da parte quântica é feito a posteriori, permitindo uma maior liberdade de escolha; além disso, não há mais dificuldades em tratar a fronteira entre as partes clássica e quântica.

Obviamente o método não goza apenas de vantagens. A principal desvantagem é que fazendo os cálculos de maneira sequencial, não há polarização do soluto pelo solvente. Uma proposta (que discutiremos a seguir) visa corrigir isso. A princípio, a parte clássica poderia ser feita com Dinâmica Molecular ou Monte Carlo; porém originalmente, tradicionalmente (inclusive nesse trabalho) e para reduzir ainda mais o esforço computacional nós usamos apenas Monte Carlo, então o S-QM/MM herda as desvantagens desse método também: por ser um método estocástico, apenas valores médios podem ser calculados; para não reduzir a eficiência do algoritmo de Metropolis, (veja a seguir) as moléculas são tratadas como rígidas durante toda simulação.

Uma vez que esse foi o método que utilizamos, vamos detalhá-lo melhor. 

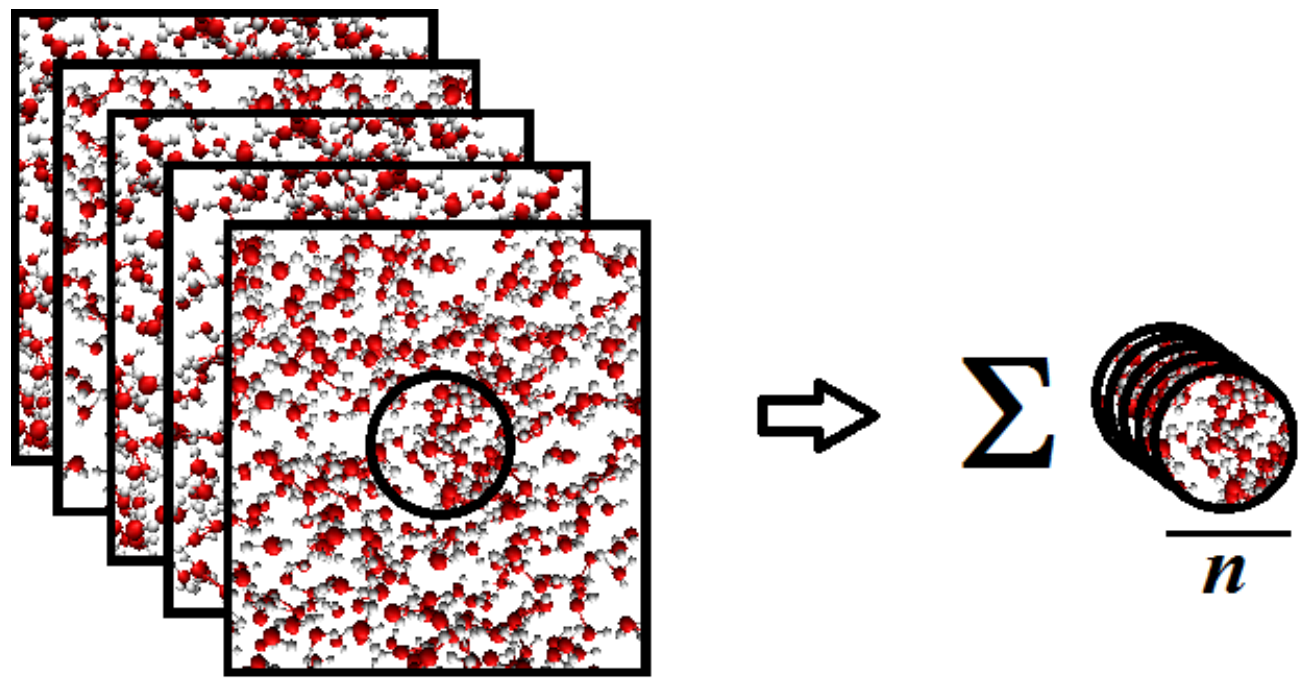

Figura 1.4: Representação esquemática do método S-QM/MM. Após uma simulação clássica, algumas configurações estatisticamente descorrelacionadas são separadas e analisadas (esquerda) permitindo assim a escolha a posteriori do que será tratado quanticamente (círculo). A propriedade de interesse é obtida como uma média simples (direita).

\subsubsection{A Simulação}

Para as simulações nós utilizamos o programa DICE [22], desenvolvido em nosso grupo. Inicialmente o programa gera uma configuração de maneira aleatória ou ordenada (o que for mais conveniente para o estudo que se irá realizar) com a quantidade de moléculas desejada distribuídas em uma caixa cúbica, gerada de acordo com a pressão ou densidade fornecida.

Para evitar efeitos de borda, a caixa é replicada em todas as direções, procedimento conhecido como Método das Imagens, garantindo que cada molécula esteja inserida no mesmo ambiente que as demais e levando a condições periódicas de contorno: se uma molécula sair por um lado da caixa, sua réplica será imediatamente reintroduzida no lado oposto (figura 1.5). Essa periodicidade é indesejável, pois permite que uma molécula interaja ao mesmo tempo com uma réplica e a própria molécula que a originou. Para evitar isso, define-se um raio de corte $r_{c}$ (que no máximo possui a metade do valor do lado da caixa), distância além da qual não se computa mais nenhuma interação. Analogamente, há um raio de sobreposição $\left(r_{\text {overlap }}=0.8 \AA\right.$ ): se a distância entre dois átomos de moléculas distintas em dada configuração é menor que o raio de sobreposição, a configuração já é rejeitada, pois para uma distância tão pequena a 
repulsão será muito forte, aumentando a energia da configuração e, consequentemente, sua probabilidade de não ser aceita. Frisamos aqui que apesar da utilização das imagens nos cálculos, apenas as moléculas na caixa original compõem a configuração salva.

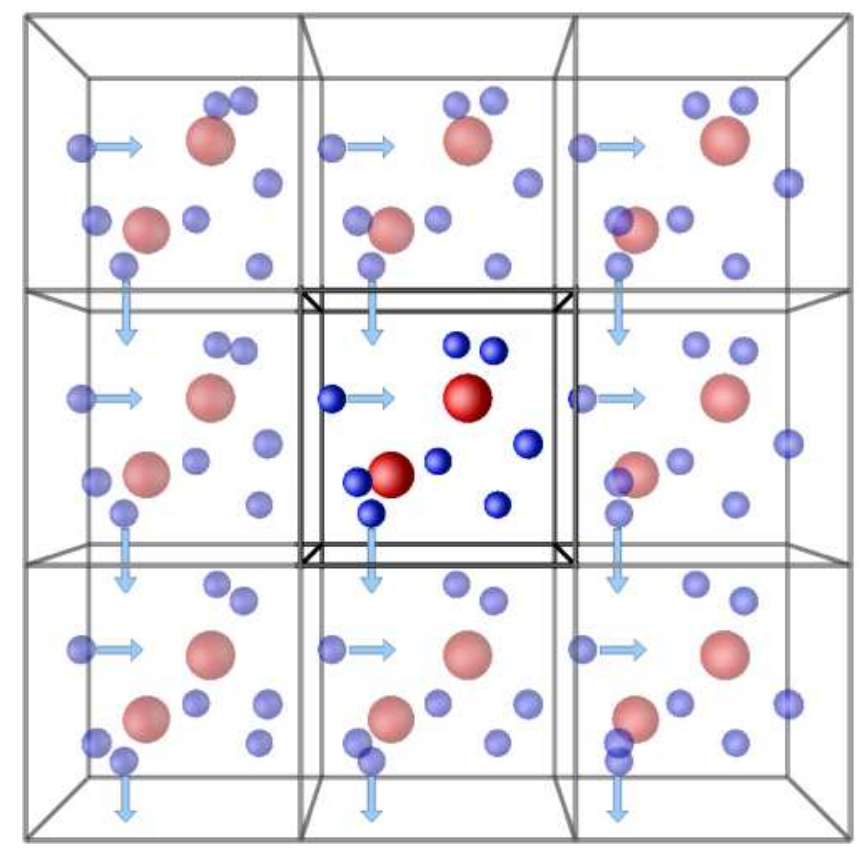

Figura 1.5: Caixa de simulação replicada em todas as direções e com condições periódicas de contorno (retirada de [23]). É mostrada replicação no plano xy apenas para melhor visualização, mas ela também é feita no eixo $z$.

Para realizar a simulação, também deve se optar entre um dos seguintes ensembles: isotérmico-isobárico (número de partículas, pressão e temperatura fixos $N P T$ ) ou canônico (número de partículas, volume e temperatura fixos - NVT). No limite termodinâmico $(N \rightarrow \infty)$ todos os ensembles são idênticos, mas a simulação é finita, o que pode implicar que para certas propriedades um ensemble pode ser mais vantajoso que outro.

Antes da simulação propriamente dita, uma etapa de termalização é realizada para que o sistema atinja o equilíbrio térmico e cujas configurações não entram na composição da média. Como a configuração inicial tem em geral uma energia muito alta (devido à proximidade irreal de algumas moléculas), nos primeiros passos da termalização um resfriamento (coolstep) é realizado, onde a próxima configuração gerada só é aceita se diminuir a energia. Após esse procedimento, a geração de uma nova configuração passa a ser através de um processo Markoviano, seguindo o 
algoritmo de Metropolis. Vale ressaltar que, como as configurações da termalização não farão parte da composição das propriedades médias, ela não necessariamente precisa ser realizado no mesmo ensemble em que será realizada a simulação.

\subsubsection{O Algoritmo de Monte Carlo Metropolis}

Para gerar as configurações, o programa utiliza o algoritmo de Monte Carlo Metropolis [24], já consagrado em muitos métodos estocásticos. A ideia é a seguinte:

1) Partindo-se da configuração inicial, seleciona-se uma molécula. Diferentemente da proposta original de Metropolis, onde essa seleção é aleatória, nós selecionamos de forma sequencial, que é equivalente, mas com a vantagem de se gerar menos números aleatórios. Sorteia-se então uma distância para transladar o centro de massa dessa molécula e em seguida um eixo e um ângulo entre $-15^{\circ} \mathrm{e}$ $15^{\circ}$ para realizar-se uma rotação. No ensemble NPT o volume também é variado, sorteando-se um incremento para os lados da caixa;

2) Calcula-se a energia dessa nova configuração: se ela for menor que a energia da configuração anterior, a configuração é aceita de imediato e retorna-se ao primeiro passo;

3) Se a energia é maior, calcula-se a probabilidade de transição de uma configuração para a outra e sorteia-se um número aleatório entre 0 e 1: se a probabilidade é maior que esse número, aceita-se a configuração; caso contrário, mantém-se a configuração anterior. Retorna-se então ao primeiro passo.

Uma vez que todas as moléculas passem por esse ciclo, temos um passo de Monte Carlo. O processo é dito Markoviano, pois cada configuração assim gerada só depende dela mesma e da anterior.

Para que ao sistema seja permitido acessar várias configurações, de modo a melhorar a amostragem do espaço de configurações, as simulações são tipicamente longas, da ordem de $10^{5}$ passos/molécula.

Aqui vale ressaltar porque MC é usado com a aproximação de moléculas rígidas. Considere a possibilidade de elas serem flexíveis: nesse caso, teríamos que considerar variações translacionais e orientacionais em cada sítio. Isto acarretaria em conformações indesejadas (porém muito prováveis) onde poderíamos ter átomos muito próximos, 
quebras de ligações poderiam ser irreais etc, tornando a energia alta e contribuindo para que grande parte das configurações fosse rejeitada, tornando as simulações muito longas para adquirir uma amostragem significativa. Para impedir estes eventos, poderíamos restringir o deslocamento translacional e rotacional a valores bem pequenos, mas isso novamente tornaria a simulação muito longa, pois muitos passos seriam necessários para se obter diferenças significativas entre uma configuração e outra. Assim, atribuir flexibilidade as moléculas mina uma das principais características do método MC que é o baixo custo computacional.

\subsubsection{Potencial de Interação}

Falamos em energia, mas ainda não dissemos como ela é calculada. Em sua forma mais geral, a energia de interação pode ser escrita como

$$
U=U_{\text {intra }}+U_{\text {inter }},
$$

onde $\mathrm{o}$ primeiro termo se refere às interações intramoleculares e o segundo às intermoleculares. Como estamos dentro da aproximação de moléculas rígidas, a energia intramolecular de cada molécula é sempre a mesma em todos os passos.

O termo restante, referente às interações intermoleculares, pode ser decomposto em várias contribuições: interação de dois corpos, de três corpos etc. Entretanto, para sistemas sem orientação preferencial, como ocorre em líquidos, a contribuição para a energia devida à interação de três corpos ou mais é muito pequena [24]. Dessa forma, o cálculo da energia é feito considerando apenas dois corpos, o que nos leva a

$$
U=\sum_{i=1}^{N_{a}} \sum_{j=1}^{N_{b}} U_{i j}
$$

sendo $N_{a}$ e $N_{b}$ o número de sítios ativos das moléculas $a$ e $b$, respectivamente. Note que esse número não necessariamente é igual ao número de átomos em cada molécula: ele pode ser inferior, quando aproximamos um grupo de átomos ou a molécula inteira por um único sítio, em geral para aumentar a eficiência computacional (como no modelo SPC para água [25], onde o único sítio está centrado no Oxigênio) ou maior, um 
artifício geralmente usado para melhor representar a distribuição de cargas ou outra propriedade (é o que ocorre com os modelos TIP4P[26] e TIP5P[27], ambos para água também, mas que contém 4 e 5 sítios ativos respectivamente).

Para representar o potencial $U_{i j}$, nós usamos a soma do potencial de LennardJones e Coulomb $(\mathrm{LJ}+\mathrm{C})$ :

$$
U_{i j}=4 \varepsilon_{i j}\left[\left(\frac{\sigma_{i j}}{r_{i j}}\right)^{12}-\left(\frac{\sigma_{i j}}{r_{i j}}\right)^{6}\right]+\frac{q_{i} q_{j}}{r_{i j}}
$$

com $\sigma_{i j}=\sqrt{\sigma_{i} \sigma_{j}}, \varepsilon_{i j}=\sqrt{\varepsilon_{i} \varepsilon_{j}}$, onde $\sigma_{i}$ e $\varepsilon_{i}$ são os parâmetros Lennard-Jones do sítio $i$ e $q_{i}$ é a carga deste mesmo sítio (análogo para $j$ ); $r_{i j}$ é a distância entre os dois sítios.

O potencial de Coulomb representa as interações eletrostáticas enquanto as demais são representadas por Lennard-Jones (LJ). O potencial LJ possui dois termos: o termo atrativo possui uma dependência com o inverso de $r^{6}$ e corresponde aos termos de van der Waals, que descrevem a atração a longas distâncias. O termo positivo está associado à repulsão a curtas distâncias, devida tanto a repulsão coulombiana quanto ao princípio de exclusão de Pauli, porém sua dependência com o inverso de $r^{12}$ não têm demonstração e vêm de ajustes de dados experimentais. Aparentemente, usar 10 ou 11 ao invés de 12 fornece um ajuste tão bom quanto: o único comportamento necessário parece ser um rápido crescimento do potencial a curtas distâncias. Lennard-Jones testou valores entre 5 e 25 e concluiu que usando 12 obtinha as melhores aproximações para diversas grandezas [28]. A preferência por esse expoente se mantém hoje também por outro motivo: eficiência computacional. Adotando a dependência com o inverso de $r^{12}$, o termo repulsivo se torna o quadrado do termo atrativo, reduzindo o número de cálculos para interações não-eletrostáticas.

Os parâmetros $\varepsilon$ e $\sigma$ estão relacionados, respectivamente, à profundidade do poço de potencial (ou seja, a intensidade da interação) e a distância (finita) para a qual o potencial de interação se torna nulo (figura 1.6). Em geral, esses parâmetros são ajustados para reproduzir valores experimentais ou dados de cálculos quânticos. 


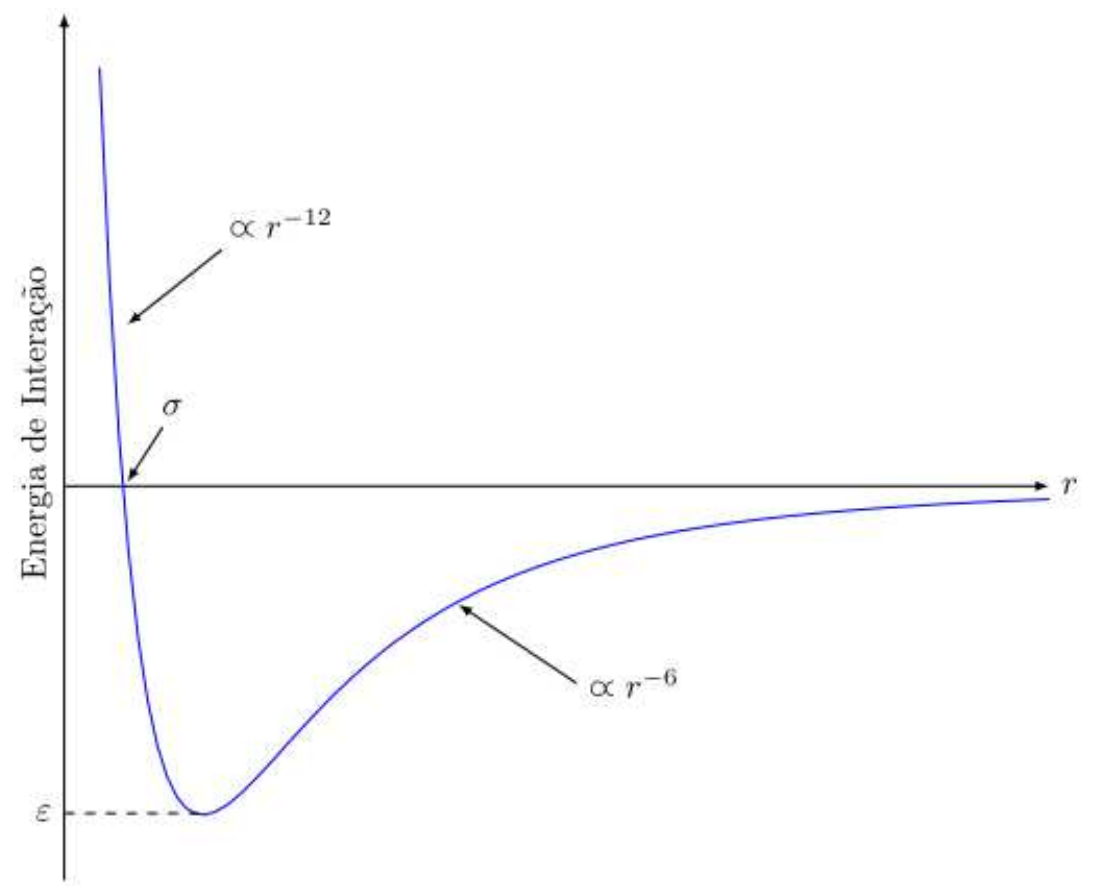

Figura 1.6: O potencial de Lennard-Jones (adaptado de [19]).

Assim, para realizar as simulações, o programa DICE precisa, além da geometria da molécula, dos parâmetros LJ e das cargas de cada sítio. De um modo geral, para o soluto, a geometria é obtida por cálculos quânticos; para os parâmetros LJ nós utilizamos o campo de força OPLS-AA [29,30]; as cargas são obtidas através de ajustes vindos de cálculos quânticos (mais detalhes na seção 2.6.2). Para o solvente nós utilizamos modelos consagrados na literatura (como SPC, TIP3P etc), que já apresentam geometria, parâmetros LJ e cargas otimizados de forma conjunta para reproduzir determinadas propriedades termodinâmicas em certos intervalos de pressão e temperatura.

A última consideração a ser feita é que para compensar o raio de corte, é necessária uma correção de longo alcance para a energia $\left(U_{C L A}\right)$. O programa DICE corrige apenas as interações correspondentes ao potencial LJ, através da expressão:

$$
U_{C L A}=\sum_{a} \sum_{b>a} \sum_{i}^{e m a} \sum_{j}^{e m b} \frac{8}{9} \pi N \rho \varepsilon_{i j} \sigma_{i j}^{3}\left[\left(\frac{\sigma_{i j}}{r_{c}}\right)^{9}-3\left(\frac{\sigma_{i j}}{r_{c}}\right)^{3}\right],
$$

Correções de longo alcance para o potencial de Coulomb são computacionalmente dispendiosas e por isso não são calculadas, uma boa aproximação para sistemas 
moleculares não carregados (para uma discussão mais ampla, bem como a demonstração da expressão 1.4, veja o capítulo 3 de [28]).

\subsubsection{Análise da Simulação}

Uma vez concluída a simulação, dispomos de um número imenso de configurações. Obviamente é impraticável e indesejável analisá-las separadamente. Nós nos atemos a algumas propriedades para extrair informações da simulação. As duas principais são:

- Função de Distribuição Radial de Pares $G(r)$ :

Essa função nos dá informação sobre a distribuição de moléculas de solvente em torno do soluto e pode ser obtida experimentalmente por difração de raios-X e nêutrons [28,31]. A $G(r)$ fornece a probabilidade de se encontrar um par de átomos a uma dada distância $r$ relativa à probabilidade de se encontrar o mesmo par em uma distribuição aleatória de mesma densidade (conhecida como distribuição de gás ideal). Ela pode ser calculada através da expressão:

$$
G(r)=\frac{N(N-1)}{\rho^{2} Z} \int \wp d \vec{r}_{n-2}
$$

onde $N$ é o número de moléculas, $\rho$ é a densidade, $Z$ é um fator de normalização e $\wp$ é a distribuição de probabilidades do ensemble no qual a simulação foi realizada $\left(\wp_{N V T}=e^{-U / k T}\right.$ e $\left.\wp_{N P T}=e^{-(U+P V) / k T}\right)$. A notação para o elemento diferencial indica que a integração é feita sobre todos os átomos, exceto os dois que definem o par que está sendo analisado.

O número de moléculas até uma dada distância é obtido integrando-se $G(r)$ sobre o volume esférico até essa distância.

$$
N=\frac{1}{V} \int_{V} G(r) r^{2} d V
$$


Na simulação, essas grandezas são determinadas na ordem inversa: a $G(r)$ é calculada usando o histograma de distância dos pares $i$ e $j$,

$$
G(r)=\frac{n_{i j}(r, r+d r)}{n_{\text {ideal }}(r, r+d r)},
$$

onde $n_{i j}$ é o número de pares $i j$ separados por uma distância entre $r$ e $r+d r$, enquanto $n_{\text {ideal }}$ é o número de pares equivalentes no gás ideal.

Assim, há mais de uma maneira de se obter a $G(r)$, posto que há mais de uma maneira de se contar as moléculas ao redor do soluto. A mais comum é considerar a distribuição não propriamente das moléculas, mas dos centros de massa delas. Observe, entretanto, que isso pode ser um problema se a molécula de interesse tiver uma das dimensões muito maior do que as outras. Uma aproximação mais realista é utilizar a distribuição de mínima distância (MDDF), onde a distância de uma molécula a outra é considerada como a menor distância entre qualquer par de átomos dessas moléculas [17,32]. Assim é possível obter uma distribuição do solvente em torno do soluto mais igualitária em todas as direções.

\section{- Autocorrelação da Energia:}

No começo da seção 1.3, apontamos como uma das vantagens do S-QM/MM o baixo número de cálculos quânticos necessários para se obter a propriedade de interesse, que advém do fato de apenas configurações relevantes para a média serem usadas. Para determinar estas configurações nós utilizamos a função de autocorrelação da energia:

$$
C(t)=\frac{\left\langle\delta E_{n} \delta E_{n+t}\right\rangle}{\left\langle\delta E^{2}\right\rangle}=\frac{\sum_{n}\left(E_{n}-\langle E\rangle\right)\left(E_{n+t}-\langle E\rangle\right)}{\sum_{n}\left(E_{n}-\langle E\rangle\right)^{2}},
$$

sendo $E_{n}$ a energia da configuração $n$ e $E_{n+t}$ a energia da configuração gerada $t$ passos de MC depois. Note então que configurações separadas por um número pequeno de passos de MC possuem uma correlação próxima a unidade o que significa que a 
inclusão de ambas simultaneamente não fornece informação estatística nova. De modo análogo, só teríamos configurações completamente descorrelacionadas em $t=\infty$. O que fazemos então é ajustar uma função aos valores calculados da autocorrelação da energia, permitindo assim ter uma estimativa de quão correlacionadas estão as configurações após um intervalo de passos de MC. Para processos Markovianos, a autocorrelação pode ser aproximada por uma soma de decaimentos exponenciais [33]:

$$
C(t)=\sum_{k} c_{k} e^{-t / \tau_{k}}
$$

Temos observado, porém, que dois termos são suficientes para obter um ajuste muito bom [11,28,31] (vide figura 3.5).

Nós consideramos estatisticamente descorrelacionadas configurações separadas por um intervalo tal que a correlação seja menor que 13\%. Apenas essas configurações são submetidas aos cálculos quânticos.

\subsubsection{Melhorando a descrição: Introduzindo polarização do soluto}

Uma das desvantagens da abordagem sequencial que apontamos é que não há polarização mútua entre o soluto e o solvente e nem relaxação de geometria, uma vez que os parâmetros que definem cada molécula (parâmetros LJ, cargas e geometria) permanecem fixos durante toda a simulação. Isso muitas vezes não é uma boa aproximação.

Para a polarização do soluto há duas soluções possíveis: a mais simples é colocála a priori, obtendo a geometria e as cargas do soluto em meio contínuo (usando o modelo PCM) ao invés de considerá-lo isolado. Em geral, isso aumenta o momento de dipolo da molécula em cerca de $60 \%$, se comparado ao valor obtido quando ela está isolada. Os valores obtidos são usados na simulação, novamente de maneira fixa. Nós chamamos esta polarização de implícita.

A outra solução é um procedimento iterativo desenvolvido em nosso grupo para atualizar as cargas da simulação [34]. Nesse procedimento faz-se um cálculo quântico em fase gasosa para determinar as cargas iniciais da simulação. Após a simulação, novas cargas são calculadas usando ASEC (que será definido a seguir). Faz-se nova simulação, calculam-se novas cargas e assim por diante até que o valor do momento de 
dipolo calculado convirja; se o soluto for uma molécula apolar pode-se acompanhar a convergência pelas cargas dos átomos. O procedimento é esquematizado na figura 1.7.

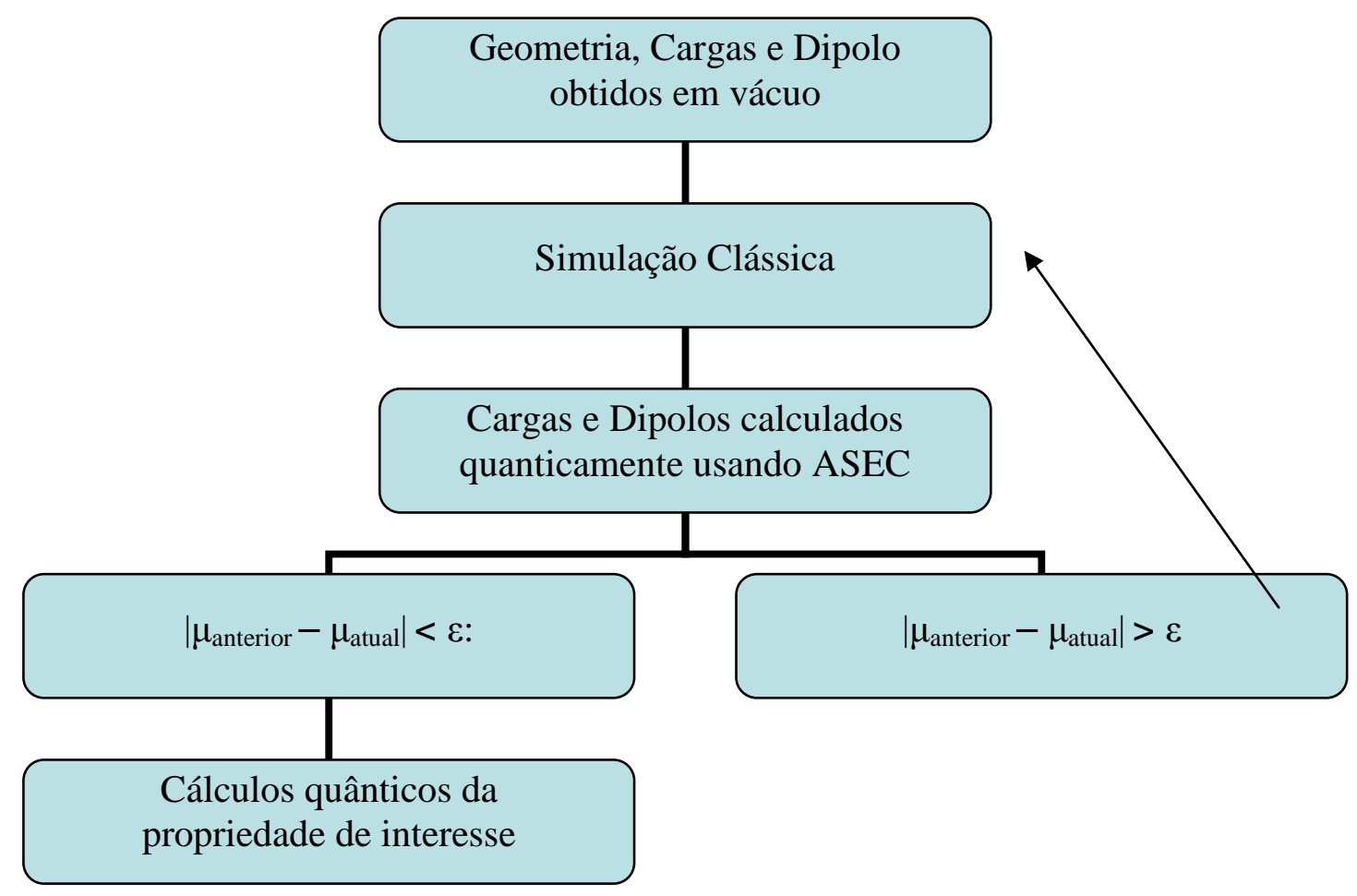

Figura 1.7: Organograma do procedimento iterativo usado para polarizar o soluto.

Resta detalhar o que é ASEC. ASEC é o acrônimo para Average Solvent Electrostatic Configuration. Ele foi proposto em nosso grupo [35] baseado nas idéias de Aguilar [36]. Como o nome sugere, é uma configuração média que representa o solvente. Para gerá-lo, nós sobrepomos as configurações estatisticamente descorrelacionadas que foram selecionadas, representando as moléculas de solvente por cargas pontuais normalizadas, isto é, divididas pelo número de configurações. Assim, ao invés de fazermos vários cálculos com o solvente sendo representado por cargas pontuais e tirarmos a média, fazemos um único cálculo da propriedade em uma configuração média, o que leva ao mesmo resultado, mas com uma economia computacional enorme. 


\subsubsection{O futuro}

$\mathrm{Na}$ sessão anterior, discutimos duas maneiras de contornar uma das principais desvantagens do método S-QM/MM que é falta de polarização. Entretanto esse não é a única restrição que deve ser melhorada: nós não consideramos a polarização que o soluto causa no solvente: é verdade que em média ela é bem menor que a causada pelo solvente no soluto, mas as moléculas na vizinhança do soluto podem ter suas cargas alteradas de maneira significativa. Outro ponto importante é a relaxação de geometria, tanto do soluto quanto do solvente, que também pode desempenhar papel decisivo no comportamento da propriedade de interesse [37].

Nós não temos expectativa de implementar efeitos de polarização no solvente, pois ainda é algo caro computacionalmente. Para a relaxação de geometria, dispomos de algumas alternativas. A primeira seria usar Dinâmica Molecular (DM) ao invés de MC para simular classicamente o sistema. Nesse caso, tanto o soluto quanto o solvente poderiam ser tratados de maneira flexível. Esse é um procedimento que nos parece promissor, principalmente para tratar solutos com um número elevado de átomos (da ordem de 100 ou mais) que, de um modo geral, apresentam grande flexibilidade. Usar DM também permite estudar a evolução temporal de uma propriedade.

As outras duas alternativas visam somente a relaxação de geometria do soluto, porém usando MC, que como já ressaltamos, é menos dispendioso computacionalmente: uma é baseada no método Quasi-Newton e no Gradiente de Energia Livre [38-40] e acrescentaria mais um ciclo no procedimento de polarização iterativa de forma que, na convergência, além das cargas do soluto polarizadas teríamos também sua geometria relaxada na presença do solvente [41]. Outra alternativa seria acrescentar mais uma variação aleatória no MC: ao invés de usarmos apenas a geometria otimizada do soluto, forneceríamos também algumas variantes (uma ligação esticada, uma leve torção, etc). Aleatoriamente, a geometria otimizada seria substituída por uma variante e aplicaríamos o teste de Metropolis; seria um procedimento de "relaxação aleatório".

Esses procedimentos estão em fase de desenvolvimento, mas ilustram a potencialidade ilimitada da metodologia S-QM/MM, na incessante busca de alcançar uma descrição o mais realista possível das interações de moléculas com um meio solvente. 


\section{Capítulo 2}

\section{Mecânica Quântica Molecular}

Desde seu surgimento, a Mecânica Quântica Moderna tem como uma de suas principais aplicações a estudo de sistemas atômicos e moleculares. Como primeiro exemplo para mostrar a validade de sua equação, Schrödinger calculou as transições do átomo de Hidrogênio. Os excelentes resultados que ele obteve logo serviram de impulso para o estudo de sistemas maiores, mas estes apresentam a dificuldade adicional do termo de repulsão elétron-elétron que, com a matemática conhecida até hoje, impede soluções analíticas. Vários métodos foram desenvolvidos para contornar essa dificuldade. Neste capítulo, descreveremos de modo sucinto aqueles utilizados em nosso estudo, mas de maneira alguma temos a pretensão de substituir a leitura dos bons textos de Mecânica Quântica Molecular e Química Quântica disponíveis hoje [42-44]. Queremos apenas fornecer uma base e referenciar tais métodos, permitindo um primeiro contato e um catálogo bibliográfico para posteriores consultas.

\subsection{Aproximação de Born-Oppenheimer}

Para estudar os estados estacionários de um sistema molecular, o caminho mais natural seria resolver a equação de Schrödinger independente do tempo

$$
H \Psi=E \Psi
$$

encontrando a função de onda $\psi$ que descreve o sistema e sua respectiva energia. Desprezando efeitos relativísticos, o operador Hamiltoniano $H$ para um sistema molecular que possui $N$ núcleos e $n$ elétrons, é: 


$$
H=-\underbrace{\sum_{A=1}^{N} \frac{1}{2 M_{A}} \nabla_{A}^{2}}_{T_{\mathrm{N}}} \underbrace{-\frac{1}{2} \sum_{i}^{n} \nabla_{i}^{2}}_{T_{\mathrm{e}}}+\underbrace{\sum_{i=1}^{n} \sum_{j<i}^{N} \frac{1}{r_{i j}}}_{V_{\mathrm{e}}}+\underbrace{\sum_{A=1}^{N} \sum_{B<A}^{N} \frac{Z_{A} Z_{B}}{R_{A B}}}_{V_{\mathrm{N}}} \underbrace{-\sum_{i=1}^{n} \sum_{A=1}^{N} \frac{Z_{A}}{r_{i A}}}_{V_{\mathrm{eN}}},
$$

onde os índices representados por letras minúsculas se referem aos elétrons e os com maiúsculas, aos núcleos, sendo $Z_{K}$ a massa do núcleo $k, R_{A B}$ a distância entre os núcleos $A$ e $B, r_{i j}$ a distância entre os elétrons $i$ e $j$ e $r_{i A}$ a distância entre o elétron $i$ e o núcleo $A$. Alertamos que a equação (2.2) está em unidades atômicas ${ }^{6}$ (a.u.), sistema de unidades que será utilizado em todo esse capítulo.

$\mathrm{Na}$ equação (2.2), os termos estão acompanhados de seus respectivos significados físicos: $T_{\mathrm{N}}$ é a energia cinética dos núcleos e $T_{\mathrm{e}}$, dos elétrons; $V_{\mathrm{e}}$ é a energia potencial eletrônica e $V_{\mathrm{N}}$, a nuclear; $V_{\mathrm{eN}}$ é a energia potencial de atração elétron-núcleo.

Este Hamiltoniano é deveras complexo de ser tratado. Assim, para simplificar o problema, evoca-se a aproximação adiabática de Born-Oppenheimer (BO), relacionada ao fato de que os elétrons, por serem muito mais leves que os núcleos, se adaptam muito rapidamente a qualquer posição que estes assumam. Essa interpretação é um pouco incômoda, pois sugere que a aproximação é sempre válida. Um tratamento mais rigoroso (de fato, é o que usamos hoje) foi feito por Born e Huang [45]. Eles usaram duas aproximações:

1) A função de onda do sistema pode ser escrita como produto de uma função de onda para os núcleos e outra para os elétrons, sendo que esta última é parametricamente dependente da posição dos núcleos:

$$
\Psi=X(R) \psi(r ; R)
$$

2) $T_{\mathrm{N}}$ não atua na função de onda eletrônica, apesar da dependência paramétrica. Essa segunda aproximação é dita adiabática, pois assume que a função de onda eletrônica varia muito lentamente com as coordenadas nucleares.

Usando essas duas aproximações é possível mostrar que (veja cap 4 de [43]):

\footnotetext{
${ }^{6}$ Sistema de unidades muito utilizado em Física Molecular. Surge naturalmente ao tornarmos a equação de Schrödinger para o átomo de Hidrogênio adimensional, fazendo $e=\hbar=a_{0}=1$. A energia é medida em hartree (1 hartree $\cong 27.2 \mathrm{eV}$ ). Uma discussão mais completa é feita no cap. 2 de [42].
} 


$$
\begin{aligned}
& \left(T_{e}+V_{\mathrm{e}}+V_{\mathrm{N}}+V_{\mathrm{eN}}\right) \psi(r ; R)=E_{e l}(R) \psi(r ; R) ; \\
& \left(T_{N}+E_{e l}(R)\right) X(R)=\xi X(R) .
\end{aligned}
$$

A equação (2.4) é a equação de Schrödinger para os elétrons e pode ser resolvida para valores fixos de $R$. A equação (2.5) mostra que uma vez resolvido o problema eletrônico, o problema nuclear pode ser resolvido usando a energia $E_{e l}(R)$ do movimento eletrônico como potencial para o movimento dos núcleos. A aproximação BO é muito boa desde que não haja um acoplamento significativo entre diferentes estados eletrônicos (discussões mais detalhadas em [43]e [44]).

Uma vez que sabemos como estudar o movimento nuclear a partir do eletrônico, podemos nos dedicar somente ao último. Assim, nas seções seguintes, apresentaremos alguns métodos aproximativos para resolver a equação (2.4). Como apenas o problema eletrônico será tratado, nós abandonaremos os subscritos que o designam e também omitiremos a dependência paramétrica com as coordenadas nucleares, que fica subentendida.

\subsection{O método de Hartree-Fock}

O método de Hartree-Fock (HF) foi o primeiro a ser desenvolvido para se estudar sistemas multieletrônicos. Para resolver a equação de Schrödinger (2.4) para o estado fundamental de um sistema de $n$ elétrons, o método propõe representar a função de onda anti-simétrica (satisfazendo o princípio de exclusão de Pauli) de camada fechada utilizando um determinante de Slater

$$
\psi=\frac{1}{\sqrt{n !}}\left|\begin{array}{cccc}
\varphi_{1}(1) & \varphi_{1}(2) & \cdots & \varphi_{1}(n) \\
\varphi_{2}(1) & \varphi_{2}(2) & \cdots & \varphi_{2}(n) \\
\vdots & \vdots & \ddots & \vdots \\
\varphi_{n}(1) & \varphi_{n}(2) & \cdots & \varphi_{n}(n)
\end{array}\right|
$$

onde $\varphi_{k}(l)$ são spin-orbitais eletrônicos, ou seja, funções de onda que contemplam a parte espacial e de spin. Substituindo este determinante na equação (2.4) e minimizando 
a energia pelo teorema variacional ${ }^{7}$ (e através da técnica dos multiplicadores de Lagrange) chegamos a $([43,44])$

$$
E=\sum_{i=1}^{n}\left\langle\varphi_{i}\left|-\frac{\nabla_{i}^{2}}{2}-\sum_{A=1}^{N} \frac{Z_{A}}{r_{i A}}\right| \varphi_{i}\right\rangle+\frac{1}{2} \sum_{i, j}^{n}\left[\left\langle\varphi_{i}\left|J_{j}-K_{j}\right| \varphi_{i}\right\rangle\right]
$$

onde

$$
\begin{gathered}
J_{j}(1) \varphi_{i}(1)=\left\langle\varphi_{j}(2)\left|\frac{1}{r_{12}}\right| \varphi_{i}(2)\right\rangle \varphi_{i}(1) \\
\mathrm{e} \\
K_{j}(1) \varphi_{i}(1)=\left\langle\varphi_{j}(2)\left|\frac{1}{r_{12}}\right| \varphi_{i}(2)\right\rangle \varphi_{j}(1)
\end{gathered}
$$

são, respectivamente, os operadores de Coulomb (relacionado a repulsão eletrônica) e Troca (que não possui análogo clássico e está relacionado com a antissimetria da função de onda). A partir de (2.7) nós podemos escrever que para cada $\varphi_{i}$ vale a relação

$$
F_{i} \varphi_{i}=\varepsilon_{i} \varphi_{i},
$$

sendo que

$$
F_{i}=-\frac{\nabla_{i}^{2}}{2}-\sum_{A=1}^{N} \frac{Z_{A}}{r_{i A}}+\sum_{j}^{n}\left(J_{j}-K_{j}\right)
$$

e é chamado de operador de Fock. Note que o operador depende da função de onda $\varphi_{i}$, de modo que a equação é resolvida de modo iterativo: fornecemos uma função de onda inicial $\varphi_{i}^{\text {inicial }}$, obtemos o operador de Fock $F_{i}$ correspondente, resolvemos a equação (2.7) para obter uma nova função de onda $\varphi_{i}$, que será usada para construir um novo operador de Fock e assim por diante até a convergência. Esse procedimento é chamado de campo autoconsistente (SCF).

\footnotetext{
${ }^{7} \mathrm{O}$ teorema variacional garante que a energia obtida através de um método variacional é maior ou igual à energia exata (veja, por exemplo, cap. 7 de [51]).
} 
Um ponto importante é como obter uma função inicial que seja razoável de modo global, ou poderemos, por exemplo, fornecer uma função que aproxima muito bem a função de onda desejada em um intervalo, mas que seja muito distinta em outros pontos, de modo que a convergência pode ser muito lenta ou pode não ocorrer. Para evitar isso, nós usualmente usamos um conjunto de bases para expandir a função de onda, ou seja, cada orbital molecular desconhecido $\varphi_{i}$ é escrito como uma combinação linear de orbitais atômicos conhecidos $\phi$ :

$$
\varphi_{i}=\sum_{\mu}^{\kappa} C_{\mu i} \phi_{\mu}
$$

de modo que o problema agora é determinar os coeficientes $C_{\mu i}$, de forma que a soma aproxime a função de onda da melhor maneira possível. Essa aproximação é dita Combinação Linear de Orbitais Atômicos (LCAO) e leva ao formalismo de HartreeFock-Roothaan [42], que é o que utilizamos hoje. Note que um conjunto de bases, a princípio, é infinito, algo computacionalmente impossível, de modo que os resultados passam a ter uma dependência com o tamanho $\kappa$ da base utilizada, com a tendência de se tornarem melhores conforme o número de elementos que compõem o conjunto aumente. Afortunadamente, a convergência com esse tamanho não é muito lenta, de modo que os resultados obtidos com esses conjuntos finitos são bem realistas. Outro problema é como descrever matematicamente os orbitais atômicos. Nós discutiremos essa questão na seção 2.6.1.

Como dissemos no começo da seção, este procedimento é válido para o estado fundamental. Para obtenção da energia dos estados excitados (que é nosso objetivo nesse trabalho) uma das alternativas é construir o determinante de Slater considerando que os elétrons estão na presença de um potencial externo e dependente do tempo, e o método passa a ser denominado TD-HF (para detalhes teóricos e de implementação computacional, veja [46]).

Apesar de toda a sua coerência, o método de HF peca ao considerar que cada elétron percebe a presença do demais como um campo médio e não individualmente, o que acarreta em discrepâncias entre o valor calculado e o valor exato da energia (o valor calculado com HF representa, em geral, 95 a 99\% do valor exato [47]). Löwdin definiu essa diferença como energia de correlação [48], pondo HF em um status privilegiado, 
como melhor método $a b$ initio de partida para se estudar um sistema molecular. E é justamente a energia de correlação que os métodos $a b$ initio posteriores a HF se propõem a calcular.

\subsection{Métodos ab initio pós Hartree-Fock}

Muitos métodos surgiram com o intuito de melhorar os resultados de HF, tentando de alguma maneira incorporar a correlação eletrônica. Aqui, discutiremos brevemente dois deles, que foram utilizados neste trabalho.

\subsubsection{Interação de Configuração}

Uma maneira sistemática de incluir a energia de correlação é usar mais de um determinante de Slater para compor a função de onda

$$
\psi=\sum_{l} c_{l} D_{l}
$$

onde $D_{0}$ é o determinante de Slater para o estado fundamental (2.6), enquanto $D_{l}(l \neq 0)$ são determinantes de Slater com um ou mais elétrons em orbitais virtuais. Esse método é chamado de Interação de Configuração (CI) [42]. O procedimento consiste em usar os orbitais moleculares (ocupados e virtuais) do cálculo HF e otimizar os coeficientes $c_{l}$ usando um procedimento variacional.

A princípio, CI pode fornecer a solução exata, desde que todas as configurações possíveis sejam incluídas no cálculo, algo que é impraticável, além de mais uma vez esbarrarmos na finitude da base. Se todas as combinações possíveis forem usadas em uma base de tamanho $\kappa$, temos um $F u l l-C I^{8}$, que é um resultado exato dentro do subespaço definido por essa base. Entretanto, esses cálculos são extremamente demorados, de modo que até hoje só são feitos para sistemas pequenos. Assim, o que normalmente se faz é definir a quantidade de elétrons que podem ser promovidos para orbitais virtuais. Se os novos determinantes são compostos por excitações monoeletrônicas, temos Interação de Configurações de Excitações Simples (CIS) [49]. O método CIS fornece energias aproximadas dos estados excitados, mas não modifica a

\footnotetext{
${ }^{8}$ Full $=$ Completo.
} 
energia do estado fundamental. Se os determinantes advêm de excitações simples e duplas, temos o método CISD [49], que influencia na energia do estado fundamental contendo parte da energia de correlação eletrônica. Analogamente, se as excitações triplas também forem incluídas temos CISDT, CISDTQ se forem incluídas até as quádruplas etc.

Apesar de ser um procedimento simples e sistemático para se obter a energia de correlação, duas são as principais críticas feitas à metodologia CI:

1. Mesmo recorrendo a truncamentos, a expansão (2.13) pode ter um número enorme de termos, o que pode acarretar numa lenta convergência da função de onda, levando a cálculos computacionais dispendiosíssimos;

2. Os métodos CI trucados não são consistentes e nem extensíveis no tamanho. A não consistência no tamanho, como definida por Pople em 1976, quer dizer que se particionarmos a molécula em alguns pedaços, a soma dos resultados destes pedaços é diferente do resultado obtido com a molécula inteira. Isso é fácil de exemplificar: se dividirmos uma molécula com 4 elétrons em duas partes e considerarmos apenas excitações duplas, temos 3 possibilidades: dois elétrons excitados em uma parte, dois excitados na outra parte ou um elétron excitado em cada parte. Ao calcularmos a função total, o resultado possui contribuições de excitações quádruplas, advindas do fato que em cada parte pode haver excitações duplas, contribuições essas que não seriam consideradas num cálculo feito na molécula como um todo. A extensividade no tamanho é um critério mais formal, que diz que a energia de um sistema deve crescer proporcionalmente ao seu tamanho. Consistência é de certa forma um caso particular de extensividade.

Uma variação muito usada de CISD consiste em adotar as excitações duplas como uma perturbação no espaço das excitações simples. Este método é chamado de CIS(D) [50], é consistente no tamanho e pode ser usado no estudo de estados excitados como uma correção aos cálculos CIS.

Muitas vezes também se opta em definir quais as configurações possíveis ou quais são os orbitais virtuais acessíveis aos elétrons, numa tentativa de aumentar a quantidade de excitações sem aumentar em demasia a exigência computacional, 
selecionando configurações que teriam contribuições realmente importantes para a função de onda e energia do sistema.

\subsubsection{Teoria de Perturbação}

A teoria de Perturbação é uma maneira de se corrigir a energia e a função de onda muito utilizada em várias aplicações da Mecânica Quântica. Aqui, nós vamos descrever apenas a fundamentos da Teoria de Perturbação de Møller-Plesset (MP), um caso particular da teoria de perturbação de Rayleigh-Schrödinger ${ }^{9}$ independente do tempo (RS) ensinada nos cursos de Mecânica Quântica.

Em RS, a ideia é que dado um Hamiltaniano $H$ para o qual é difícil (ou até impossível) resolver a equação de Schrödinger, podemos tentar escrevê-lo como

$$
H=H_{0}+\lambda H^{\prime}
$$

onde $H_{0}$ é um Hamiltoniano para o qual sabemos como resolver a equação de Schrödinger. $\mathrm{O}$ termo restante de $H$ é dito ser uma perturbação $\lambda H^{\prime}$ do sistema definido por $H_{0}$, que passa a ser o sistema não-perturbado. Nessas condições é possível estabelecer correções sistemáticas para encontrar a energia e a função de onda de $H$ a partir da função de onda e da energia de $H_{0}$. Supondo que $\lambda$ é pequeno, nós podemos expandir a função de onda e a energia em uma série de potências:

$$
\begin{aligned}
& \psi_{n}=\psi_{n}^{(0)}+\lambda \psi_{n}^{(1)}+\lambda^{2} \psi_{n}^{(2)}+\cdots+\lambda^{k} \psi_{n}^{(k)}+\cdots ; \\
& E_{n}=E_{n}^{(0)}+\lambda E_{n}^{(1)}+E^{2} \psi_{n}^{(2)}+\cdots+\lambda^{k} E_{n}^{(k)}+\cdots
\end{aligned}
$$

Aqui estamos usando a notação usual: $\psi_{n}^{(0)}$ e $E_{n}^{(0)}$ são, respectivamente, a função de onda e a energia do $n$-ésimo estado do sistema não-perturbado, enquanto $\psi_{n}$ e $E_{n}$ denotam a função de onda e a energia do $n$-ésimo estado do Hamiltoniano perturbado; $\psi_{n}^{(k)}$ e $E_{n}^{(k)}$, com $k>0$, são as correções perturbativas de $k$-ésima ordem para a função de onda e para a energia do n-ésimo estado perturbado, respectivamente. Essas

\footnotetext{
${ }^{9}$ Essa, por sua vez, é um caso particular da Teoria de Perturbação de Brillouin-Wigner, uma teoria menos usada, pois suas equações são muito complexas e de difícil implementação computacional.
} 
correções podem ser calculadas analiticamente: por exemplo, para estados nãodegenerados, as correções de primeira e segunda ordem para a energia e a função de onda são [51,52]:

$$
\begin{gathered}
E_{n}^{(1)}=\left\langle\psi_{n}^{(0)}\left|H^{\prime}\right| \psi_{n}^{(0)}\right\rangle ; \\
E_{n}^{(2)}=\left\langle\psi_{n}^{(0)}\left|H^{\prime}\right| \psi_{n}^{(1)}\right\rangle=\sum_{m \neq n} \frac{\left|\left\langle\psi_{m}^{(0)}\left|H^{\prime}\right| \psi_{n}^{(0)}\right\rangle\right|^{2}}{E_{n}^{(0)}-E_{m}^{(0)}} ; \\
\psi_{n}^{(1)}=\sum_{m \neq n} \frac{\left\langle\psi_{m}^{(0)}\left|H^{\prime}\right| \psi_{n}^{(0)}\right\rangle}{E_{n}^{(0)}-E_{m}^{(0)}} \psi_{m}^{(0)} ; \\
\psi_{n}^{(2)}=\sum_{l, m \neq n} \frac{\left\langle\psi_{m}^{(0)}\left|H^{\prime}\right| \psi_{l}^{(0)}\right\rangle\left\langle\psi_{l}^{(0)}\left|H^{\prime}\right| \psi_{n}^{(0)}\right\rangle}{\left(E_{n}^{(0)}-E_{l}^{(0)}\right)\left(E_{n}^{(0)}-E_{m}^{(0)}\right)} \psi_{m}^{(0)}-E_{n}^{(1)} \sum_{m \neq n} \frac{\left\langle\psi_{m}^{(0)}\left|H^{\prime}\right| \psi_{n}^{(0)}\right\rangle}{\left(E_{n}^{(0)}-E_{m}^{(0)}\right)^{2}} \psi_{m}^{(0)} .
\end{gathered}
$$

MP é um caso particular de RS, pois propõem que para um sistema molecular o Hamiltoniano não-perturbado é uma soma de operadores de Fock sobre todos os elétrons, sendo o restante tratado como perturbação. Assim de (2.11) e (2.14) vêm que:

$$
\begin{aligned}
H^{\prime} & =H-H_{0}=\sum_{i=1}^{n}\left(-\frac{\nabla_{i}^{2}}{2}-\sum_{A=1}^{N} \frac{Z_{A}}{K_{A}}\right)+V_{e}-\sum_{i=1}^{n}\left(-\frac{Z_{i}^{2}}{2}-\sum_{A=1}^{N} \frac{Z_{A}}{X_{X}}+\sum_{j}^{n} J_{j}-K_{j}\right)= \\
& =V_{e}-\sum_{i=1}^{n} \sum_{j=1}^{n}\left(J_{j}-K_{j}\right) .
\end{aligned}
$$

Note que o segundo termo de $H^{\prime}$ pode ser interpretado fisicamente como a energia potencial média dos elétrons (contada duas vezes, posto que a somas não têm restrição). Finalmente temos que

$$
H^{\prime}=V_{e}-2\left\langle V_{e}\right\rangle
$$

uma perturbação deveras elegante para um problema tão complexo. Já que conseguimos escrever o Hamiltoniano na forma de (2.14) todo o formalismo de RS passa a ser aplicável ao problema. Usando (2.7) e (2.10) em (2.17), é fácil mostrar que a correção da energia em primeira ordem é nula [42], de modo que a menor correção possível é a de segunda ordem. Códigos atuais de grande utilização, como o Gaussian 03 [53], 
possuem MP implementado até a quinta ordem. Infelizmente não é vantajoso usar ordens muito grandes pois, além de ser um cálculo demorado, não há garantias de que as séries 2.15 e 2.16 irão convergir. De fato, há vários exemplos de que elas divergem [54]. A própria aplicação que Schrödinger fez em seu artigo, o átomo de hidrogênio sujeito a um campo elétrico externo, era divergente (e ele não percebeu!).

\subsection{Teoria do Funcional da Densidade}

A Teoria do Funcional da Densidade (DFT) advém de um formalismo alternativo ao que estamos acostumados em QM: ao invés de funções de ondas, o sistema é descrito em função da densidade eletrônica (daí o nome da teoria). Esse formalismo é equivalente ao formalismo usual e tem sido largamente utilizado por permitir o estudo de sistemas moleculares com um tamanho bem maior que os permitidos por HF e seus derivados. Isso porque enquanto HF transforma o problema de $n$ corpos em $n$ problemas de um corpo, DFT transforma a busca da função de onda de $3 n$ variáveis numa busca por uma função de 3 variáveis que represente a densidade eletrônica do sistema [55].

A DFT está calcada em dois teoremas demonstrados por Hohenberg e Kohn $(\mathrm{HK})^{10}$ :

$1^{0}$ Teorema de HK: Para o estado fundamental, o potencial externo ${ }^{11} v(r)$ é funcional $^{12}$ único da densidade $\rho(r)$;

$2^{\text {o }}$ Teorema de HK: A energia do estado fundamental é mínima para a densidade exata $\rho_{0}(r)$ (nada mais que uma aplicação do teorema variacional).

Usando o $1^{\mathbf{0}}$ teorema e fixando os núcleos, nós podemos reescrever a equação (2.4) na forma

\footnotetext{
${ }^{10}$ Para a demonstração de ambos e detalhes da teoria, veja [55]. Para um texto mais resumido, veja o cap. 6 de [43] e o capítulo 3 de [44].

${ }^{11} \mathrm{O}$ potencial externo é constituído, normalmente, pelas posições e cargas dos núcleos dos átomos que formam a molécula.

${ }^{12}$ Funcional é um ente matemático que, a partir de uma função, gera um número.
} 


$$
E[\rho]=\langle\psi|T+V| \psi\rangle+\int \rho(r) v(r) d r
$$

Kohn e Sham (KS) reescreveram (2.23), tornando explícita a repulsão elétronelétron de Coulomb [44]:

$$
E[\rho]=G[\rho]+\frac{1}{2} \iint \frac{\rho\left(r_{1}\right) \rho\left(r_{2}\right)}{r_{12}} d r_{1} d r_{2}+\int \rho(r) v(r) d r
$$

sendo $G[\rho]$ um funcional universal definido por

$$
G[\rho]=T_{s}[\rho]+E_{x c}[\rho]
$$

onde $T_{s}[\rho]$ é o funcional de energia cinética de um sistema de elétrons com mesma densidade mas que não interagem, de modo que $E_{x c}[\rho]$, chamado de funcional de troca e correlação, passa a incluir não só esses dois termos não-clássicos, como também a energia cinética residual $T[\rho]-T_{s}[\rho]$.

KS simplificaram a resolução do problema usando um Hamiltoniano de referência $H_{\text {ref }}$

$$
\underbrace{\left(-\frac{1}{2} \nabla^{2}+v_{e f}\right)}_{H_{\text {ref }}} \psi_{i}^{K S}=\varepsilon_{i}^{K S} \psi_{i}^{K S},
$$

com as funções de onda $\psi_{i}^{K S}$ escritas como determinantes de Slater (equação 2.6), e que se conecta com o problema real escolhendo-se o potencial efetivo $v_{e f}$ de modo que a densidade eletrônica resultante $\rho_{s}$ seja igual à densidade eletrônica $\rho$ do problema original

$$
\rho_{s}(r)=\sum_{i}^{N}\left|\psi_{i}^{K S}\right|^{2}=\rho(r)
$$

Dessa forma, $T_{s}[\rho]$ é calculado exatamente [44] e $v_{\text {ef }}$ é determinado pela minimização de (2.26). Temos então um procedimento SCF: para uma dada densidade eletrônica $\rho(r)$, pode-se calcular o potencial efetivo $v_{e f}$ que, através do Hamiltoniano 
de referência, permite o cálculo da função de onda $\psi_{i}^{K S}$ e que por sua vez determina uma nova densidade. Como nenhuma aproximação foi feita, o resultado convergido é exato.

Infelizmente na prática não é assim: como nos métodos $a b$ initio, a descrição matemática dos orbitais é dependente do conjunto de funções base utilizado para representá-los. Além disso, nós não conhecemos a forma do funcional de troca e correlação. Esse é o Santo Graal da DFT: a busca da melhor representação para o termo $E_{x c}[\rho]$. Isso também é uma das críticas do método: não há uma maneira sistemática de se construir tal funcional. A falta de sistemática para melhorar os resultados também é um ponto muito criticado: diferentemente dos métodos $a b$ initio, onde conforme melhoramos as aproximações, melhoramos os resultados (começando com HF e partindo para métodos de inclusão da correlação eletrônica), não há como melhorar as aproximações de DFT; tudo o que se pode fazer é construir outro funcional, o que leva a um ciclo das críticas.

Os desenvolvedores de funcionais admitem que, num futuro próximo, não deverá existir um funcional que descreva bem todas as propriedades de modo que os funcionais, de um modo geral, são desenvolvidos com finalidades específicas [44]. Discutiremos um pouco sobre esses funcionais na seção 2.4.2.

\subsubsection{Teoria do Funcional da Densidade Dependente do Tempo}

Até agora, tudo o que discutimos sobre DFT vale para o estado fundamental, devido às hipóteses usadas nos teoremas de HK. Runge e Gross (RG) estenderam o $1^{\underline{o}}$ teorema de HK, mostrando que pode-se também estabelecer uma correspondência unívoca entre a densidade dependente do tempo $\rho(r, t)$ e o potencial externo dependente do tempo $v(r, t)$, o que deu origem a Teoria do Funcional da Densidade Dependente do Tempo (TD-DFT). Eles então usaram a equação de Schrödinger dependente do tempo

$$
i \hbar \frac{d}{d t} \psi(r, t)=H \psi(r, t)
$$

para estender as equações de KS $(2.24$ - 2.27) para o caso dependente do tempo. 
Porém, surge um problema: não há como minimizar (2.24) para se obter $v_{e f}$, já que não existe princípio variacional para sistemas dependentes do tempo, posto que nesses sistemas não há conservação da energia. Para contornar isso, RG mostraram que a ação de Dirac

$$
\mathfrak{A}[\psi]=\int_{t_{0}}^{t_{1}}\left\langle\psi(t)\left|i \frac{\partial}{\partial t}-H\right| \psi(t)\right\rangle .
$$

é um funcional de $\rho(r, t)$; mais que isso, como de (2.29) podemos obter (2.28), a função de onda $\psi(t)$ que torna (2.29) estacionária é solução de (2.28), o que leva a um princípio estacionário, que não é a mesma coisa que um princípio de mínima energia, mas que permite o cálculo de $v_{e f}$ e, consequentemente, da densidade.

Para se estudar a energia de excitação, introduz-se uma perturbação dependente do tempo no estado fundamental e utiliza-se a Teoria de Resposta Linear para calcular o efeito dessa perturbação na densidade. A função resposta da densidade será

$$
\chi\left(r, r^{\prime}, \omega\right)=\lim _{\eta \rightarrow 0^{+}} \sum_{m}\left[\frac{\langle 0|\rho(r)| m\rangle\left\langle m\left|\rho\left(r^{\prime}\right)\right| 0\right\rangle}{\omega-\left(E_{m}-E_{0}\right)+i \eta}-\frac{\left\langle 0\left|\rho\left(r^{\prime}\right)\right| m\right\rangle\langle m|\rho(r)| 0\rangle}{\omega+\left(E_{m}-E_{0}\right)+i \eta}\right] .
$$

onde os pólos dessa expressão correspondem as energias de excitação do sistema e os numeradores estão relacionados as correspondentes forças de oscilador (para maiores detalhes, vide [56]).

\subsubsection{Funcionais de Troca e Correlação}

No coração da DFT estão os funcionais de troca e correlação. Apesar de não haver uma maneira sistemática de construí-los, algumas aproximações são muito usadas. As principais são [57]:

Aproximação de Densidade Local (LDA): essa aproximação assume que, localmente, $\rho(r)$ é idêntica a de um gás de elétrons uniforme. A energia de troca passa a ser dada por 


$$
E_{x}^{L D A}[\rho]=-C_{x} \int \rho^{4 / 3}(r) d r
$$

Aproximação de Densidade Local de Spin (LSDA): é uma extensão da LDA, tratando separadamente as densidades de spin $\alpha$ e $\beta$ :

$$
E_{x}^{L S D A}[\rho]=-2^{1 / 3} C_{x} \int \rho_{\alpha}^{4 / 3}+\rho_{\beta}^{4 / 3} d r .
$$

Aproximação de Gradiente Generalizado (GGA): a aproximação se mantém local, mas considera o gradiente da densidade na mesma coordenada. Um exemplo é o funcional de troca, proposto por Becke em 1988 (B88) [58], que consiste em adicionar um termo para correção do comportamento assintótico da densidade eletrônica:

$$
E_{x}^{B 88}=E_{x}^{L D A}-\beta \rho^{1 / 3} \frac{x^{2}}{1+6 \beta x \sinh ^{-1} x} .
$$

onde $\beta$ foi definido ajustando-se dados atômicos e $x=\frac{\nabla \rho}{\rho^{4 / 3}}$.

Para a correlação, uma das propostas mais utilizadas é a de Lee, Yang e Parr (LYP) [59]:

$$
\begin{aligned}
E_{c}^{L Y P} & =-a \frac{\gamma}{1+f \rho^{1 / 3}}-a b \frac{\gamma e^{c \rho^{1 / 3}}}{9\left(1+d \rho^{1 / 3}\right) \rho^{8 / 3}}\left[1 8 ( 2 ^ { 2 / 3 } ) C _ { F } \left(\rho_{\alpha}^{8 / 3}+\right.\right. \\
& \left.\left.+\rho_{\beta}^{8 / 3}\right)-18 \rho t_{W}++\rho_{\alpha}\left(2 t_{W}^{\alpha}+\nabla^{2} \rho_{\alpha}\right)+\rho_{\beta}\left(2 t_{W}^{\beta}+\nabla^{2} \rho_{\beta}\right)\right],
\end{aligned}
$$

com $\gamma=2\left(1-\frac{\rho_{\alpha}^{2}+\rho_{\beta}^{2}}{\rho^{2}}\right), t_{W}^{\vartheta}=\frac{1}{8}\left(\frac{\left|\nabla \rho_{\vartheta}\right|^{2}}{\rho_{\vartheta}}-\nabla^{2} \rho_{\vartheta}\right)$ e $a, b, c$ e $f$ parâmetros obtidos através de um ajuste em um conjunto de moléculas.

Outra proposta para a troca e correlação foi feita por Perdew, Berke e Ernzerhof (PBE) [60]:

$$
E_{x c}^{P B E}=-\frac{3 e^{2} k_{F}}{4 \pi} \int(1+\kappa) \rho(r)-\frac{\kappa^{2} \rho(r)}{\kappa+\mu s^{2}} d r,
$$


sendo $\mu$ e $\kappa$ parâmetros e $s=\frac{|\nabla \rho|}{2 \rho k_{F}}$.

Esses são apenas alguns exemplos. Entretanto, os funcionais baseados em LDA, LSDA e GGA muitas vezes não apresentam a precisão necessária para um resultado confiável. Surgiu então o conceito de funcional híbrido, um funcional que combina frações do termo de troca do método HF com frações dos funcionais de troca da DFT e aproximações GGA para a correlação.

Neste trabalho, quatro diferentes funcionais híbridos foram utilizados:

○ B3LYP [61]: provavelmente o mais conhecido funcional da atualidade. A energia de troca é composta por $20 \%$ do HF e $80 \%$ da LSDA, mais uma correção proveniente do B88. A correlação é proveniente de $81 \%$ de LYP (local e não-local) e $19 \%$ do terceiro funcional para correlação local proposto por Vosko, Wilk e Nusair (VWN) [62]. Esses pesos foram determinados de modo semi-empírico.

$$
E_{x c}^{B 3 L Y P}=0.8 E_{x}^{H F}+0.2 E_{x}^{L S D A}+0.72 \Delta E_{x}^{B 88}+0.81 E_{c}^{L Y P}+0.19 E_{c}^{V W N} .
$$

○ O3LYP [63]: é uma modificação do B3LYP proposta por Handy. Além de alterar os pesos dos termos que compõem a energia de troca, a correção passa a ser feita pelo funcional OPTX [64]. A correlação local também é alterada para VWN5 (quinto funcional proposto por Vosko, Wilk e Nusair [62]). A composição fica então:

$$
E_{x c}^{O 3 L Y P}=0.1161 E_{x}^{H F}+0.9269 E_{x}^{L S D A}+0.8133 \Delta E_{x}^{O P T X}+0.81 E_{c}^{L Y P}+0.19 E_{c}^{V W N 5} .
$$

- PBEO [65]: também conhecido como PBE1PBE, foi proposto por Adamo e Barone e sua composição é

$$
E_{x c}^{P B E 0}=E_{x c}^{P B E}+0.25 E_{x}^{H F}-0.25 E_{x}^{P B E} .
$$

○ BHandHLYP: um funcional híbrido cujo o termo de troca é composto metade por HF e metade pela LSDA (half-and-half), mais uma correção proveniente do Becke 88. A correlação é dada por LYP. 


$$
E_{x c}^{H a n d H}=0.5 E_{x}^{L S D A}+0.5 E_{x}^{H F}+0.5 \Delta E_{x}^{B 88}+E_{c}^{L Y P}
$$

É importante frisar que essa composição não é a mesma proposta por Becke [66].

\subsection{Métodos Semiempíricos}

Devido ao enorme gasto computacional, métodos $a b$ initio muitas vezes não são a melhor saída para o estudo de sistemas grandes. Mesmo DFT, apesar de ser mais barata em termos computacionais, não é eficiente a tal ponto. Desse modo, existe outra alternativa: Métodos Semiempíricos. A ideia central desses métodos é usar valores vindos de experimentos e/ou cálculos ab initio com o intuito de parametrizar os valores de integrais mais demoradas ou até mesmo negligenciá-las. A grande crítica a essa abordagem é que uma parametrização pode não ser suficiente para prever a fenomenologia de todo e qualquer sistema molecular (algumas vezes não é capaz nem de reproduzir fenômenos já conhecidos!). Do outro lado, o grande argumento a favor é a eficiência computacional que os métodos semiempíricos possuem: estimativas apontam que 1 dia de cálculo semiempírico pode equivaler até 2.7 anos de cálculo ab initio.

De um modo geral, os métodos semiempíricos tratam apenas elétrons de valência, usando um conjunto mínimo de funções bases (vide seção 2.6.1). Os demais elétrons são tratados como uma blindagem do núcleo, fazendo com que os elétrons de valência sintam uma carga nuclear efetiva. No que tange as integrais, a aproximação essencial dos métodos semiempíricos é chamada de ZDO e consiste em desconsiderar todos os produtos entre funções base que dependam das coordenadas do mesmo elétron

localizadas em sítios atômicos distintos. Assim, se $\phi_{\mu}(i)$ e $\phi_{v}(i)$ são funções bases que dependem das coordenadas do elétron $i$ e estão localizadas, respectivamente, em átomos distintos $A$ e $B$, segue que

$$
\phi_{\mu}^{A}(i) \phi_{v}^{B}(i)=0
$$

Como consequência, a matriz de recobrimento se reduz a uma matriz identidade e integrais de um elétron envolvendo 3 centros se anulam, bem como as integrais de dois elétrons com 3 ou 4 centros (que são de longe as mais numerosas [67]). Aqui entra a parametrização, como forma de corrigir os desvios provenientes de (2.40) e das outras 
aproximações feitas. ZDO apresenta um inconveniente: não é invariante por uma rotação do sistema de coordenadas [43]. Para driblar essa dificuldade, outras aproximações foram desenvolvidas.

Nesse trabalho, os cálculos semiempíricos foram feitos dentro da aproximação INDO que utiliza, além das aproximações já mencionadas, uma aproximação adicional: despreza todas as integrais de dois elétrons em dois centros que não sejam integrais coulombianas. Além disso, com o intuito de preservar a invariância rotacional, algumas integrais têm de ser independentes do tipo do orbital ( $s$ ou p). Dessa forma temos $[43,67]$

$$
\left\langle\phi_{\mu}^{A}\left|-\frac{1}{2} \nabla^{2}-\sum_{A^{\prime}} \frac{Z_{A^{\prime}}^{\prime}}{r_{i A^{\prime}}}\right| \phi_{v}^{A}\right\rangle=-\delta_{\mu \nu} \sum_{A^{\prime}}\left\langle\phi_{\mu}^{A}\left|\frac{Z_{A^{\prime}}^{\prime}}{r_{i A^{\prime}}}\right| \phi_{v}^{A}\right\rangle,
$$

que são as integrais de um elétron. $\mathrm{O}$ apóstrofo usado na notação é para indicar que estamos lidando com um núcleo efetivo. Para dois elétrons temos

$$
\left\langle\phi_{\mu}^{A} \phi_{v}^{B} \mid \phi_{\lambda}^{C} \phi_{\sigma}^{D}\right\rangle=\delta_{A C} \delta_{B D}\left\langle\phi_{\mu}^{A} \phi_{v}^{B} \mid \phi_{\lambda}^{A} \phi_{\sigma}^{B}\right\rangle
$$

Tanto em (2.41) quanto em (2.42), a integral do lado direito independe do tipo de orbital que está sendo descrito pela função $\phi$.

Nossos cálculos semiempíricos foram realizados utilizando o programa ZINDO [68] cuja parametrização é espectroscópica e visa principalmente o estudo do espectro de absorção [69].

\subsection{Alguns Complementos}

Neste tópico nós vamos discutir dois aspectos que também são importantes para os cálculos quânticos presentes neste trabalho. Primeiro, vamos retomar a discussão sobre conjuntos de bases que iniciamos na seção 2.2. Depois, explicaremos resumidamente dois métodos utilizados para aproximar cargas atômicas, informação necessária para realizar a simulação clássica. 


\subsubsection{Conjunto de Bases}

Na seção 2.2 enquanto discutíamos HF, dissemos que os orbitais moleculares $\varphi_{i}$ eram obtidos a partir dos orbitais atômicos $\phi_{\mu}$, usando a aproximação LCAO, definida na expressão 2.12. Entretanto, restou um ponto em aberto: como representar $\phi_{\mu}$ matematicamente.

Isso na verdade é uma grande questão e dificuldade em Mecânica Quântica Molecular e que envolve, além da descrição realista, a eficiência computacional e a precisão dos resultados. Várias são as propostas para enfrentar esse problema, mas de um modo geral, as funções encontradas na literatura podem ser subdivididas em dois grupos: as do tipo Slater (STO) e as do tipo Gaussianas (GTO).

As funções STO têm como inspiração o comportamento da função de onda do átomo de Hidrogênio que é conhecida analiticamente. Assim, funções STO apresentam um decaimento exponencial em função da distância ao núcleo e podem ser escritas, em coordenadas esféricas, como

$$
\phi_{n l m \zeta}(r, \theta, \phi)=\frac{(2 \zeta)^{n+\frac{1}{2}}}{[(2 n) !]^{\frac{1}{2}}} Y_{l m}(\theta, \phi) r^{n-1} e^{-\zeta r}
$$

com $n, l, m$ os números quânticos usuais, $Y_{l m}(\theta, \phi)$ os Harmônicos Esféricos e $\zeta$ uma constante relacionada com a carga efetiva do núcleo.

Apesar do comportamento correto, essas funções podem tornar os cálculos das integrais multieletrônicas muito complexos.

As funções GTO se aproveitam do fato que o produto de duas gaussianas em dois pontos distintos do espaço é igual a uma gaussiana centrada em um ponto ao longo do eixo que as conecta, de tal maneira que as integrais de três e quatro índices tornam-se facilmente integrais de dois índices. Funções GTO, em coordenadas cartesianas, podem ser escritas na forma

$$
\phi_{l_{x} l_{y} l_{z} \zeta}(x, y, z)=\left(\frac{2 \zeta}{\pi}\right)^{\frac{3}{4}}\left[\frac{l_{x} ! l_{y} ! l_{z} !(8 \zeta)^{l_{x}+l_{y}+l_{z}}}{\left(2 l_{x}\right) !\left(2 l_{y}\right) !\left(2 l_{z}\right) !}\right]^{\frac{1}{2}} x^{l_{x}} y^{l_{y}} z^{l_{z}} e^{-\zeta\left(x^{2}+y^{2}+z^{2}\right)}
$$


onde $\zeta$ é a largura da gaussiana e $l_{k}$ é a componente do momento angular na direção $k$.

Um problema surge com orbitais do tipo $d$ e maiores, pois a degenerescência em coordenadas cartesianas é maior do que em coordenadas esféricas. Para o caso do orbital $d$, temos 6 combinações possíveis para $l_{x}+l_{y}+l_{z}=2$, ao invés de 5 . Isso pode ser corrigido definindo combinações lineares desses fatores; procedimento análogo deve ser feito para orbitais $f$.

Outro problema é que uma gaussiana não reflete o comportamento de um orbital atômico, sendo necessária uma combinação de gaussianas para isso, cujos coeficientes são otimizados para certos átomos.

Apesar desses inconvenientes, essas funções têm sido largamente empregadas, pois apresentam um bom compromisso entre eficiência computacional e precisão, além de que um dos pacotes de química quântica mais utilizado da atualidade, o Gaussian, como o próprio nome sugere, as utiliza. Parte da eficiência vem de outra propriedade matemática das gaussianas: um conjunto de gaussianas pode ser representado por uma única gaussiana (que é dita contraída, enquanto as que a compõem são as primitivas). Assim, uma escolha adequada de gaussianas diminui em muito a quantidade de coeficientes que precisam ser otimizados para compor a base.

Como nossos cálculos quânticos a nível ab initio e DFT foram feitos utilizando o Gaussian 03, nós usamos bases GTO, de modo que vamos detalhá-las um pouco mais.

\section{Algumas funções gaussianas e suas auxiliares}

O primeiro conjunto de bases gaussianas foi construído por Hehre et al e foi batizado de STO-XG (Slater Type Orbitals approximated by X gaussians) [67]. Eles demonstraram que o menor $\mathrm{X}$ possível para se obter os aspectos mais básicos dos orbitais é 3; esse conjunto (STO-3G) passou a ser conhecido como base mínima. No entanto, essa base possui apenas uma função para cada tipo de orbital, não contribuindo muito para a melhora dos resultados.

Uma melhor descrição pode ser obtida usando funções diferentes para descrever orbitais de valência e de caroço. Essas funções são chamadas de split valence e um dos conjuntos mais utilizados foi desenvolvido por Pople et al. [67]: trata-se das funções $i$ $j k G$. A nomenclatura pode parecer um pouco estranha, mas é bem útil: $i$ é o número de funções gaussianas contraídas usadas para descrever orbitais do caroço, $j k$ indica que os 
orbitais de valência são subdivididos em duas partes: uma composta pelos orbitais de valência mais internos e que são representados pela contração de $j$ gaussianas primitivas, e a outra, com os orbitais de valência mais externos e representados pela contração de $k$ gaussianas primitivas (o G, obviamente, é de gaussianas). Há também funções com três índices após o hífen, indicando que a região de valência está subdividida em três partes (triple split valence).

Outro conjunto de bases muito utilizado é o de Dunning e Huzinaga (DH) [67], chamado de correlation consistent polarized $V n-\zeta(c c-p V n Z)$, cujos os coeficientes são otimizados para cálculos que incluem correlação eletrônica em elétrons de valência (daí o nome correlation consistent), além do conjunto incluir polarização; $V$ é para indicar que o conjunto descreve apenas orbitais de valência; $n-\zeta$ indica que há $n$ funções base para cada tipo de orbital (essa nomenclatura remota ao fato que $\zeta$ é geralmente utilizado para designar o expoente das funções STO, como em 2.43 [67]). Essas bases, diferentemente das de Pople, não tem a restrição de usarem os mesmos expoentes para descrever os orbitais $s$ e $p$, o que as torna mais flexíveis e também computacionalmente mais dispendiosas, pois possuem um maior número de funções.

As bases de Pople e de DH são as mais usadas atualmente por sua eficiência e pelos bons resultados que apresentam. Há também funções complementares que podem ser usadas para melhorar ainda mais a descrição:

- Funções Polarizadas: Essas funções visam incluir o efeito de deformação que um orbital pode sofrer por estar na presença de outro orbital. Para as bases de Pople, funções polarizadas são indicadas no final do nome da base, usando um “*” ou "(d)" para indicar que um conjunto de funções $d$ foi adicionado para polarizar as funções $p$; “**” ou “(d,p)” é usado para indicar que além da polarização anterior, funções $p$ foram acrescentadas nos átomos de $\mathrm{H}$ e $\mathrm{He}$; um número natural $n$ é acrescentado antes do $d$ e/ou $p$ para designar que foram acrescentadas $n$ funções daquele tipo. Não há como especificar funções polarizadas para bases $\mathrm{DH}$, posto que elas já pressupõem polarização em sua construção;

- Funções Difusas: acrescentam mais funções ao mesmo tipo de orbital, numa tentativa de descrever a tendência que os elétrons fracamente ligados possuem 
de se localizar em regiões mais afastadas dos orbitais. Nas bases de Pople, essas funções são designadas com "+” antes do $G$ (um para indicar funções difusas nos átomos mais pesados, dois para adicioná-las também aos de $\mathrm{H}$ e $\mathrm{He}$ ). Para $\mathrm{DH}$, funções difusas para todos os átomos são especificadas com o prefixo "aug".

Neste trabalho nós utilizamos as bases aug-cc-pVDZ, 6-311++G(d,p) e $6-311++G(2 d, 2 p)$.

\subsubsection{Métodos para calcular cargas atômicas parciais}

Na seção 1.3.3, vimos que as cargas de cada átomo fazem parte das informações necessárias para realizar a simulação clássica, posto que usamos um potencial $\mathrm{LJ}+\mathrm{C}$. Em nosso trabalho, dois métodos para ajustar cargas foram utilizados: Merz-SinghKollman (MK) [70] e CHELPG (CHarges from ELectrostatic Potentials using a Grid based method) [71]. CHELPG foi o método propriamente utilizado, sendo que ajustes usando MK foram realizados por completeza, apenas para mostrar que as cargas obtidas dependem muito pouco do método utilizado. Descreveremos a seguir os conceitos envolvidos nesses métodos.

- CHELPG: Nesse procedimento, cargas atômicas são ajustadas para reproduzir o potencial eletrostático molecular (PEM) com certo número de pontos ao redor da molécula. Primeiramente, o PEM é calculado em pontos de uma grade tridimensional, que contém a molécula e da qual foi descontada a região referente às esferas definidas pelo raio de van der Waals da cada átomo. Os pontos estão espaçados de 3.0 pm e a grade é 28 pm maior que a molécula em todas as direções (figura 2.1).

Após o cálculo do PEM em todos os pontos de grade válidos, as cargas são ajustadas nos átomos de forma a reproduzi-lo, com a única restrição de que a soma deve ser igual à carga total do sistema. As cargas obtidas dessa maneira não necessariamente reproduzem o momento de dipolo da molécula, mas esse vínculo também pode ser imposto. CHELPG é muito utilizado por ser um método que apresenta pouca dependência com o tamanho da base quando utilizado com HF, MP2 e B3LYP [72]. A fraqueza é a determinação das cargas 
para moléculas grandes: nesse caso, os átomos mais internos estarão muito longe da grade e quase não contribuirão para o PEM, de forma que os valores de cargas ajustados neles podem ser muito irreais.

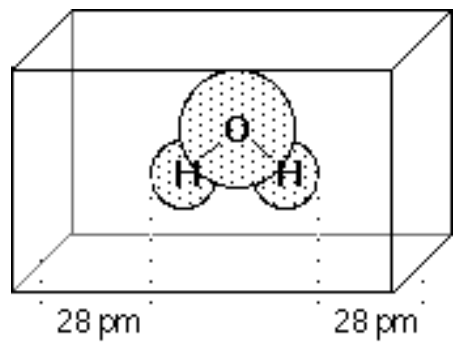

Figura 2.1: Construção da grade tridimensional usada no método CHELPG para ajustar cargas atômicas em moléculas. Como exemplo, utilizamos a molécula de água (extraída de [73]).

- MK: Este procedimento é análogo ao anterior sendo a principal diferença a construção da grade para calcular o PEM: aqui ela é composta por quatro camadas que seguem o formato definido pelas esferas de van der Waals, mas com os raios multiplicados por 1.4, 1.61 .8 e 2.0 (figura 2.2).

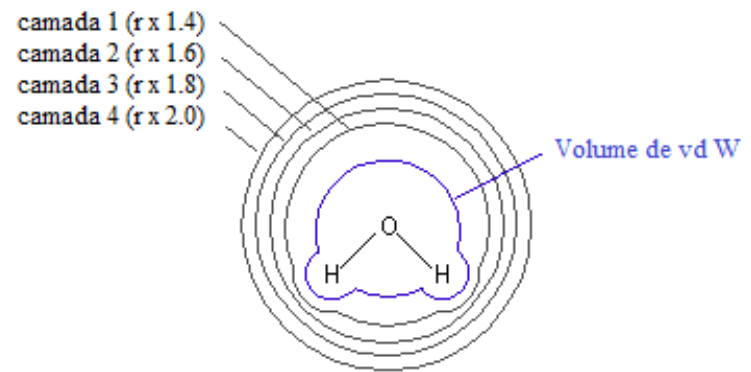

Figura 2.2: Grade usada pelo procedimento MK para calcular o potencial eletrostático que é usado para ajustar as cargas atômicas. A molécula de água é usada como exemplo (adaptada de [74]).

Novamente, a única restrição é que a soma das cargas obtidas seja igual a carga total do sistema. MK tem uma leve dependência com o método utilizado [72]. O método também é dependente do número de camadas: aparentemente, um número maior de camadas fornece um valor mais realista das cargas. 


\section{Capítulo 3 Resultados}

Agora que estamos familiarizados com toda a metodologia empregada neste trabalho, podemos discutir os resultados obtidos. Como dissemos na introdução, nosso objetivo é a determinação dos valores da energia de excitação da $5 F U$ quando interagindo com água e com acetonitrila e a análise de uma possível inversão desses estados excitados quando comparados com a molécula isolada. Valendo-se do fato que a variação do espectro da 5FU de um solvente para outro é pequena, nós utilizamos os valores obtidos como um parâmetro para avaliar os diferentes procedimentos teóricos utilizados.

\subsection{Otimização de Geometria}

O primeiro ponto a ser considerado é que há mais de uma geometria possível para a 5FU, devido aos seus tautômeros e rotâmeros, como mostra a figura 3.1. Assim, em um primeiro momento, uma discrição correta englobaria cálculos que seguissem a distribuição populacional dessas formas. No caso do método S-QM/MM, a média teria que ser composta seguindo a proporção desta distribuição.

Entretanto, em estudos experimentais realizados em moléculas simulares, como U, apenas a forma A (topo da figura 3.1) foi encontrada [75,76]. Markova et al [77] obtiveram esse mesmo resultado experimental para a 5FU e explicaram esse resultado otimizando as possíveis geometrias usando um nível de cálculo apreciável (MP4/6$31++\mathrm{G}(\mathrm{d}, \mathrm{p}) / / \mathrm{MP} 2 / 6-31+\mathrm{G}(\mathrm{d}, \mathrm{p}))$. Eles encontraram que o estado fundamental da forma A tem uma energia que é $8.55 \mathrm{kcal} / \mathrm{mol}$ mais baixa que a segunda forma mais estável, que foi identificada como sendo a forma B. Esse estudo também apresenta como essas energias variam considerando a interação com 3 moléculas de água, formando um 
pequeno aglomerado. Nesse caso, a diferença diminuiu para $7.76 \mathrm{kcal} / \mathrm{mol}$. Apesar de essa diferença ser considerável, ela poderia ser vencida simplesmente por flutuações térmicas do líquido. Assim, a barreira de ativação também foi calculada (figura 3.2), mostrando que o processo da forma A ser convertida em B ou D (a terceira mais estável) é totalmente desfavorável, corroborando o resultado experimental. Essa forma é chamada na literatura de forma diketo $^{13}$ e também, menos comumente, de dioxi.<smiles>O=c1[nH]c(I)c(F)c(=O)[nH]1</smiles><smiles>O=c1[nH]c(O)ncc1F</smiles>

B<smiles>O=c1nc(O)[nH]cc1F</smiles>

$\mathrm{C}$<smiles>O=c1nc(O)c(F)c[nH]1</smiles>

D<smiles>Oc1nc(O)c(F)c(O)n1</smiles>

E<smiles>O=c1ncc(F)c(O)[nH]1</smiles>

F<smiles>O=c1[nH]c(O)ncc1F</smiles>

B1<smiles>O=c1nc(O)[nH]cc1F</smiles>

C1<smiles>O=c1nc(O)c(F)c[nH]1</smiles>

D1<smiles>Oc1nc(O)c(F)c(O)n1</smiles>

E1

E2

E3

Figura 3.1: Tautômeros e rotâmeros da 5FU. Extraído de [77].

${ }^{13} \mathrm{O}$ grupo keto ou ketone é composto pela estrutura $\mathrm{RC}(=\mathrm{O}) \mathrm{R}$ '. Seu nome vem da palavra alemã para acetona (Aketon), o exemplo mais simples desse grupo. 


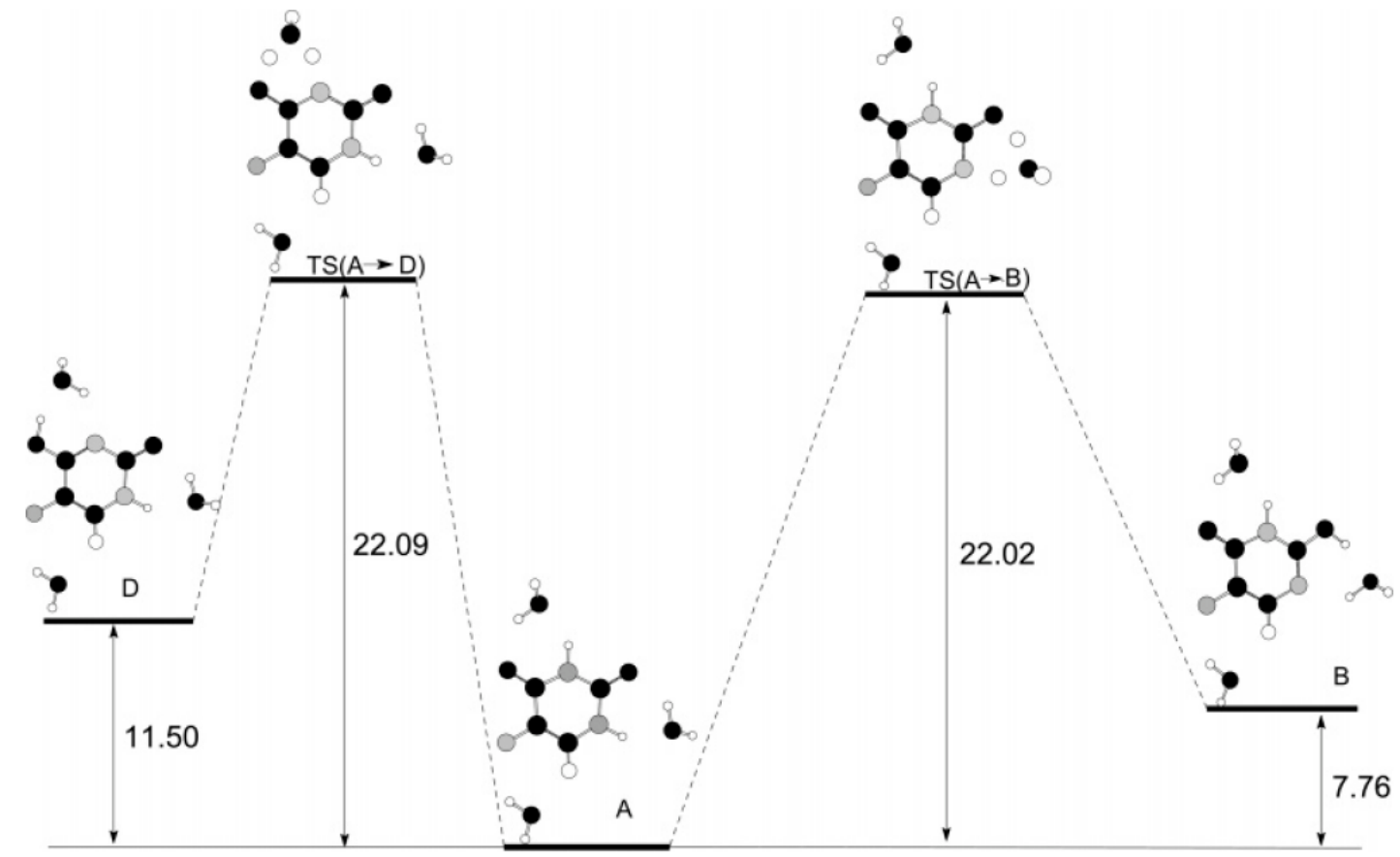

Figura 3.2: Energia de ativação dos três tautômeros mais estáveis da 5FU. Extraído de [77].

A partir desses resultados, consideramos em nosso estudo apenas a forma diketo da 5FU. Sua geometria foi obtida utilizando o funcional híbrido $B 3 L Y P$, com a base aug-cc-pvdz, usando o programa Gaussian 03, em duas situações: i) 5FU em vácuo e ii) 5FU em meio, aqui representado pelo PCM, considerando dois solventes distintos: água $(\varepsilon=78,39)$ e acetonitrila $\left(\mathrm{CH}_{3} \mathrm{CN}, \varepsilon=36,64\right)$. Cálculos de espectro de infravermelho na aproximação harmônica foram realizados apenas para verificar se as geometrias obtidas representavam pontos de mínimo. Não observamos mudança significativa entre as diferentes geometrias obtidas (figura 3.3). Para os cálculos subsequentes, as geometrias obtidas em meio foram utilizadas.

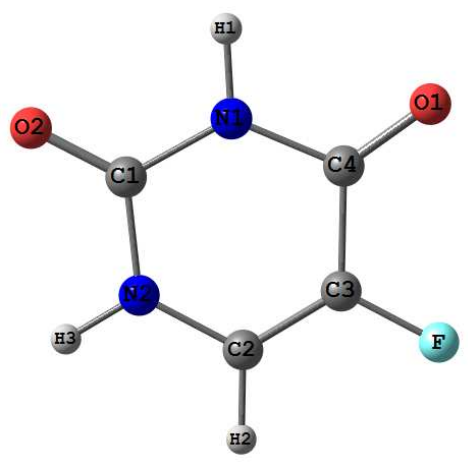

Figura 3.3: Geometria otimizada da 5FU em vácuo. Os números após cada átomo são apenas para diferenciá-los, afim de melhor indicá-los no texto. 


\subsection{Simulação Clássica}

\subsubsection{Parâmetros}

Para a simulação clássica nós utilizamos o programa Dice que, como explicado no Capítulo 1, utiliza o potencial de LJ + C (equação 1.3) para descrever as interações sítio-sítio. Dessa maneira, além da geometria do soluto e do solvente, é necessário fornecer as cargas e os parâmetros $\mathrm{LJ} \varepsilon$ e $\sigma$.

Os parâmetros LJ são bem estabelecidos na literatura, em especial os parâmetros OPLS-AA, que foram os que nós utilizamos (tabela 3.1).

Tabela 3.1: Parâmetros OPLS para os

\begin{tabular}{ccc} 
átomos da molécula 5FU. \\
\hline \hline Átomo & $\boldsymbol{\varepsilon}(\mathbf{k c a l} / \mathbf{m o l})$ & $\boldsymbol{\sigma}(\mathbf{A})$ \\
\hline $\mathrm{N}$ & 0.170 & 3.25 \\
$\mathrm{C}$ em C = O & 0.105 & 3.75 \\
outros C & 0.080 & 3.50 \\
H ligado a N & 0.000 & 0.00 \\
H ligado a C & 0.050 & 2.50 \\
O & 0.210 & 2.96 \\
$\mathrm{~F}$ & 0.061 & 2.94 \\
\hline \hline
\end{tabular}

As cargas foram obtidas utilizando dois métodos diferentes: CHELPG e MK (seção 2.6.2), usando o nível de cálculo MP/aug-cc-pVDZ. Os resultados são apresentados na tabela 3.2 (página seguinte).

A comparação de cálculos teóricos com resultados experimentais de momento de dipolo de moléculas imersas em solução líquida é difícil, pois esses estudos são escassos na literatura e nós não encontramos nenhum resultado para a 5FU. Mesmo valores para a fase gasosa são poucos, e novamente não foi encontrado nenhum para a 5FU. Há um resultado experimental do momento de dipolo da $\mathrm{U}$ em fase gasosa, cujo valor é 3.87D [78], muito próximo do valor que obtivemos para a 5FU isolada. Isso vem do fato da carga do F ser pequena (-0.17), o mesmo ocorrendo com a carga do $\mathrm{H}$ da $\mathrm{U}$ nessa posição (0.17 como calculado em [79]) e, portanto, ambas contribuem pouco para o momento de dipolo de suas respectivas moléculas.

Observando as colunas fica muito claro que os esquemas MK e CHELPG levam a resultados muito próximos. Os resultados em PCM obtidos com MK são ligeiramente 
Tabela 3.2: Cargas (em Coulomb) e momentos de dipolo (em Debye) da 5FU otimizada em vácuo e em meio (PCM), obtidos usando CHELPG e MK.

\begin{tabular}{|c|c|c|c|c|c|c|c|c|c|c|}
\hline \multirow{3}{*}{$\begin{array}{l}\text { 5FU otimiz. em: } \\
\text { meio }^{+}: \\
\text {esquema: }\end{array}$} & \multicolumn{6}{|c|}{ vácuo } & \multicolumn{4}{|c|}{ meio } \\
\hline & \multicolumn{2}{|c|}{ vácuo } & \multicolumn{2}{|c|}{ água } & \multicolumn{2}{|c|}{ acetonitrila } & \multicolumn{2}{|c|}{ água } & \multicolumn{2}{|c|}{ acetonitrila } \\
\hline & chelpg & $M K$ & chelpg & $M K$ & chelpg & $M K$ & chelpg & $M K$ & chelpg & $M K$ \\
\hline N1 & -0.6469 & -0.6168 & -0.6911 & -0.6619 & -0.6910 & -0.6624 & -0.7018 & -0.6121 & -0.7029 & -0.6147 \\
\hline $\mathrm{C} 1$ & 0.7933 & 0.7535 & 0.8741 & 0.8369 & 0.8726 & 0.8357 & 0.8886 & 0.7970 & 0.8874 & 0.7969 \\
\hline $\mathrm{N} 2$ & -0.5238 & -0.5225 & -0.5603 & -0.5608 & -0.5596 & -0.5601 & -0.5613 & -0.5216 & -0.5613 & -0.5222 \\
\hline $\mathrm{C} 2$ & 0.0077 & -0.0382 & 0.0488 & 0.0043 & 0.0473 & 0.0025 & 0.0689 & 0.0098 & 0.0674 & 0.0083 \\
\hline C3 & 0.0349 & 0.0341 & 0.0045 & 0.0044 & 0.0054 & 0.0053 & -0.0110 & -0.0008 & -0.0106 & -0.0011 \\
\hline $\mathrm{C} 4$ & 0.6965 & 0.6765 & 0.7688 & 0.7524 & 0.7666 & 0.7505 & 0.7886 & 0.7319 & 0.7871 & 0.7314 \\
\hline $\mathrm{H} 1$ & 0.3672 & 0.3662 & 0.4263 & 0.4249 & 0.4247 & 0.4235 & 0.4357 & 0.4211 & 0.4340 & 0.4198 \\
\hline O1 & -0.5112 & -0.5024 & -0.6267 & -0.6202 & -0.6229 & -0.6164 & -0.6471 & -0.6327 & -0.6424 & -0.6280 \\
\hline $\mathrm{F}$ & -0.1746 & -0.1611 & -0.2017 & -0.1893 & -0.2006 & -0.1882 & -0.2056 & -0.1917 & -0.2042 & -0.1901 \\
\hline $\mathrm{H} 2$ & 0.1744 & 0.1965 & 0.2134 & 0.2349 & 0.2125 & 0.2342 & 0.2110 & 0.2334 & 0.2100 & 0.2326 \\
\hline H3 & 0.3551 & 0.3703 & 0.4233 & 0.4386 & 0.4218 & 0.4370 & 0.4292 & 0.4358 & 0.4274 & 0.4341 \\
\hline $\mathrm{O} 2$ & -0.5728 & -0.5561 & -0.6796 & -0.6644 & -0.6768 & -0.6616 & -0.6952 & -0.6701 & -0.6919 & -0.6670 \\
\hline$\overline{\text { dipolo esq. }{ }^{\dagger}:}$ & 3.901 & 3.892 & 5.550 & 5.546 & 5.504 & 5.500 & 5.904 & 5.913 & 5.834 & 5.844 \\
\hline dipolo : & 3.8 & & 5.5 & & 5.5 & & 5.9 & & & \\
\hline
\end{tabular}

${ }^{+}$Meio em que a carga foi obtida;

† Dipolo resultante das cargas do esquema;

₹Dipolo obtido com nível de cálculo MP2/aug-cc-pVDZ. 
mais próximos dos valores quânticos, já que MK usa uma grade para o cálculo que possui forma semelhante ao contínuo construído pelo método PCM. Entretanto, optamos trabalhar com as cargas obtidas utilizando CHELPG, já que esse método tem sido largamente utilizado pelo nosso grupo e vem apresentando excelentes resultados [34,79-81]. Também fica clara a importância da polarização, que neste caso foi obtida implicitamente com PCM, (compare os resultados para a molécula isolada e em meio). Vemos não só a alteração nas cargas, como também um considerável acréscimo no momento de dipolo, cujo valor em meio é cerca de $50 \%$ maior do que o valor obtido em vácuo. Note, porém, que o valor em ambos os solventes é muito próximo, o que não parece ser razoável, dada a grande diferença na constante dielétrica e na composição. Discutiremos mais sobre isso na seção 3.3.1, onde estudaremos esses resultados com mais detalhes e abordaremos a obtenção da polarização utilizando um procedimento iterativo.

Um dos cuidados que tomamos foi o de arredondar o valor das cargas para que essas somassem zero, pois mesmo pequenos valores de carga residual podem contribuir para resultados espúrios.

Quanto às moléculas de solvente, ambas já foram exaustivamente estudadas e seus parâmetros e geometria são bem conhecidos. Para a água, há uma infinidade de modelos (uma discussão detalhada sobre os principais deles é feita na referência [82]). Esses modelos são construídos para representar as propriedades termodinâmicas da água em certos intervalos de temperatura e pressão e tentam até representar algumas de suas anomalias, mas eles não são pensados para reproduzir propriedades quânticas. Assim, uma vez que se use no intervalo de validade apropriado, todos são equivalentes para os cálculos quânticos. Nossa escolha foi o modelo Simple Point Charge (SPC) [25], proposto em 1981 por Berendsen et al., para simular água líquida em condições normais de temperatura e pressão com um baixo custo computacional ${ }^{14}$. Nesse modelo apenas o oxigênio possui parâmetros LJ, sendo os hidrogênios representados simplesmente por cargas pontuais, daí o nome do modelo (tabela 3.3). Apesar de sua simplicidade, o modelo apresenta bons resultados e é largamente utilizado até hoje.

\footnotetext{
${ }^{14}$ Eles estavam interessados em estudos de dinâmica molecular de proteínas em água. Lembrando que na época, o computador mais rápido do mundo era o supercomputador CRAY-1, instalado em Los Alamos, com 8Mb de Memória RAM e velocidade de processamento de 160 Megaflops.
} 
Tabela 3.3: Modelo SPC para a água. Extraído de [25].

\begin{tabular}{ccccccc}
\hline \hline Átomo & $\mathbf{x}$ & $\mathbf{y}$ & $\mathbf{z}$ & carga & $\boldsymbol{\varepsilon}(\mathbf{k c a l} / \mathbf{m o l})$ & $\boldsymbol{\sigma}(\dot{\mathbf{A}})$ \\
\hline $\mathrm{O}$ & 0.0000 & 0.0000 & 0.0000 & -0.8200 & 0.1550 & 3.1650 \\
$\mathrm{H}$ & 0.5774 & 0.8165 & 0.0000 & 0.4100 & 0.0000 & 0.0000 \\
$\mathrm{H}$ & 0.5774 & -0.8165 & 0.0000 & 0.4100 & 0.0000 & 0.0000 \\
\hline \hline
\end{tabular}

Para a acetonitrila, a quantidade de modelos é bem mais escassa. Optamos pelo modelo mais comumente usado na literatura [83] (tabela 3.4).

Tabela 3.4: Modelo para a acetonitrila. Extraído de [83].

\begin{tabular}{ccccccc}
\hline \hline Átomo & $\mathbf{x}$ & $\mathbf{y}$ & $\mathbf{z}$ & $\mathbf{c a r g a}$ & $\boldsymbol{\varepsilon}(\mathbf{k c a l} / \mathbf{m o l})$ & $\boldsymbol{\sigma}(\mathbf{A})$ \\
\hline $\mathrm{C}$ & -1.3645 & -1.245 & -0.8138 & 0.488 & 0.0998 & 3.4 \\
$\mathrm{~N}$ & -0.4452 & -0.9266 & -0.1637 & -0.514 & 0.0998 & 3.3 \\
$\mathrm{C}$ & -2.5116 & -1.6424 & -1.6249 & -0.577 & 0.0998 & 3.0 \\
$\mathrm{H}$ & -2.4031 & -1.2505 & -2.633 & 0.201 & 0.0200 & 2.2 \\
$\mathrm{H}$ & -2.5736 & -2.7267 & -1.6687 & 0.201 & 0.0200 & 2.2 \\
$\mathrm{H}$ & -3.4259 & -1.2505 & -1.1866 & 0.201 & 0.0200 & 2.2 \\
\hline \hline
\end{tabular}

\subsubsection{Simulação e Análise}

Usando o programa DICE realizamos simulações de 200000 passos/molécula de 1 molécula de 5FU imersa em 499 moléculas de solvente (água e acetonitrila) no ensemble NVT, em condições normais de temperatura e pressão, após uma etapa de termalização de 50000 passos/molécula no mesmo ensemble e condições.

Analisando-as, nós obtemos as seguintes informações:

- Função de distribuição radial de pares:

Como discutido na seção 1.3.4, a função de distribuição radial de pares $G(r)$ pode ser usada para obter informações da distribuição do solvente em torno do soluto. As funções $G(r)$ obtidas usando MDDF da 5FU em meio solvente são apresentadas na figura 3.4 . 
a)

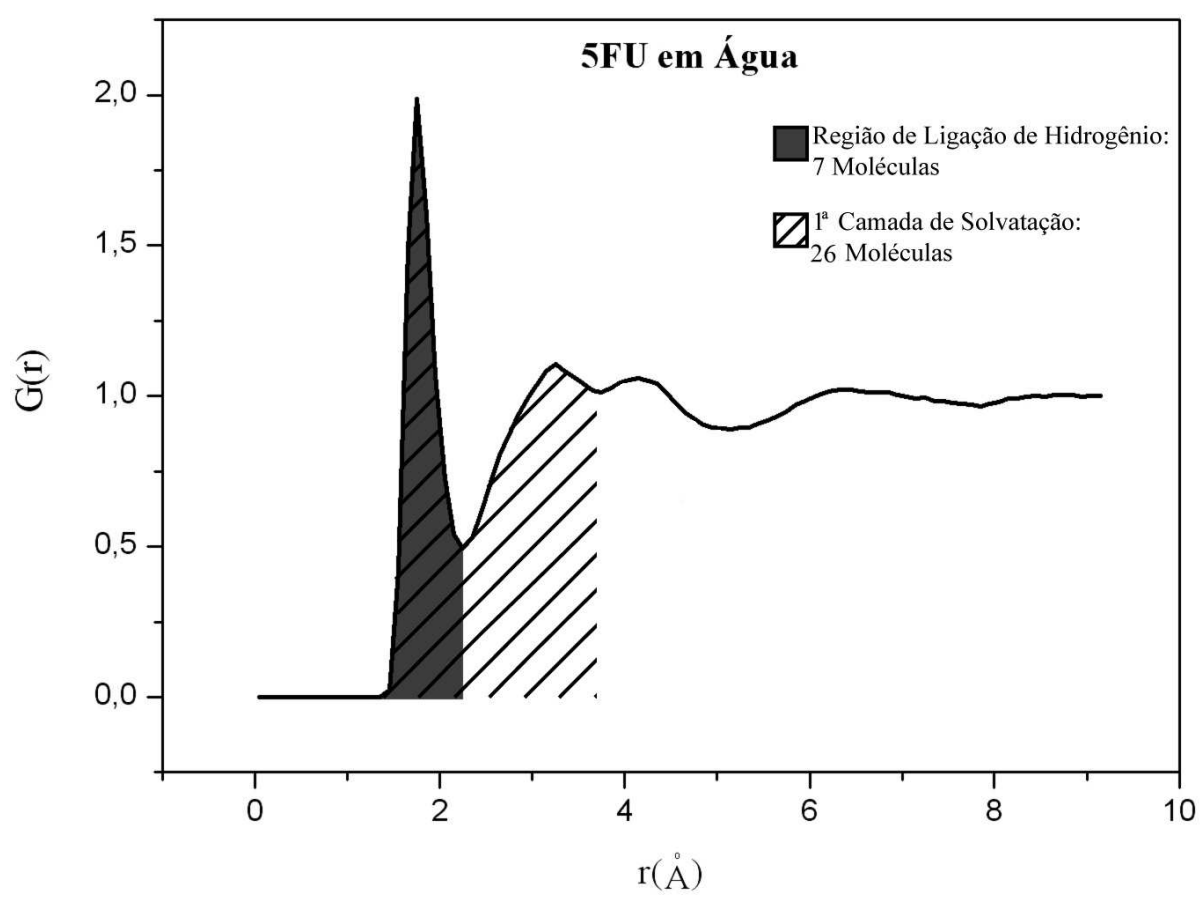

b)

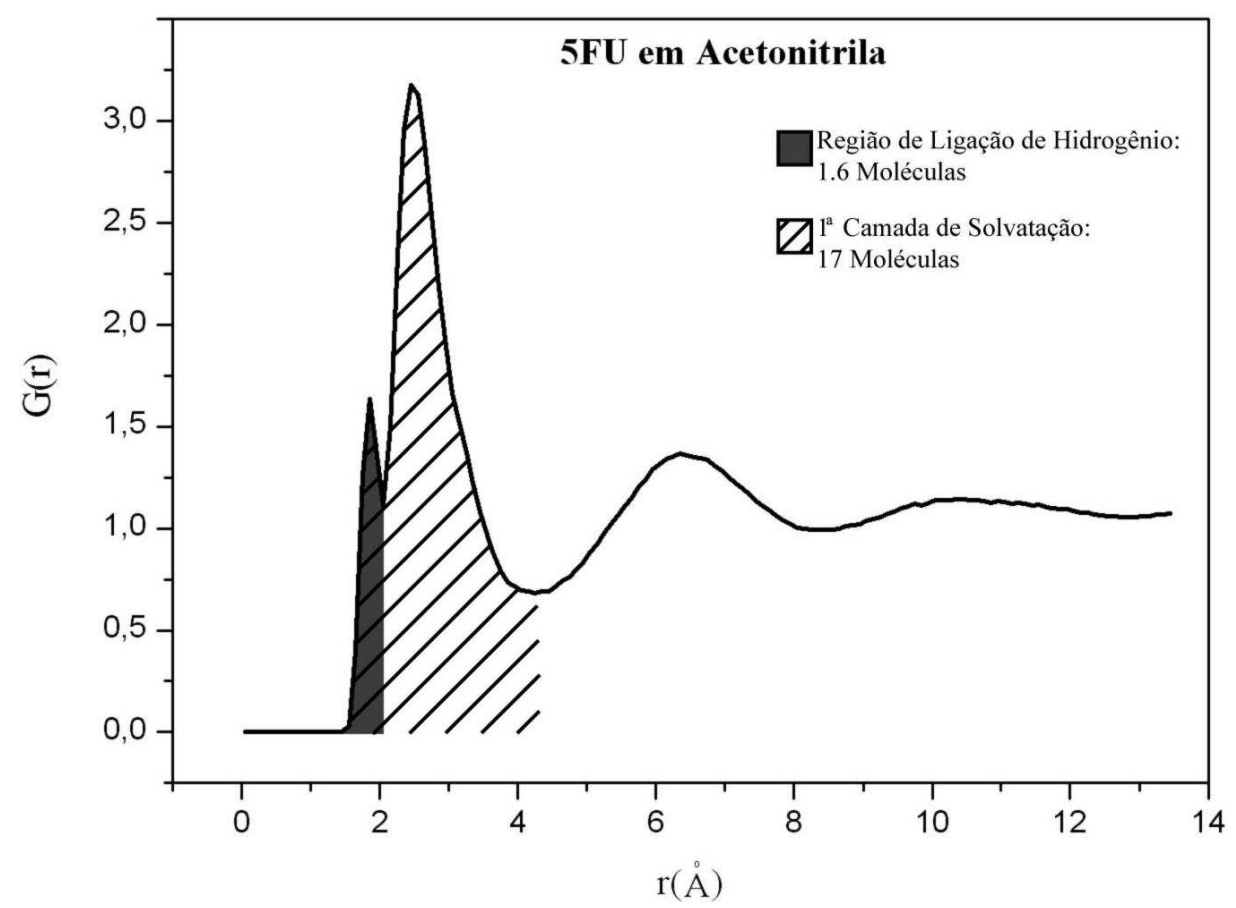

Figura 3.4: Função de distribuição radial de pares $G(r)$, considerando a distribuição de mínima distância, obtida simulando 5FU em meio solvente: a) água; b) acetonitrila. A quantidade de moléculas até uma dada distância é obtida integrando-se a curva até essa distância. 
A G(r) da 5FU em água (figura 3.4a) apresenta um primeiro pico bem definido que termina pouco após $2 \AA$. Este pico está associado às pontes de hidrogênio que o solvente faz com o soluto. No fim do pico temos 7 moléculas de água, o que parece exagerado para um soluto não muito grande como a 5FU. Olhando para a figura 3.3, podemos notar apenas 5 sítios disponíveis para tal fim: os dois oxigênio e os três hidrogênios, o que parece levar a uma inconsistência. Porém, a distância entre átomos não é o único critério para estabelecer uma ligação de hidrogênio. Usualmente usam-se também critérios para o ângulo dos átomos participantes e para a energia entre eles. Nós não fizemos este tipo de análise, de forma que nos basearemos apenas na distância.

Depois da região de ligação de hidrogênio, a função G(r) cresce e estabelece um novo pico, apresentando novamente um mínimo por volta de $4 \AA$. Essa nova região, somada à camada anterior, compõe a primeira camada de solvatação, que contém 26 moléculas de água. Temos então um novo pico e novo vale, definindo a segunda camada de solvatação, que contém 30 moléculas de água, totalizando 56 moléculas até uma distância de $5.3 \AA$.

Para a 5FU em acetonitrila, a G(r) é similar, mas têm características próprias, a começar pelo primeiro pico, relacionado às pontes, que é bem menor e pouco pronunciado se comparado com a água, terminando rapidamente e indicando a presença de apenas 2 moléculas. Isso se deve ao fato da acetonitrila ser um solvente aprótico, diminuindo a quantidade de pontes. Apressadamente, poderia-se dizer que seriam ligações dos hidrogênios da acetonitrila com os oxigênios da 5FU. Note, porém, que as cargas dos hidrogênios usadas no modelo para acetonitrila são pequenas (tabela 3.4). O átomo com a maior carga positiva é o carbono ligado ao nitrogênio. $\mathrm{O}$ nitrogênio tem a carga mais negativa e, como está ligado a apenas um carbono, está suscetível a interagir com os hidrogênios da 5FU (obviamente, isto não é uma ponte de hidrogênio no sentido usual, é apenas um indicativo das moléculas de solvente que interagem mais fortemente com o soluto).

Essa breve região de interações mais fortes é seguida de um novo pico da função G(r) e um mínimo local pouco após $4 \AA ̊$. Juntas, elas definem a primeira camada de solvatação, contendo 17 moléculas de acetonitrila, pouco mais que a metade se compararmos com a primeira camada de água, o que é coerente já que a molécula de acetonitrila é praticamente 2 vezes maior que a de água. A segunda camada termina por volta de $8.7 \AA ̊$, tendo 56 moléculas, totalizando 73 até essa distância. 
- Autocorrelação da energia:

Como discutido também na seção 1.3.4, uma das grandes vantagens da metodologia S-QM/MM é o baixo número de cálculos quânticos que são necessários para compor a média convergida da propriedade de interesse. Para que isso ocorra, usamos a função de autocorrelação da energia (equação 1.8), de modo a calcular a correlação estatística entre as configurações geradas por MC e separar algumas poucas mais representativas.

Como dissemos também, para processos markovianos, essa função apresenta um decaimento exponencial (equação 1.9). Na prática, duas exponenciais são suficientes para descrever essa função, como mostrado na figura 3.5.

a)

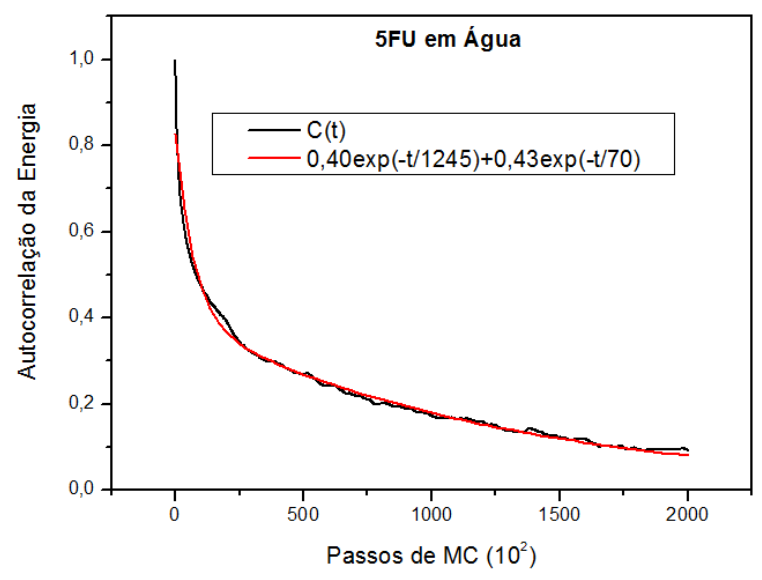

b)

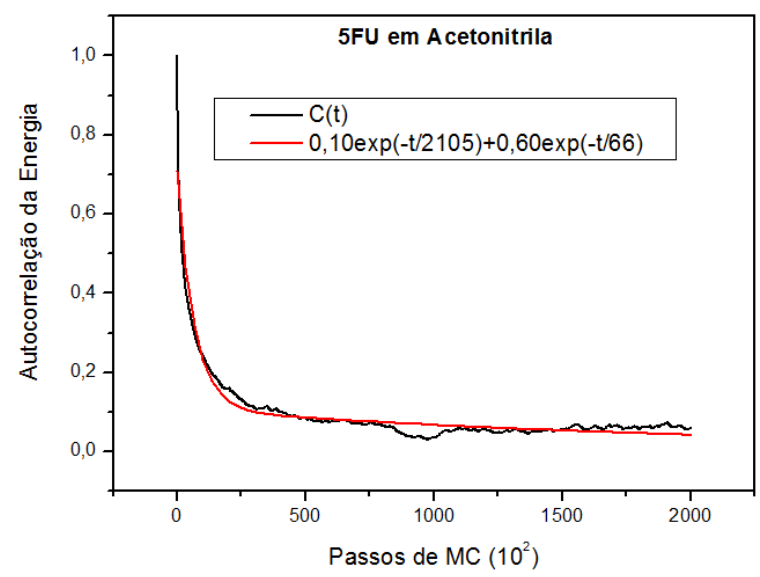

Figura 3.5: Ajuste da função de autocorrelação da energia para simulação de uma molécula de 5FU em 499 moléculas de solvente: a) água; b) acetonitrila.

A partir dos ajustes obtidos, optamos em usar uma configuração a cada $2000 \mathrm{em}$ ambos os casos, um total de 100 configurações cada, o que dá uma correlação de aproximadamente $8 \%$ para as configurações cujo solvente é a água e $4 \%$ para as configurações em que o solvente é a acetonitrila. 


\subsection{Cálculos Quânticos e Resultados Obtidos}

\subsubsection{Determinação do deslocamento espectral da transição de maior intensidade da 5FU em água e em acetonitrila}

Uma vez determinadas as configurações estatisticamente relevantes, iniciamos os cálculos quânticos para a determinação do deslocamento espectral.

Para a escolha do nível de cálculo levamos em consideração dois pontos: resultados experimentais e teóricos já conhecidos [4,84] e limitações computacionais.

Inicialmente, para determinação da energia de excitação, nossos testes em fase gasosa e modelo PCM mostravam dois modelos como sendo os mais promissores: B3LYP/aug-cc-pVDZ e CIS(D)/aug-cc-pVDZ.

Para representar o solvente, uma boa aproximação seria incluir no cálculo a primeira camada de solvatação de maneira explícita e o restante das moléculas como um Electrostatic Embedding (EE), representando seus átomos por cargas pontuais (c.p). Mas, como pode ser observado na figura 3.4, essa camada possui 26 moléculas para água e 17 para a acetonitrila, o que torna os cálculos inviáveis.

Passamos então a outra abordagem: tratando inicialmente do caso em que a água é o solvente, incluímos moléculas de solvente explícitas aos poucos para ver o quanto sua presença influencia o resultado. Primeiramente representamos o solvente apenas pelo EE. Depois incluímos 07, 10, 12, 14 e finalmente 16 moléculas explícitas de água mais próximas do soluto segundo o critério de mínima distância, sempre envolvidas pelo EE e mantendo o número total de moléculas fixo, 255, pouco mais da metade das moléculas contidas na caixa (figura 3.6).

Entretanto, a inclusão de moléculas explícitas tornou os cálculos muito custosos. Reduzimos então a base para 6-311++G(d,p), já que tal alteração influi pouco nos resultados, porém torna os cálculos bem menos dispendiosos [85]. Mesmo assim os cálculos que envolviam solvente explícito usando o método CIS(D) permaneceram inviáveis: além do tempo para calcular cada configuração ser alto (em nosso cluster, na época composto por 12 Quad Cores com 8GB de memória RAM, cerca de 200h), os cálculos facilmente exigem mais memória em disco rígido do que o que possuímos (1TB), de forma que com esse método, fizemos cálculos usando cargas pontuais. 
A tabela 3.5 apresenta os resultados obtidos utilizando B3LYP. Todos são médias convergidas (figura 3.7). As transições estão definidas como $n$ - $\pi^{*}$ (dominada pela transição $\operatorname{HOMO}-1(n) \rightarrow \operatorname{LUMO}(\pi)$ ) e $\pi-\pi^{*}$ (dominada pela transição $\operatorname{HOMO}(\pi)$ $\rightarrow \operatorname{LUMO}(\pi)$ ), baseando-se não apenas nos orbitais moleculares (figura 3.8), mas principalmente na intensidade. Isso é um detalhe importante para compor a média: em grande parte das configurações a transição intensa é a primeira, mas em algumas poucas é a segunda. Nesse último caso, as transições foram reagrupadas com as demais de intensidade semelhante. Dessa maneira, a média apresentada foi composta considerando as intensidades e não as posições das transições.

Outro detalhe importante está relacionado às classificações HOMO, LUMO etc. Quando há apenas uma molécula esta definição é inequívoca. Isso não é mais verdade quando temos uma supermolécula: ao colocarmos moléculas explícitas de água, surgem orbitais localizados nessas moléculas, cuja energia é muito próxima entre si e entre os orbitais que estão mais localizados na 5FU. Devido a essa proximidade de energia, esses orbitais podem mudar de posição de uma configuração para outra e o que é, por exemplo, o HOMO para uma configuração, pode ser HOMO-2 para outra. Para evitar essa complicação, consideramos em nossa análise apenas orbitais localizados na 5FU. Assim, na figura 3.8, o orbital chamado de HOMO-1 para o caso em que temos 16 moléculas de água explícita corresponde no cálculo dessa configuração ao orbital HOMO-5.

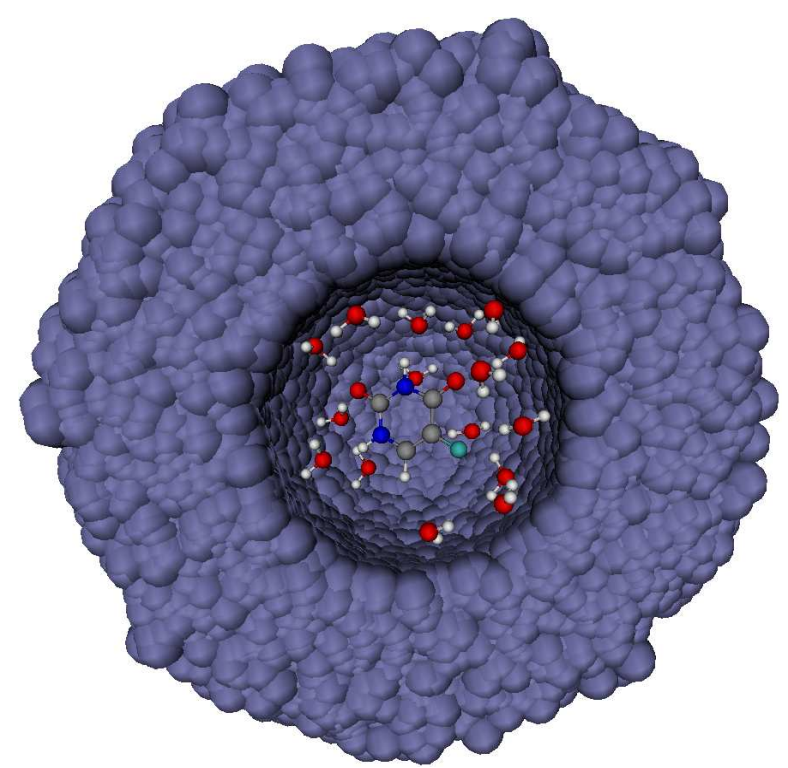

Figura 3.6: Uma das configurações utilizada nos cálculos quânticos. Aqui, temos uma molécula de 5FU e 16 moléculas de água explícitas, com um EE composto por 238 moléculas de água que são representadas pelas cargas pontuais de seus átomos. 
Tabela 3.5: Transições de mais baixa energia da 5FU em água, considerando diferentes tratamentos para o solvente, obtidas com nível B3LYP/6-311++G(d,p). O resultado é a média convergida de 100 configurações que possuem uma correlação estatística de $8 \%$. Também são apresentados os resultados obtidos com PCM, ASEC e o valor experimental. Apesar de não mostrada, a terceira transição também foi calculada e sua energia é cerca de 0.2 a 1 eV maior que a segunda, dependendo do modelo de solvente utilizado. A incerteza estatística não é apresentada por ser inferior a casa decimal exibida.

\begin{tabular}{|c|c|c|c|c|c|c|}
\hline \multirow[b]{2}{*}{ Modelo de Solvente } & \multicolumn{3}{|c|}{ Transição $\pi-\pi^{*}$} & \multicolumn{3}{|c|}{ Transição $n-\pi^{*}$} \\
\hline & $\mathrm{E}(\mathrm{eV})$ & $\lambda(\mathbf{n m})$ & f & $\bar{E}(\mathrm{eV})$ & $\lambda(\mathrm{nm})$ & $\mathbf{f}$ \\
\hline PCM & 4.81 & 258 & 0.176 & 4.99 & 248 & 0.000 \\
\hline $5 \mathrm{FU}+254 \mathrm{H}_{2} \mathrm{O}$ (c.p.) & 4.87 & 255 & 0.137 & 5.09 & 244 & 0.001 \\
\hline ASEC $\left[5 F U+254 \mathrm{H}_{2} \mathrm{O}\right.$ (c.p.)] & 4.88 & 254 & 0.139 & 5.10 & 243 & 0.000 \\
\hline $5 \mathrm{FU}+07 \mathrm{H}_{2} \mathrm{O}$ & 4.42 & 282 & 0.034 & 4.40 & 283 & 0.003 \\
\hline $5 \mathrm{FU}+07 \mathrm{H}_{2} \mathrm{O}+247 \mathrm{H}_{2} \mathrm{O}$ (c.p.) & 4.82 & 257 & 0.164 & 5.07 & 245 & 0.003 \\
\hline $5 \mathrm{FU}+10 \mathrm{H}_{2} \mathrm{O}+244 \mathrm{H}_{2} \mathrm{O}$ (c.p.) & 4.81 & 258 & 0.164 & 5.07 & 245 & 0.003 \\
\hline $5 \mathrm{FU}+12 \mathrm{H}_{2} \mathrm{O}+242 \mathrm{H}_{2} \mathrm{O}$ (c.p.) & 4.80 & 258 & 0.161 & 5.05 & 246 & 0.004 \\
\hline $5 \mathrm{FU}+14 \mathrm{H}_{2} \mathrm{O}+240 \mathrm{H}_{2} \mathrm{O}$ (c.p.) & 4.79 & 259 & 0.156 & 5.05 & 246 & 0.004 \\
\hline $5 \mathrm{FU}+16 \mathrm{H}_{2} \mathrm{O}+238 \mathrm{H}_{2} \mathrm{O}$ (c.p.) & 4.79 & 259 & 0.154 & 5.04 & 246 & 0.004 \\
\hline Experimental [84] & 4.66 & 266 & -- & -- & -- & -- \\
\hline
\end{tabular}

O modelo PCM mostra um valor para a transição $\pi-\pi^{*}$ bem acima do resultado experimental, que é de 4,66 eV [84] (figura 3.9). Quando passamos para o modelo discreto, o resultado superestima ainda mais o valor experimental, porém isso já é esperado uma vez que apenas contribuições eletrostáticas são consideradas. O modelo ASEC mostra-se eficiente para representar a média das configurações onde o solvente é tratado discretamente. Apenas incluir as moléculas de água mais próximas explicitamente no cálculo é insuficiente, mostrando que contribuições de longo alcance também são relevantes. Ao combinar o modelo discreto para as moléculas de água mais distantes com o tratamento explícito para as mais próximas da 5FU, o resultado tende a se aproximar do valor experimental, melhorando conforme o número de moléculas de água explícitas incluídas no cálculo aumenta. Entretanto, começa a haver uma saturação, ou seja, mesmo incluindo mais moléculas explícitas (tornando os cálculos muito mais custosos), o resultado não melhora significativamente, mostrando que dentro das aproximações feitas, esse é o melhor resultado possível. 
Uma comparação direta com valores experimentais para a transição $n-\pi^{*}$ não é possível, pois além de possuir uma baixíssima intensidade (o valor médio convergido para a força de oscilador é de 0.004 ), ela está muito próxima da transição $\pi$ - $\pi *$ que é muito intensa, o que dificulta sua observação. O valor mais próximo disponível para comparação é uma evidência não-conclusiva dessa transição no espectro de dicroísmo circular de alguns derivados de $\mathrm{U}$, que apresenta um valor de $5.17 \mathrm{eV}$ [86], um pouco maior que os resultados por nós obtidos.

Médias Convergidas

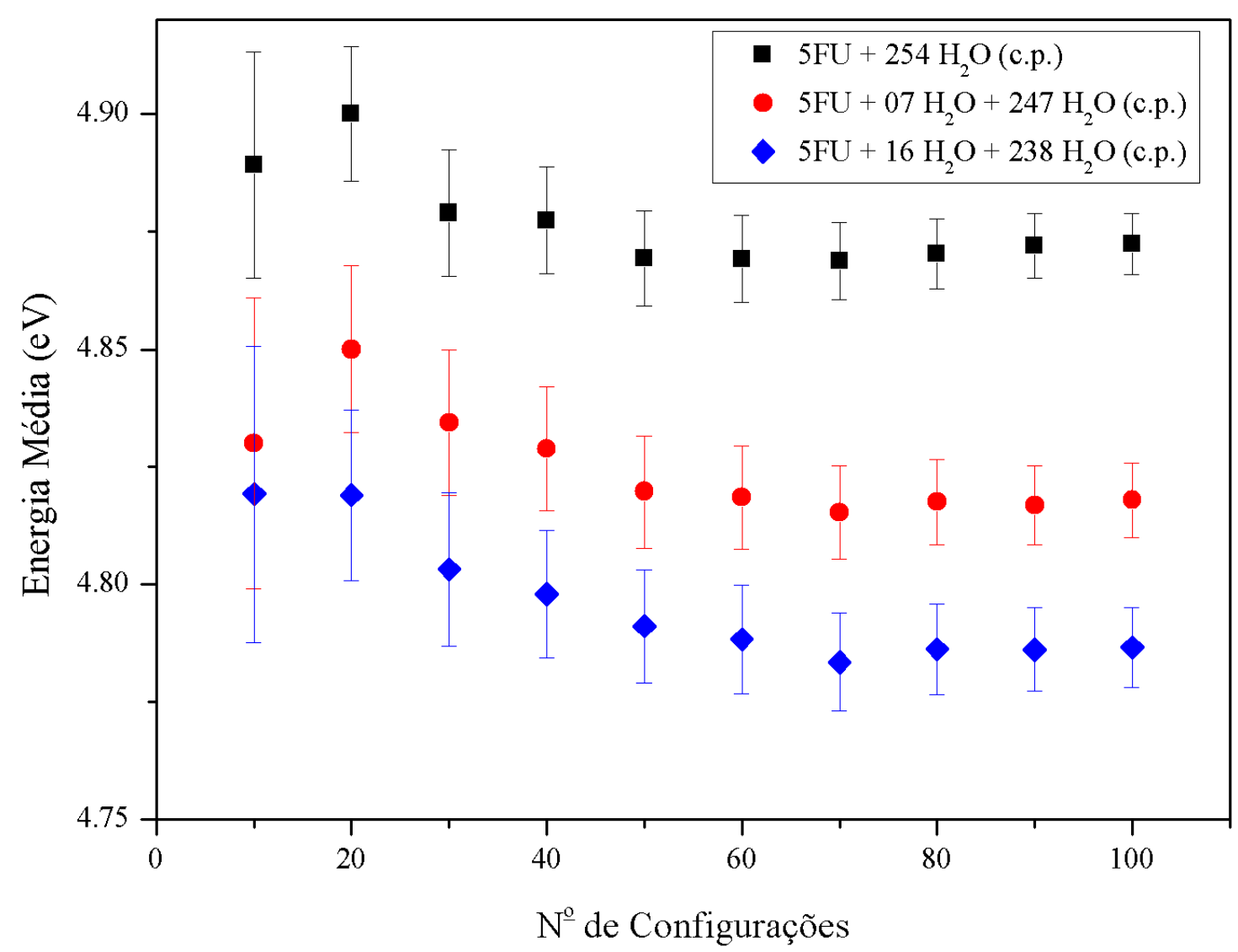

Figura 3.7: Médias convergidas para a transição $\pi-\pi^{*}$ de menor energia da $5 \mathrm{FU}$ em água. Apenas alguns níveis de tratamento são mostrados para uma melhor visualização, já que todos apresentam o mesmo comportamento. 


$$
5 \mathrm{FU}+\mathrm{H}_{2} \mathrm{O}(\mathrm{PCM})
$$

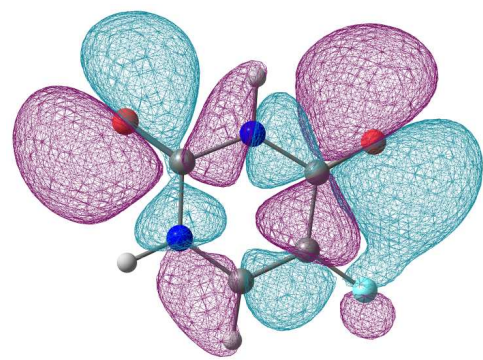

HOMO-1 (n)

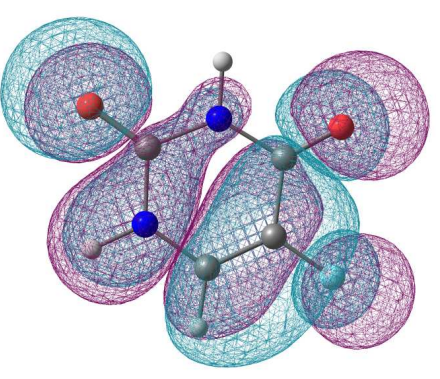

HOMO $(\pi)$

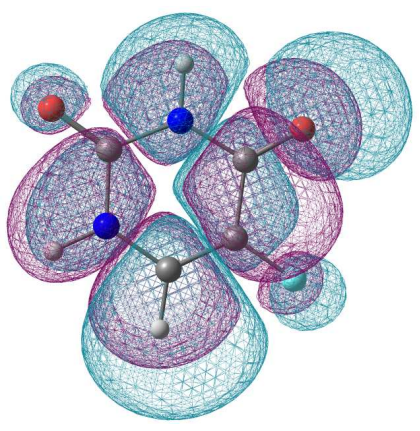

$\operatorname{LUMO}(\pi)$

$$
5 \mathrm{FU}+7 \mathrm{H}_{2} \mathrm{O}+247 \mathrm{H}_{2} \mathrm{O} \text { (c.p.) }
$$

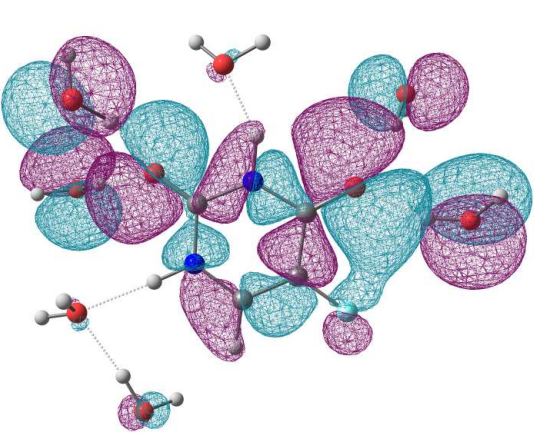

HOMO-1 (n)

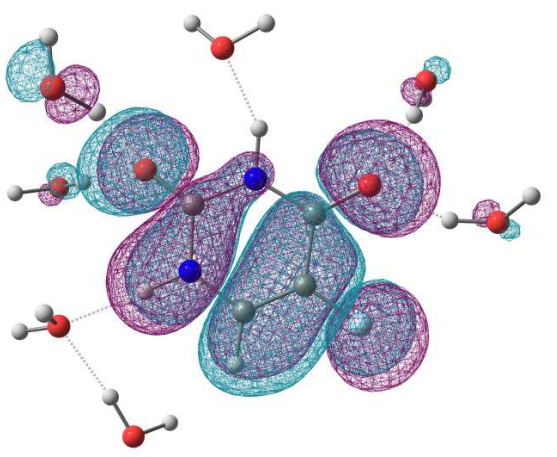

$\operatorname{HOMO}(\pi)$

$$
5 \mathrm{FU}+16 \mathrm{H}_{2} \mathrm{O}+247 \mathrm{H}_{2} \mathrm{O} \text { (c.p.) }
$$

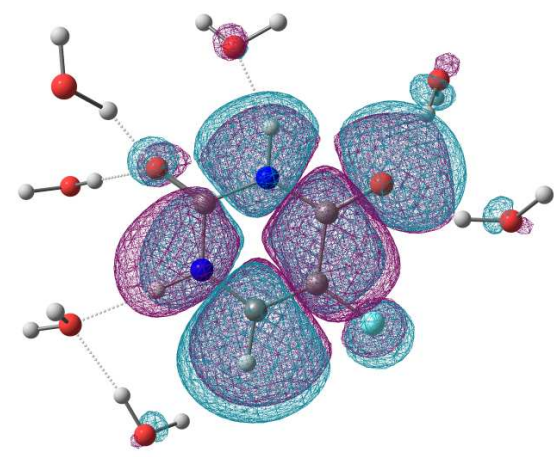

LUMO $(\pi)$

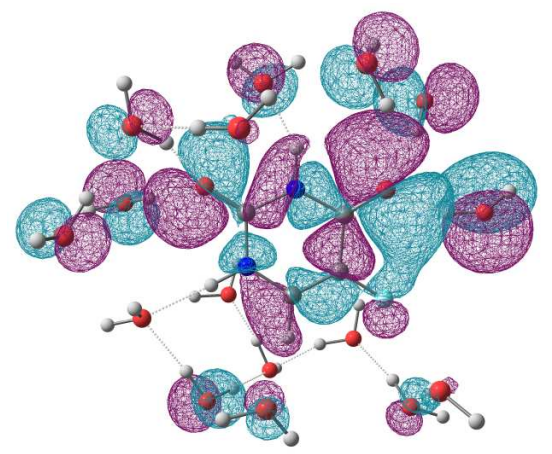

HOMO-1 (n)

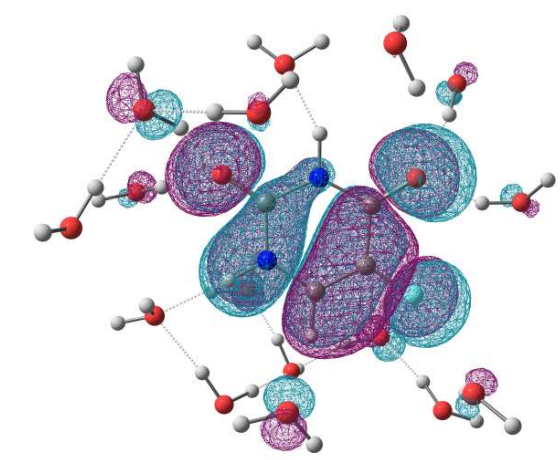

HOMO $(\pi)$

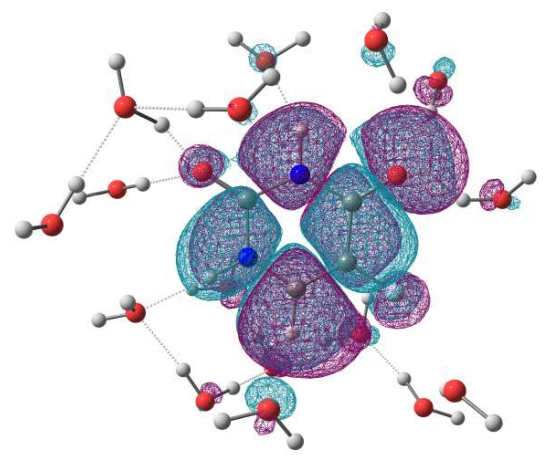

LUMO $(\pi)$

Figura 3.8: Orbitais moleculares envolvidos na excitação da 5FU em água. 


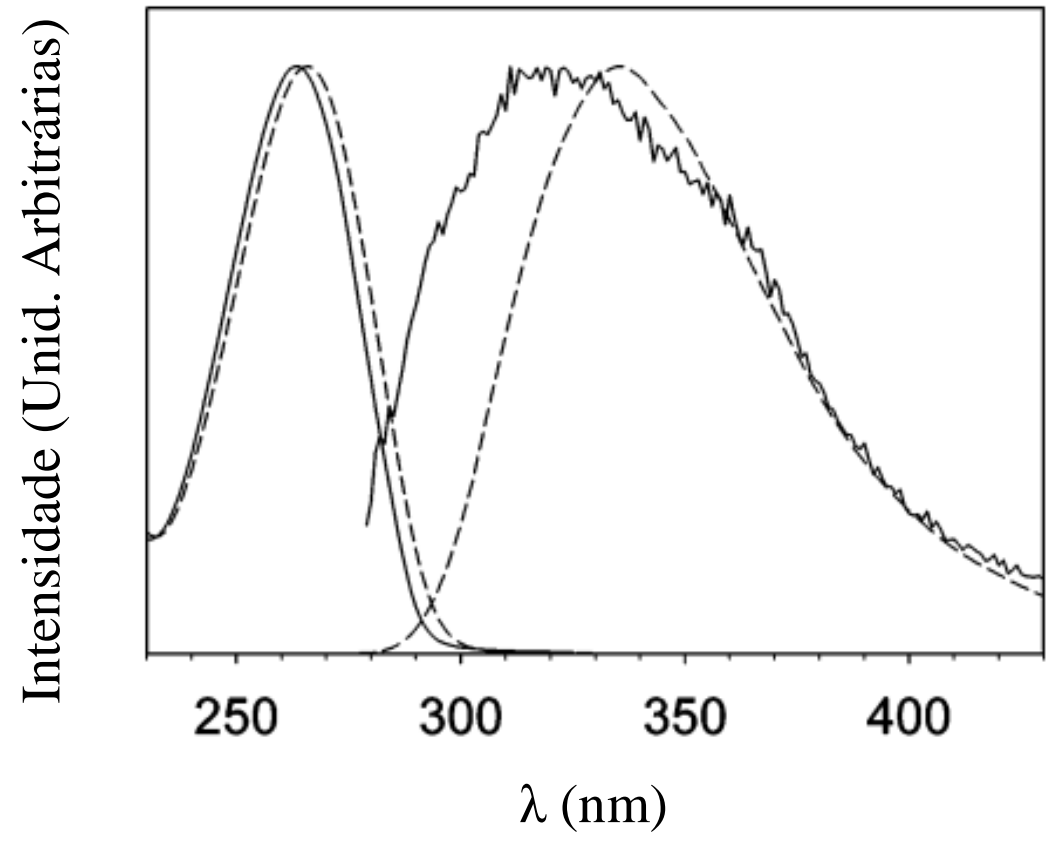

Figura 3.9: Espectro de absorção e emissão da $5 \mathrm{FU}$ medido em acetonitrila (linha contínua) e em água (linha tracejada). Extraído de [84].

Para o cálculo da 5FU em acetonitrila, tentamos manter a metodologia a mais próxima possível para eliminar possíveis erros sistemáticos, uma vez que estamos interessados no deslocamento espectral de um solvente para o outro. Assim, o mesmo nível de cálculo foi utilizado (B3LYP/6-311++G(d,p)) e a média foi obtida da mesma maneira. Novamente os cálculos foram feitos utilizando as três aproximações para o solvente: contínua, discreta e explícita. No entanto, dessa vez o tratamento explícito não contempla uma aproximação sucessiva já que, como observamos acima, o resultado melhora quanto mais moléculas de solvente explícitas são incluídas nos cálculos, até saturar. Na tentativa de minimizar os erros sistemáticos, 8 moléculas explícitas de acetonitrila foram inseridas, de modo que o sistema tratado quanticamente tem o mesmo número de átomos e considera as moléculas até aproximadamente a mesma distância que no caso de 16 águas explícitas. Os resultados são apresentados na tabela 3.6. Novamente as médias são estatisticamente convergidas (figura 3.10). Os orbitais moleculares envolvidos na transição também são apresentados (figura 3.11).

O mesmo comportamento que foi observado para água aqui se repete: O PCM apresenta um valor maior que o experimental, o modelo discreto apresenta um valor mais superestimado ainda e o tratamento que combina inclusão das moléculas explícitas de acetonitrila mais próximas da 5FU com o modelo discreto para as demais é o que apresenta o melhor resultado. 
Tabela 3.6: Transições de mais baixa energia da $5 \mathrm{FU}$ em acetonitrila, considerando diferentes tratamentos para o solvente, obtidas com nível B3LYP/6-311++G(d,p). O resultado é a média convergida de 100 configurações que possuem uma correlação estatística de 4\%. Também são apresentados os resultados obtidos com PCM, ASEC e o valor experimental. Apesar de não mostrada, a terceira transição também foi calculada e sua energia é cerca de 0.7 a $1 \mathrm{eV}$ maior que a segunda, dependendo do modelo de solvente utilizado. A incerteza estatística não é apresentada por ser inferior a casa decimal exibida.

\begin{tabular}{|c|c|c|c|c|c|c|}
\hline \multirow[b]{2}{*}{ Modelo de Solvente } & \multicolumn{3}{|c|}{ Transição $\pi-\pi^{*}$} & \multicolumn{3}{|c|}{ Transição $n-\pi^{*}$} \\
\hline & $\mathrm{E}(\mathrm{eV})$ & $\lambda(\mathrm{nm})$ & $\mathbf{f}$ & $\mathrm{E}(\mathrm{eV})$ & $\lambda(\mathbf{n m})$ & f \\
\hline PCM & 4.81 & 258 & 0.177 & 4.98 & 249 & 0.000 \\
\hline $5 \mathrm{FU}+254 \mathrm{CH}_{3} \mathrm{CN}$ (c.p.) & 4.84 & 256 & 0.126 & 4.82 & 257 & 0.002 \\
\hline ASEC $\left[5 F U+254 \mathrm{CH}_{3} \mathrm{CN}\right.$ (c.p.)] & 4.84 & 256 & 0.128 & 4.83 & 257 & 0.001 \\
\hline $5 \mathrm{FU}+8 \mathrm{CH}_{3} \mathrm{CN}+246 \mathrm{CH}_{3} \mathrm{CN}$ (c.p.) & 4.77 & 260 & 0.152 & 4.84 & 256 & 0.003 \\
\hline Experimental [84] & 4.70 & 264 & -- & -- & -- & -- \\
\hline
\end{tabular}

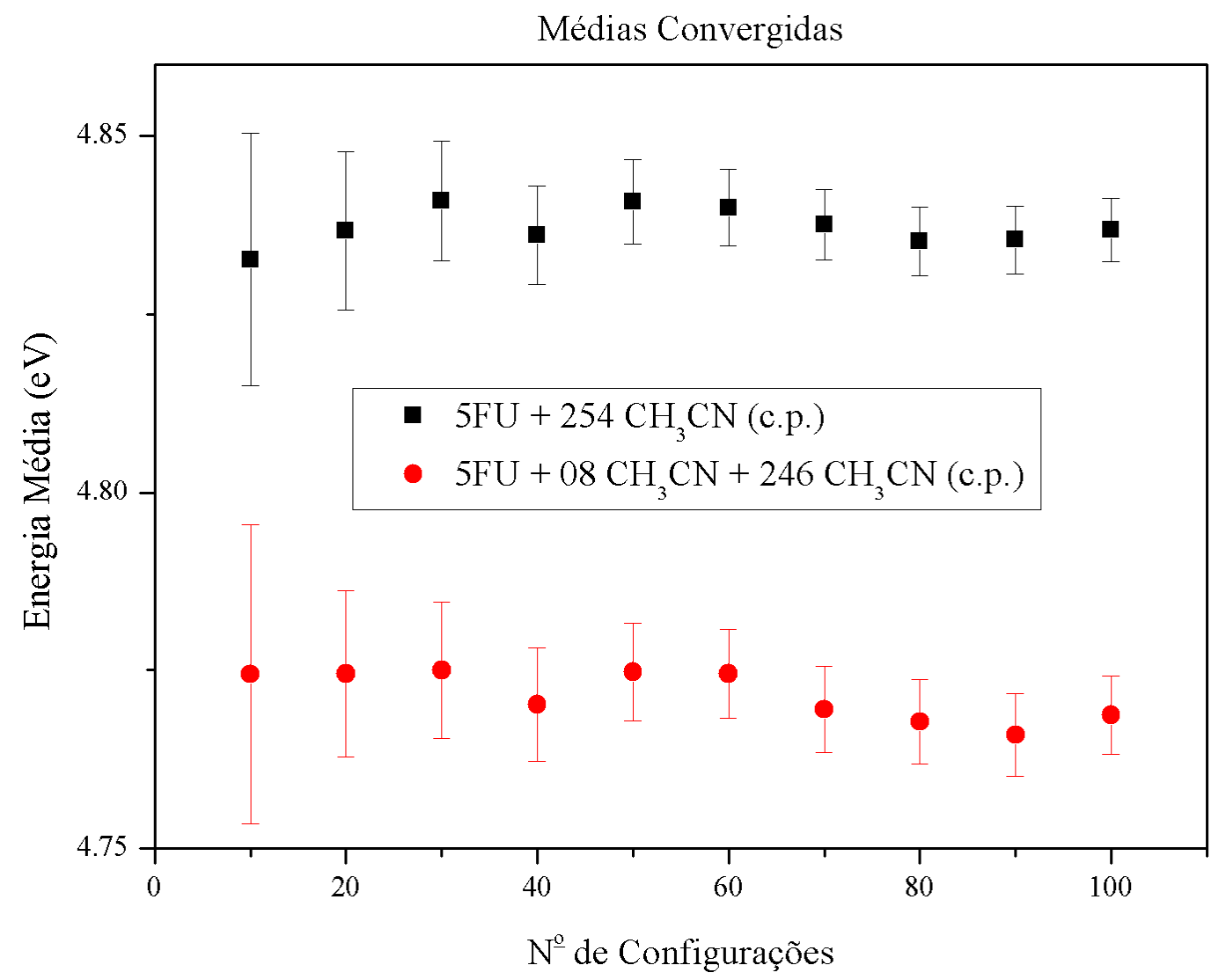

Figura 3.10: Médias convergidas para a transição $\pi-\pi^{*}$ de menor energia da $5 \mathrm{FU}$ em acetonitrila. 


\section{$5 \mathrm{FU}+\mathrm{CH}_{3} \mathrm{CN}(\mathrm{PCM})$}

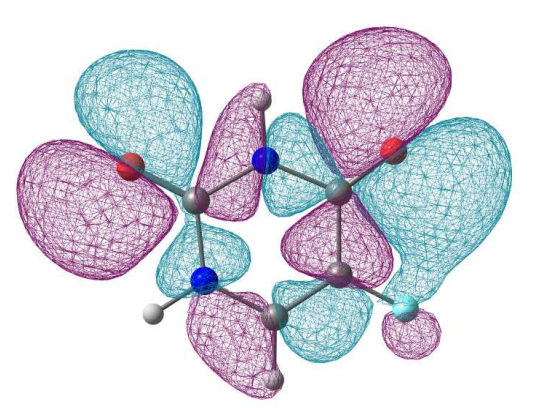

HOMO-1 (n)

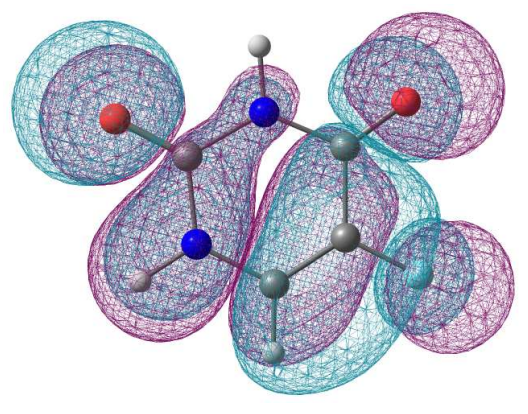

$\operatorname{HOMO}(\pi)$

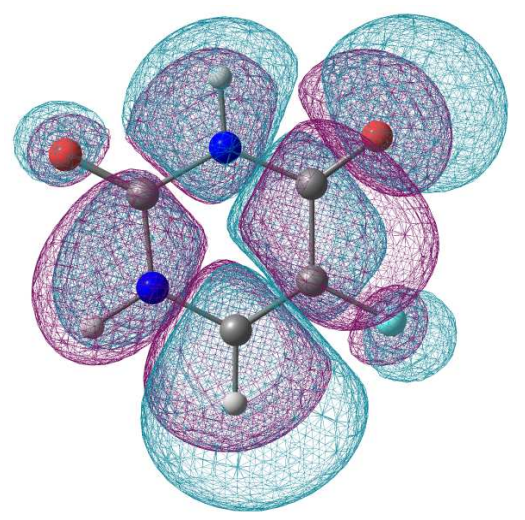

$\operatorname{LUMO}(\pi)$

\section{$5 \mathrm{FU}+8 \mathrm{CH}_{3} \mathrm{CN}+246 \mathrm{CH}_{3} \mathrm{CN}$ (c.p.)}

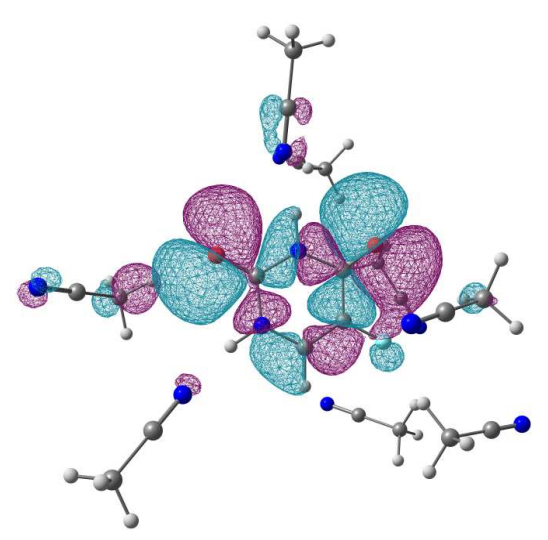

HOMO-1 (n)

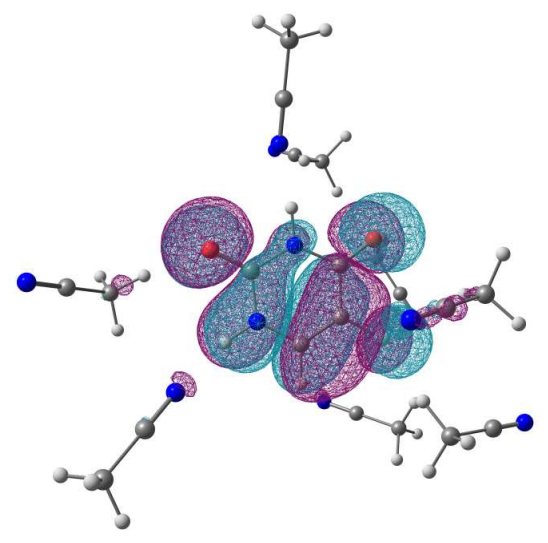

$\operatorname{HOMO}(\pi)$

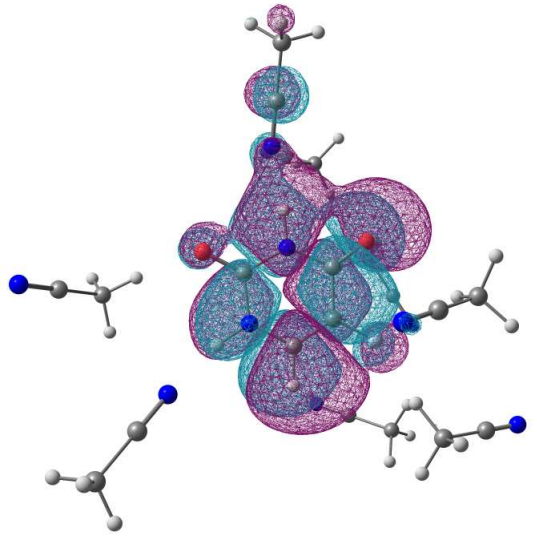

$\operatorname{LUMO}(\pi)$

Figura 3.11: Orbitais moleculares envolvidos na excitação da 5FU em acetonitrila.

Esses resultados individualmente podem até ser considerados bons. Mas observe o que acontece ao determinarmos a variação de um solvente para o outro (tabela 3.7). 
Tabela 3.7: Variação da transição $\pi-\pi^{*}$ de menor energia da $5 F U$ em acetonitrila com relação à transição em água. As incertezas são provenientes dos erros estatísticos. A incerteza no resultado experimental é inferior a casa decimal mostrada na tabela.

\begin{tabular}{lc}
\hline \hline Modelo de Solvente & $\mathbf{E}_{\text {acetonitrila }}-\mathbf{E}_{\text {água }}(\mathbf{e V})$ \\
\hline PCM & 0.00 \\
Discreto & $-0.04 \pm 0.01$ \\
ASEC & -0.04 \\
Explícito & $-0.02 \pm 0.01$ \\
\hline Experimental [84] & 0.04 \\
\hline \hline
\end{tabular}

O PCM simplesmente não mostra diferença nas transições, ressaltando a importância de considerar moléculas explícitas de solvente no tratamento. Os outros modelos apresentam uma variação, mas no sentido oposto a determinada experimentalmente. Dessa forma nossos resultados são bons, mas mostram a tendência errada! Eles são bons no sentido que, individualmente, são próximos dos resultados experimentais. Mas mostram a tendência errada no sentido em que a energia de absorção calculada em água é maior do que em acetonitrila, quando experimentalmente é medido o oposto.

$\mathrm{Na}$ referência [84], de onde retiramos os valores experimentais, os autores apresentam também um resultado teórico usando nível de cálculo PBE0/6-311+G(2d,2p) que apresenta a variação correta, apesar de individualmente os resultados serem mais distantes do experimental do que os por nós obtidos. Entretanto eles usaram diferentes tratamentos para o solvente: para 5FU em acetonitrila somente PCM foi usado, mas para a água, ao invés da 5FU isolada, um pequeno aglomerado otimizado de $5 \mathrm{FU}+4 \mathrm{H}_{2} \mathrm{O}$ foi utilizado como soluto. Desta forma é de se esperar que o resultado em água seja melhor, pois um sistema maior foi tratado quanticamente além de que a otimização do aglomerado contribui para diminuir ainda mais o valor da energia. Isso não corresponde a um líquido real, onde temos um enorme espaço amostral de possíveis configurações acessíveis em uma dada temperatura.

Mas já que no trabalho supracitado um nível de cálculo diferente foi usado, passamos a repensar nossas considerações e fazer hipóteses sobre o que poderia estar contribuindo para tal resultado, testando e verificando sua veracidade. Aqui vale ressaltar mais uma vez uma das grandes vantagens do método S-QM/MM: Para testar 
novos tratamentos quânticos para o sistema, nenhuma simulação clássica precisa ser refeita.

Eis as hipóteses levantadas:

- A base escolhida pode não ser adequada: Essa hipótese é pouco provável, pois a base é grande e como já dissemos, há estudos que mostram que ela é suficiente para descrever bem a energia de absorção, mesmo se comparada a outras bases maiores como aug-cc-pVDZ que, como já foi dito, é inviável para nosso estudo.

Decidimos pelo menos aumentar o número de funções polarizáveis para observar a influência (tabela 3.8). Apenas o modelo discreto foi utilizado, pois o tratamento explícito só valeria o esforço se observássemos diferenças significativas.

Tabela 3.8: Transições de mais baixa energia da 5FU em água e em acetonitrila, obtidas com nível B3LYP/6-311++G(2d,2p), tratando o solvente de maneira discreta e usando ASEC.

\begin{tabular}{|c|c|c|c|c|c|c|}
\hline \multirow[b]{2}{*}{ Modelo de Solvente } & \multicolumn{3}{|c|}{ Transição $\pi-\pi^{*}$} & \multicolumn{3}{|c|}{ Transição $n-\pi^{*}$} \\
\hline & $\mathrm{E}(\mathrm{eV})$ & $\lambda(\mathrm{nm})$ & f & $\bar{E}(e V)$ & $\lambda(\mathbf{n m})$ & f \\
\hline $5 \mathrm{FU}+254 \mathrm{H}_{2} \mathrm{O}$ (c.p.) & 4.84 & 256 & 0.130 & 5.10 & 243 & 0.002 \\
\hline $5 \mathrm{FU}+254 \mathrm{CH}_{3} \mathrm{CN}$ (c.p.) & 4.68 & 265 & 0.099 & 4.62 & 269 & 0.002 \\
\hline $\mathbf{E}_{\text {acetonitrila }}-\mathbf{E}_{\text {água }}(\mathrm{eV})$ & -0.16 & & & & & \\
\hline ASEC [5FU + $254 \mathrm{H}_{2} \mathrm{O}$ (c.p.)] & 4.84 & 256 & 0.132 & 5.11 & 243 & 0.000 \\
\hline ASEC $\left[5 F U+254 \mathrm{CH}_{3} \mathrm{CN}\right.$ (c.p.) $]$ & 4.68 & 265 & 0.101 & 4.63 & 268 & 0.000 \\
\hline $\mathbf{E}_{\text {acetonitrila }}-\mathbf{E}_{\text {agua }}(\mathbf{e V})$ & -0.16 & & & & & \\
\hline
\end{tabular}

O resultado piorou! E olhando a tabela isso é facilmente explicável: a mudança na base foi suficiente para melhorar ainda mais o resultado em acetonitrila, mas não em água. Dessa forma, a base inicialmente escolhida continua sendo adequada.

- O funcional híbrido B3LYP não é adequado para estudar esse sistema: Em nosso grupo temos muitos exemplos de sucesso usando o funcional B3LYP, não só para estudar o espectro de absorção como outras propriedades [80]. Mas como nosso foco tem sido o meio aquoso, decidimos testar outros funcionais, 
pois não podemos garantir o comportamento em acetonitrila. Escolhemos os funcionais O3LYP e BHandHLYP, pois assim mantemos um tratamento muito próximo para a correlação, variando apenas a composição do funcional de troca, e o funcional PBE0, variando assim ambos os termos, além de ser o funcional usado na referência supramencionada. O solvente foi tratado de maneira discreta, pelo mesmo motivo do item anterior (tabela 3.9).

Tabela 3.9: Transições de mais baixa energia da 5FU em água e em acetonitrila, obtidas com os funcionais PBE0, O3LYP e BHandHLYP, todos com a base 6-311++G(d,p), tratando o solvente de maneira discreta (para os dois primeiros) e usando ASEC (todos).

\begin{tabular}{|c|c|c|c|c|c|c|}
\hline \multirow[b]{2}{*}{ Modelo de Solvente } & \multicolumn{3}{|c|}{ Transição $\pi-\pi^{*}$} & \multicolumn{3}{|c|}{ Transição $n-\pi^{*}$} \\
\hline & $\mathrm{E}(\mathrm{eV})$ & $\lambda(\mathbf{n m})$ & $\mathbf{f}$ & $\mathrm{E}(\mathrm{eV})$ & $\lambda(\mathbf{n m})$ & $\mathbf{f}$ \\
\hline $5 \mathrm{FU}+254 \mathrm{H}_{2} \mathrm{O}$ (c.p.) & 4.76 & 261 & 0.114 & 4.89 & 254 & 0.002 \\
\hline $5 \mathrm{FU}+254 \mathrm{CH}_{3} \mathrm{CN}$ (c.p.) & 4.71 & 263 & 0.104 & 4.61 & 269 & 0.001 \\
\hline$\overline{\mathbf{E}_{\text {acetonitrila }}-\mathbf{E}_{\text {água }}(\mathbf{e V})}$ & \multicolumn{2}{|c|}{$-0.05 \pm 0.01$} & & & & \\
\hline ๑ $\mathrm{ASEC}\left[5 \mathrm{FU}+254 \mathrm{H}_{2} \mathrm{O}\right.$ (c.p.) $]$ & 4.76 & 260 & 0.117 & 4.90 & 253 & 0.000 \\
\hline ASEC [5FU + $254 \mathrm{CH}_{3} \mathrm{CN}$ (c.p.) $]$ & 4.71 & 263 & 0.106 & 4.62 & 268 & 0.000 \\
\hline $\mathrm{E}_{\text {acetonitrila }}-\mathrm{E}_{\text {agua }}(\mathbf{e V})$ & \multicolumn{2}{|c|}{-0.05} & & & & \\
\hline $5 \mathrm{FU}+254 \mathrm{H}_{2} \mathrm{O}$ (c.p.) & 4.98 & 249 & 0.149 & 5.22 & 238 & 0.001 \\
\hline $5 \mathrm{FU}+254 \mathrm{CH}_{3} \mathrm{CN}$ (c.p.) & 4.95 & 250 & 0.139 & 4.95 & 251 & 0.002 \\
\hline $\mathbf{E}_{\text {acetonitrila }}-\mathrm{E}_{\text {água }}(\mathrm{eV})$ & \multicolumn{2}{|c|}{$-0.03 \pm 0.01$} & \multirow{4}{*}{$\begin{array}{l}0.151 \\
0.137\end{array}$} & \multirow{4}{*}{$\begin{array}{l}5.22 \\
4.95\end{array}$} & \multirow{4}{*}{$\begin{array}{l}237 \\
251\end{array}$} & \multirow{4}{*}{$\begin{array}{l}0.000 \\
0.006\end{array}$} \\
\hline ASEC [5FU + $254 \mathrm{H}_{2} \mathrm{O}$ (c.p.)] & 4.99 & 249 & & & & \\
\hline ASEC $\left[5 \mathrm{FU}+254 \mathrm{CH}_{3} \mathrm{CN}\right.$ (c.p.)] & 4.95 & 250 & & & & \\
\hline$\overline{\mathbf{E}_{\text {acetonitrila }}-\mathbf{E}_{\text {agua }}(\mathbf{e V})}$ & \multicolumn{2}{|c|}{-0.03} & & & & \\
\hline \multirow{3}{*}{$\begin{array}{l}\text { ASEC [5FU + 254 } \mathrm{H}_{2} \mathrm{O} \text { (c.p.)] } \\
\frac{\mathrm{ASEC}\left[5 \mathrm{FU}+254 \mathrm{CH}_{3} \mathrm{CN}(\text { c.p. })\right]}{\mathbf{E}_{\text {acetonitrila }}-\mathbf{E}_{\text {água }}(\mathbf{e V})}\end{array}$} & 5.37 & 231 & 0.218 & 5.77 & 215 & 0.000 \\
\hline & 5.36 & 231 & 0.217 & 5.48 & 226 & 0.000 \\
\hline & \multicolumn{2}{|c|}{$-0.01 \pm 0.01$} & & & & \\
\hline
\end{tabular}

Os resultados para a energia de excitação obtidos usando O3LYP são melhores que os obtidos usando B3LYP, algo previsível já que aquele funcional é uma melhoria desse; o oposto ocorre com o funcional PBE0, piorando ainda mais com BHandHLYP. Entretanto, comportamento de todos é essencialmente o mesmo (a transição da 5FU em acetonitrila é menos energética que em água), mostrando que muito possivelmente não é um problema específico do funcional. Seria um problema com a teoria em si? Aqui vale relembrar que a DFT tem 
todos os seus teoremas demonstrados para o estado fundamental, mas sua extensão para o estado excitado, a TD-DFT, não goza da mesma propriedade (seção 2.4.1), além de ser fato conhecido que os funcionais têm problemas para descrever as interações de van der Waals. Esse é o questionamento da próxima hipótese.

- O problema seria a própria TD-DFT: diante do que foi dito no item anterior, decidimos testar outros métodos.

Escolhemos três métodos: TD-HF, que é o método $a b$ initio menos custoso computacionalmente, mas que não inclui correlação eletrônica, e outros dois métodos bem opostos: CIS(D), um método ab initio extremamente custoso (mas que inclui correlação) e o método semiempírico INDO, com função de onda CI e parametrização espectroscópica (INDO/CIS), como implementadas por Zerner em seu programa (ZINDO).

Como dito no início da seção 3.3.1, os cálculos com CIS(D) são tão dispendiosos que só foi possível usar o solvente na aproximação discreta. O extremo oposto ocorre com o método INDO/CIS: por ser um método semiempírico, ele é muito eficiente computacionalmente, de modo que todas as moléculas até a distância de $8 \AA$ foram incluídas explicitamente (150 moléculas de água e 63 moléculas de acetonitrila). A tabela 3.10 sumariza os resultados que foram obtidos usando os programas Gaussian para HF e CIS(D), e ZINDO para o INDO/CIS. Como para o método CIS(D) é necessário primeiramente calcular a energia com o método CIS para depois fazer a correção perturbativa, esses valores também são apresentados.

Os resultados individualmente são ruins, o que já era esperado para HF, CIS e CIS(D). Além disso, HF e CIS não foram capazes de diferenciar o efeito de solvente. Isso poderia ser atribuído justamente a aproximação usada para o solvente: cargas pontuais. Entretanto usando CIS(D) com essa mesma aproximação, a variação é idêntica a experimental, mostrando o quão importante é a correlação eletrônica.

O método INDO/CIS também apresentou a variação na direção correta, mas ela é quase cinco vezes o valor determinado experimentalmente. Essa separação demasiada grande já foi observada anteriormente em nosso grupo na 
Tabela 3.10: Transições de mais baixa energia da 5FU em água e em acetonitrila, obtidas usando CIS e CIS(D) com a base 6-311++G(d,p), tratando o solvente de maneira discreta e usando ASEC e com o método INDO/CIS, considerando o solvente explicitamente até uma distância de $8 \AA$.

\begin{tabular}{|c|c|c|c|c|c|c|}
\hline \multirow[b]{2}{*}{ Modelo de Solvente } & \multicolumn{3}{|c|}{ Transição $\pi-\pi^{*}$} & \multicolumn{3}{|c|}{ Transição $n-\pi^{*}$} \\
\hline & $\mathrm{E}(\mathrm{eV})$ & $\lambda(\mathrm{nm})$ & f & $\bar{E}(\mathrm{eV})$ & $\lambda(\mathbf{n m})$ & $\mathbf{f}$ \\
\hline $5 \mathrm{FU}+254 \mathrm{H}_{2} \mathrm{O}$ (c.p.) & 5.95 & 209 & 0.331 & 6.68 & 186 & 0.000 \\
\hline $5 \mathrm{FU}+254 \mathrm{CH}_{3} \mathrm{CN}$ (c.p.) & 5.95 & 208 & 0.342 & 6.33 & 196 & 0.000 \\
\hline$\overline{\mathbf{E}_{\text {acetonitrila }}-\mathrm{E}_{\text {agua }}(\mathrm{eV})}$ & \multicolumn{2}{|c|}{$0.00 \pm 0.01$} & & & & \\
\hline ASEC [5FU + $254 \mathrm{H}_{2} \mathrm{O}$ (c.p.)] & 5.95 & 208 & 0.332 & 6.68 & 186 & 0.000 \\
\hline ASEC $\left[5 \mathrm{FU}+254 \mathrm{CH}_{3} \mathrm{CN}\right.$ (c.p.)] & 5.95 & 208 & 0.344 & 6.33 & 196 & 0.000 \\
\hline 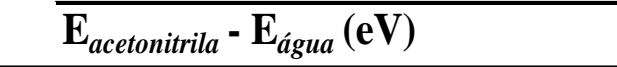 & \multicolumn{2}{|c|}{0.00} & & & & \\
\hline $5 \mathrm{FU}+254 \mathrm{H}_{2} \mathrm{O}$ (c.p.) & 6.25 & 199 & 0.416 & 6.82 & 182 & 0.000 \\
\hline $5 \mathrm{FU}+254 \mathrm{CH}_{3} \mathrm{CN}$ (c.p.) & 6.25 & 198 & 0.429 & 6.49 & 191 & 0.000 \\
\hline $\mathscr{\mathbf { E } _ { \text { acetonitrila } } - \mathbf { E } _ { \text { agua } } ( \mathbf { e V } )}$ & \multicolumn{2}{|c|}{$0.00 \pm 0.01$} & & & & \\
\hline ASEC $\left[5 \mathrm{FU}+254 \mathrm{H}_{2} \mathrm{O}\right.$ (c.p.)] & 6.25 & 198 & 0.418 & 6.82 & 182 & 0.000 \\
\hline ASEC [5FU + $254 \mathrm{CH}_{3} \mathrm{CN}$ (c.p.)] & 6.26 & 198 & 0.431 & 6.49 & 191 & 0.000 \\
\hline $\mathbf{E}_{\text {acetonitrila }}-\mathbf{E}_{\text {agua }}(\mathbf{e V})$ & \multicolumn{2}{|c|}{0.00} & & & & \\
\hline $5 \mathrm{FU}+254 \mathrm{H}_{2} \mathrm{O}$ (c.p.) & 5.17 & 240 & 0.416 & 5.33 & 233 & 0.000 \\
\hline $5 \mathrm{FU}+254 \mathrm{CH}_{3} \mathrm{CN}$ (c.p.) & 5.22 & 238 & 0.429 & 5.09 & 244 & 0.000 \\
\hline$\bigoplus_{\mathscr{Q}} \mathbf{E}_{\text {acetonitrila }}-\mathbf{E}_{\text {agua }}(\mathbf{e V})$ & \multicolumn{2}{|c|}{$0.05 \pm 0.01$} & & & & \\
\hline$\circlearrowright$ ASEC [5FU + $254 \mathrm{H}_{2} \mathrm{O}$ (c.p.)] & 5.18 & 239 & 0.418 & 5.32 & 233 & 0.000 \\
\hline ASEC $\left[5 \mathrm{FU}+254 \mathrm{CH}_{3} \mathrm{CN}\right.$ (c.p.) $]$ & 5.22 & 237 & 0.431 & 5.09 & 244 & 0.000 \\
\hline $\mathbf{E}_{\text {acetonitrila }}-\mathbf{E}_{\text {agua }}(\mathbf{e V})$ & 0.04 & & & & & \\
\hline \multirow{3}{*}{$\begin{array}{l}5 \mathrm{FU}+150 \mathrm{H}_{2} \mathrm{O} \\
5 \mathrm{FU}+63 \mathrm{CH}_{3} \mathrm{CN} \\
\mathbf{E}_{\text {acetonitrila }}-\mathbf{E}_{\text {agua }}(\mathbf{e V})\end{array}$} & 5.05 & 246 & 0.441 & 4.40 & 282 & 0.003 \\
\hline & 5.23 & 237 & 0.502 & 4.87 & 255 & 0.002 \\
\hline & \multicolumn{2}{|c|}{$0.19 \pm 0.01$} & & & & \\
\hline
\end{tabular}

molécula de Uracil [79] e está relacionado com o cálculo em fase gasosa feito pelo programa ZINDO. Discutiremos mais sobre isso no final da seção 3.3.2.

Apesar de esses resultados indicarem que a TD-DFT possa ser o problema no comportamento errôneo que obtivemos anteriormente, eles não são o suficiente para desequilibrá-la com a pluma de Maat ${ }^{15}$. Há ainda outras duas possíveis fontes de erros.

\footnotetext{
${ }^{15}$ Deusa egípcia da justiça e do equilíbrio. Segundo a mitologia egípcia, Maat julgava a bondade dos que haviam morrido retirando seu coração e o colocando-o em uma balança. Se o coração não se equilibrasse com a pluma da verdade, a pessoa era considerada má e estava condenada.
} 
- A polarização implícita não é adequada: Mencionamos na seção 3.2.1 o fato de o valor do momento de dipolo da $5 \mathrm{FU}$ em meio obtido com a polarização implícita via PCM ser praticamente o mesmo para ambos os solventes (5.92D para a 5FU em água e 5.87D em acetonitrila). Isso não é razoável dada a diferenças entre ambos (constante dielétrica, composição etc) e provavelmente é proveniente da incapacidade do PCM de descrever interações específicas, porém não necessariamente é um problema, já que esse valor é apenas o ponto de partida para a simulação e deve ser recalculado após ela, uma vez que o solvente deixa de ser um meio contínuo. Em geral nós fazemos isso utilizando o ASEC e o procedimento é chamado PCM+MM/QM. Os novos valores obtidos foram 6.32D para a 5FU em água e 5.47D em acetonitrila. Como já dissemos na seção 3.2.1, os resultados experimentais são escassos e uma discussão mais rica se faz impossível.

Apesar dos momentos de dipolo obtidos usando PCM+MM/QM diferirem, o que é mais razoável, eles suscitam outra questão: no caso em que o solvente é a água, o momento de dipolo aumentou após a simulação, sendo o oposto verdade quando o solvente é a acetonitrila. Se isso estiver correto, então a polarização implícita usando PCM falha em descrever o momento de dipolo da 5FU em ambos os solventes, subestimando o valor em água e superestimando o valor em acetonitrila. Mais ainda, se isso ocorre, não há garantias que apenas uma simulação seja capaz de sanar essa falha. Também não sabemos como isso afetaria o espectro de absorção calculado.

Por essa razão utilizamos um procedimento iterativo proposto em nosso grupo para atualizar as cargas da simulação de modo a permitir a polarização do soluto pelo solvente, descrito na seção 1.3.5.

Empregando esse procedimento nós obtivemos novos valores para ambos os solventes (figura 3.12). Todos os cálculos de momento de dipolo foram realizados com nível MP2/aug-cc-pVDZ.

$\mathrm{O}$ ajuste dos pontos foi feito utilizando uma função exponencial:

$$
y(x)=y_{0}+A e^{-R x}
$$


assim, a constante $y_{0}$ corresponde ao momento de dipolo convergido. Esse valor é de 6.29(3) D para 5FU em água, que concorda muito bem com o valor obtido usando PCM + MM/QM. Para a 5FU em acetonitrila, a situação é bem diferente: o método iterativo apresenta um momento de dipolo de 5.10(2)D, menor que o valor obtido usando PCM+MM/QM (5.47D), que por sua vez já era menor que o valor obtido com PCM (5.85D). Isso nos levou a verificar se usando o resultado obtido com $\mathrm{PCM}+\mathrm{MM} / \mathrm{QM}$ como início para um novo procedimento iterativo, o momento de dipolo convergiria para o mesmo valor (círculos vazados na figura 3.12b). Como a figura mostra, o valor convergido é o mesmo. Esse é o primeiro caso em que observamos o procedimento iterativo convergindo a partir de valores maiores que o valor final. Isso demonstra a robustez do procedimento, pois ele é capaz de convergir para o mesmo valor, mesmo iniciando de um ponto desfavorável.

A fim de verificar como esses resultados alteram a energia de absorção da 5FU, foram separadas 100 configurações estatisticamente descorrelacionadas da última simulação feita para cada solvente para gerar o ASEC (correspondendo a uma correlação de $7 \%$ para as configurações da $5 \mathrm{FU}$ em água e $1 \%$ para as configurações em acetonitrila), sobre o qual realizamos cálculos quânticos usando B3LYP, BHandHLYP e CIS(D). Cálculos considerando moléculas explícitas também foram feitos usando o funcional B3LYP (tabela 3.11).

Comparando os resultados agora obtidos com B3LYP com os obtidos anteriormente, vemos que o resultado muda pouco, porém a variação da energia é menor em ambas as aproximações usadas para o solvente: a diferença com ASEC que era de -0.04 passou para -0.01 e a diferença com moléculas explícitas passou de -0.02 para -0.01. Ou seja, ao melhorarmos os valores para o momento de dipolo (e consequentemente das cargas), nosso resultado melhora, caminhando na direção do resultado experimental, mas não o suficiente. Isso é mais claro quando observamos os resultados obtidos com BHandHLYP, CIS e CIS(D): para CIS não havia diferença entre os solventes e agora obtivemos um resultado muito próximo do experimental; BHandHLYP mostrava uma diferença de -0.01 e agora temos um valor que é a metade do experimental e, como apenas cargas pontuais foram utilizadas, é de se esperar que a inclusão de 
a)

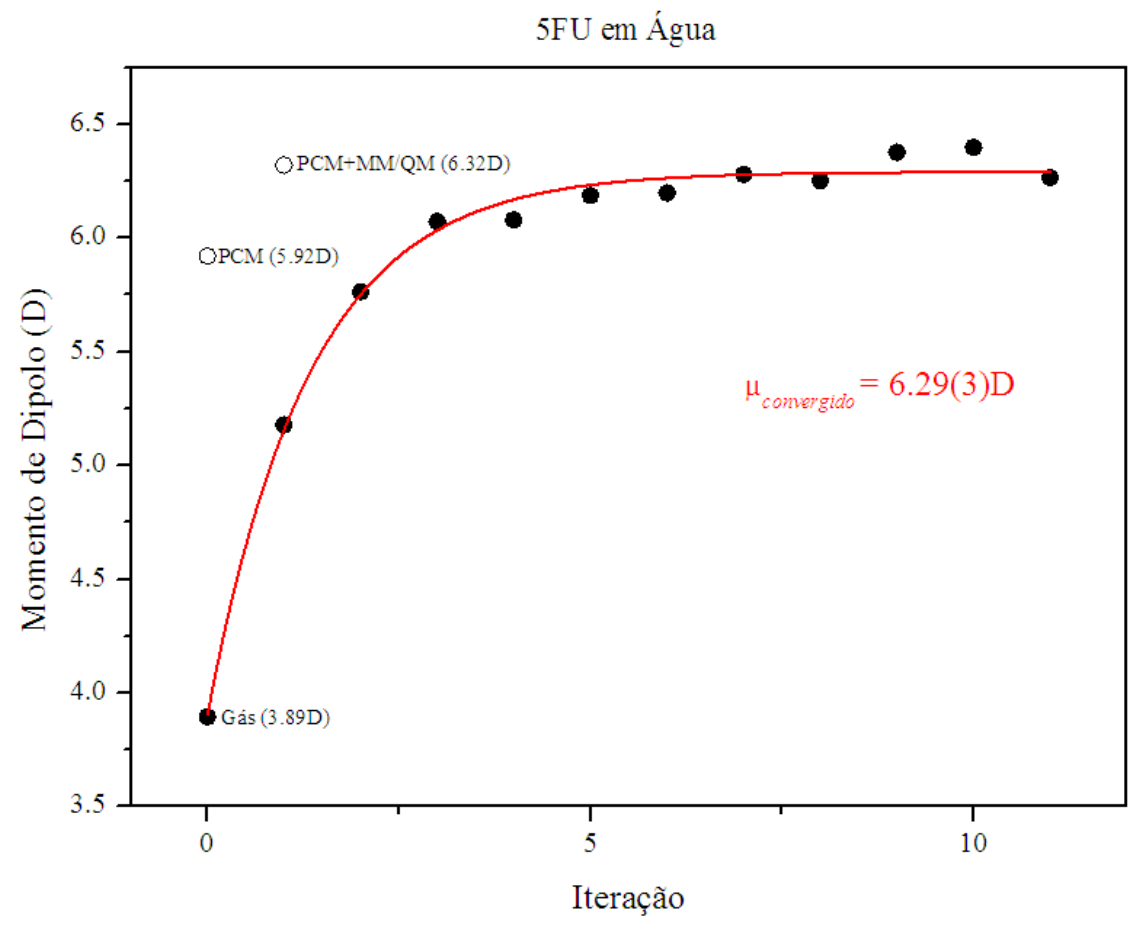

b)

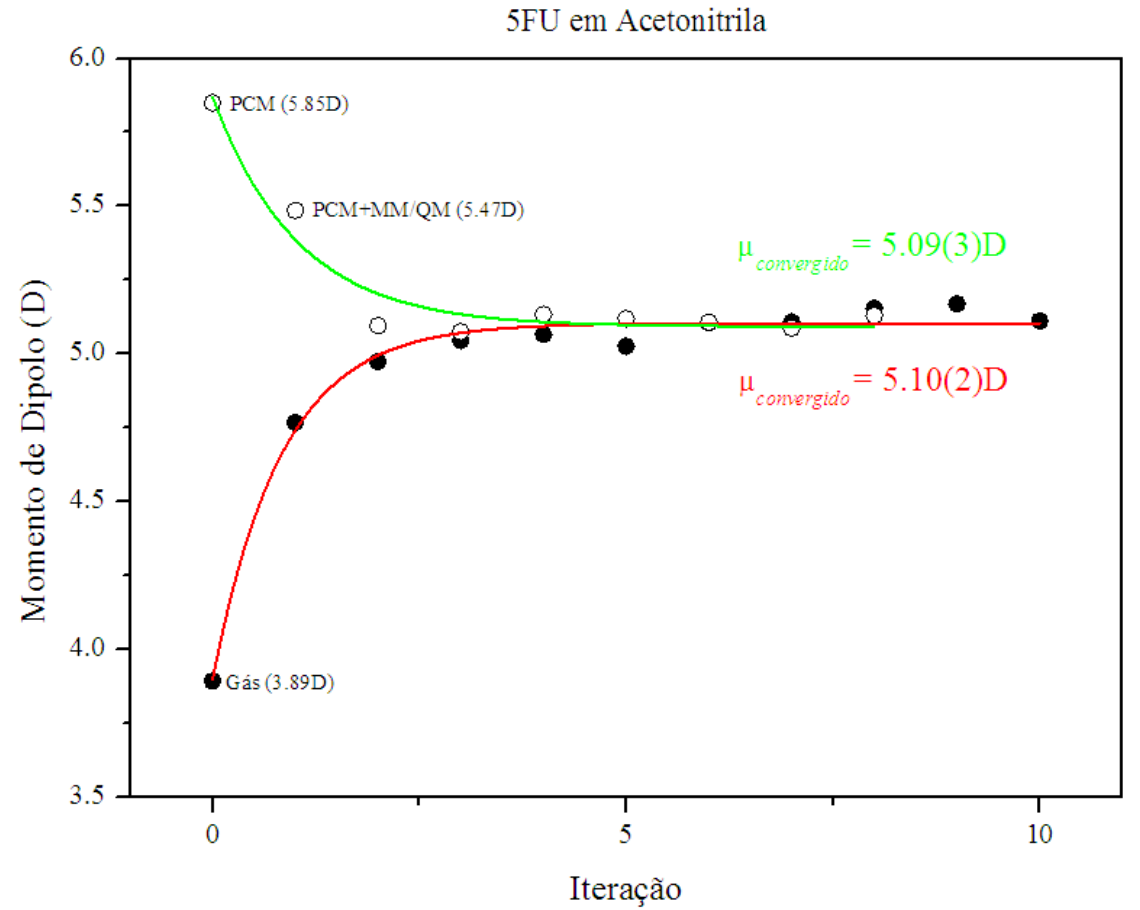

Figura 3.12: Convergência do momento de dipolo da $5 \mathrm{FU}$ em a) água e b) acetonitrila, obtida usando o procedimento iterativo. "Gás" indica que o dipolo foi obtido usando a geometria otimizada da molécula isolada; "PCM" indica que o dipolo foi calculado considerando o efeito de solvente nessa aproximação em geometria obtida também usando esse modelo; "PCM+MM/QM" significa que o dipolo foi calculado usando para representar o solvente o ASEC obtido após uma simulação de MC que usa os valores obtidos em "PCM" como ponto de partida. O momento de dipolo convergido é obtido ajustando aos dados uma função exponencial. 
Tabela 3.11: Transições de mais baixa energia da 5FU em água e em acetonitrila, cuja polarização foi obtida iterativamente. Os resultados foram obtidos usando B3LYP, representando o solvente por ASEC e moléculas explícitas, e BHandHLYP, CIS e CIS(D), representando o solvente por ASEC, todos com a base 6-311++G(d,p).

\begin{tabular}{|c|c|c|c|c|c|c|}
\hline \multirow[b]{2}{*}{ Modelo de Solvente } & \multicolumn{3}{|c|}{ Transição $\pi-\pi^{*}$} & \multicolumn{3}{|c|}{ Transição $n-\pi^{*}$} \\
\hline & $\mathrm{E}(\mathrm{eV})$ & $\lambda(\mathrm{nm})$ & f & $\mathbf{E}(\mathrm{eV})$ & $\lambda(\mathbf{n m})$ & f \\
\hline ASEC $\left[5 F U+254 \mathrm{H}_{2} \mathrm{O}\right.$ (c.p.) $]$ & 4.90 & 253 & 0.140 & 5.30 & 234 & 0.000 \\
\hline ASEC $\left[5 \mathrm{FU}+254 \mathrm{CH}_{3} \mathrm{CN}\right.$ (c.p.)] & 4.89 & 254 & 0.132 & 4.92 & 252 & 0.000 \\
\hline$\nabla \overline{\mathbf{E}_{\text {acetonitrila }}-\mathrm{E}_{\text {agua }}(\mathrm{eV})}$ & -0.01 & & & & & \\
\hline $5 \mathrm{FU}+16 \mathrm{H}_{2} \mathrm{O}+238 \mathrm{H}_{2} \mathrm{O}$ (c.p.) & 4.80 & 259 & 0.156 & 5.14 & 242 & 0.006 \\
\hline $5 \mathrm{FU}+08+\mathrm{CH}_{3} \mathrm{CN}+254 \mathrm{CH}_{3} \mathrm{CN}$ (c.p.) & 4.79 & 259 & 0.148 & 4.92 & 252 & 0.010 \\
\hline $\mathbf{E}_{\text {acetonitrila }}-\mathbf{E}_{\text {agua }}(\mathbf{e V})$ & 0.00 & \pm 0.01 & & & & \\
\hline ASEC $\left[5 \mathrm{FU}+254 \mathrm{H}_{2} \mathrm{O}\right.$ (c.p.) $]$ & 5.38 & 230 & 0.215 & 5.95 & 209 & 0.000 \\
\hline$\underset{\#}{ } \mathrm{ASEC}\left[5 \mathrm{FU}+254 \mathrm{CH}_{3} \mathrm{CN}\right.$ (c.p.)] & 5.40 & 230 & 0.217 & 5.55 & 223 & 0.000 \\
\hline $\mathbf{E}_{\text {acetonitrila }}-\mathbf{E}_{\text {agua }}(\mathbf{e V})$ & 0.02 & & & & & \\
\hline ASEC $\left[5 \mathrm{FU}+254 \mathrm{H}_{2} \mathrm{O}\right.$ (c.p.)] & 6.28 & 198 & 0.409 & 6.96 & 178 & 0.000 \\
\hline$\stackrel{\mathscr{2}}{\circlearrowright} \mathrm{ASEC}\left[5 \mathrm{FU}+254 \mathrm{CH}_{3} \mathrm{CN}\right.$ (c.p.)] & 6.30 & 197 & 0.428 & 6.51 & 191 & 0.000 \\
\hline $\mathbf{E}_{\text {acetonitrila }}-\mathbf{E}_{\text {água }}(\mathbf{e V})$ & 0.03 & & & & & \\
\hline$\widehat{A S E C}\left[5 \mathrm{FU}+254 \mathrm{H}_{2} \mathrm{O}\right.$ (c.p.)] & 5.19 & 239 & 0.409 & 5.55 & 224 & 0.000 \\
\hline$\approx \mathrm{ASEC}\left[5 \mathrm{FU}+254 \mathrm{CH}_{3} \mathrm{CN}\right.$ (c.p.)] & 5.29 & 234 & 0.428 & 5.21 & 238 & 0.000 \\
\hline$\circlearrowright \overline{\mathbf{E}_{\text {acetonitrila }}-\mathbf{E}_{\text {agua }}(\mathbf{e V})}$ & 0.10 & & & & & \\
\hline
\end{tabular}

moléculas de solvente explícitas aproxime o resultado ainda mais do valor experimental; já para CIS(D), cujo resultado era idêntico ao experimental, a separação entre os valores aumentou, dobrando o valor obtido para a diferença da energia de excitação.

O resultado obtido com CIS(D) poderia nos levar a questionar a possibilidade de o método iterativo estar superpolarizando a 5FU em água ou subpolarizando em acetonitrila, resultando em cargas irreais, o que, por conseguinte, leva a separação maior do que a observada experimentalmente. Todavia, note que o procedimento iterativo atualiza as cargas somente do soluto. As moléculas de solvente mais próximas do soluto podem ter uma mudança significativa em suas cargas e isso não está sendo considerado. Outro ponto importante é a geometria tanto do soluto como do solvente, que podem sofrer alterações conforme as moléculas interagem. Mas, como já dissemos, 
devido às restrições para a eficiência computacional de $\mathrm{MC}$, trabalhamos apenas com moléculas rígidas. Atualmente, métodos para a atualização simultânea das cargas e da geometria do soluto estão sendo desenvolvidos (seção 1.3.6)

Concluindo: uma descrição mais acurada da polarização é importante e o método iterativo se mostra adequado para tal. Entretanto, a atualização das cargas apenas do soluto e a não atualização de geometrias pode levar a discrepâncias com os valores reais.

- A geometria obtida como mínima não é boa elou há algum problema com a simulação clássica. Verificamos que as simulações estavam termalizadas e convergidas, de modo que essa hipótese é pouco provável.

Apesar de a geometria encontrada ter sido submetida a cálculos de frequência na aproximação harmônica de mesmo nível de precisão, apresentando todas as frequências positivas, indicativo de que a geometria encontrada era mesmo de mínimo e não máximo local, vimos que a DFT não descreve os espectros corretamente, então o mesmo poderia ocorrer com a geometria.

Assim, nós reotimizamos a 5FU usando o nível MP2/aug-cc-pVDZ e refizemos as simulações.

A nova geometria obtida não apresentava mudanças significativas e foi também testada em um cálculo de freqüência na aproximação harmônica. As simulações tiveram o mesmo número de passos que as anteriores, mostrando-se novamente convergidas.

Separamos novamente 100 configurações estatisticamente mais relevantes, resultando em uma correlação de 4\% para ambos os caso, as quais foram utilizadas para cálculos quânticos usando B3LYP, onde o solvente foi aproximado por cargas pontuais, pelo ASEC e por moléculas explícitas; cálculos usando os métodos CIS e CIS(D), aproximando o solvente pelo ASEC, também foram realizados (tabela 3.12).

Observamos novamente o mesmo comportamento obtido com a otimização e simulação anteriores: B3LYP apresenta bons valores individuais das transições, mas não descreve corretamente a variação da energia de um solvente para outro; CIS superestima os valores das energias de transição e praticamente não diferencia os solventes; CIS(D) também superestima a 
energia, porém apresenta a variação em boa concordância com a variação experimental. Assim, a geometria e a simualção anteriores também não são fontes de erro.

Tabela 3.12: Transições de mais baixa energia da 5FU (otimizada com nível MP2/aug-cc-pVDZ) em água e em acetonitrila, obtidas usando B3LYP, representando o solvente por cargas pontuais, ASEC e moléculas explícitas, e CIS e CIS(D), representando o solvente por ASEC, todos com a base $6-311++\mathrm{G}(\mathrm{d}, \mathrm{p})$.

\begin{tabular}{|c|c|c|c|c|c|c|}
\hline \multirow[b]{2}{*}{ Modelo de Solvente } & \multicolumn{3}{|c|}{ Transição $\pi-\pi^{*}$} & \multicolumn{3}{|c|}{ Transição $n-\pi^{*}$} \\
\hline & $\mathrm{E}(\mathrm{eV})$ & $\lambda(\mathbf{n m})$ & f & $\mathrm{E}(\mathrm{eV})$ & $\lambda(\mathbf{n m})$ & $\mathbf{f}$ \\
\hline $5 \mathrm{FU}+254 \mathrm{H}_{2} \mathrm{O}$ (c.p.) & 4.83 & 257 & 0.133 & 5.05 & 246 & 0.001 \\
\hline $5 \mathrm{FU}+254 \mathrm{CH}_{3} \mathrm{CN}$ (c.p.) & 4.80 & 258 & 0.123 & 4.77 & 260 & 0.004 \\
\hline$\overline{\mathbf{E}_{\text {acetonitrila }}-\mathbf{E}_{\text {água }}(\mathrm{eV})}$ & \multicolumn{2}{|c|}{$-0.03 \pm 0.01$} & & & & \\
\hline$\approx \overline{\mathrm{ASEC}\left[5 \mathrm{FU}+254 \mathrm{H}_{2} \mathrm{O} \text { (c.p.)] }\right.}$ & 4.84 & 256 & 0.135 & 5.06 & 245 & 0.000 \\
\hline$\stackrel{\vec{m}}{\mathrm{ASEC}}\left[5 \mathrm{FU}+254 \mathrm{CH}_{3} \mathrm{CN}\right.$ (c.p.)] & 4.81 & 258 & 0.127 & 4.77 & 260 & 0.000 \\
\hline$\oplus \overline{\mathbf{E}_{\text {acetonitrila }}-\mathbf{E}_{\text {agua }}(\mathrm{eV})}$ & \multicolumn{2}{|l|}{-0.03} & & & & \\
\hline $5 \mathrm{FU}+07 \mathrm{H}_{2} \mathrm{O}+238 \mathrm{H}_{2} \mathrm{O}$ (c.p.) & 4.78 & 260 & 0.161 & 5.02 & 247 & 0.004 \\
\hline $5 \mathrm{FU}+08+\mathrm{CH}_{3} \mathrm{CN}+254 \mathrm{CH}_{3} \mathrm{CN}$ (c.p.) & 4.73 & 262 & 0.151 & 4.79 & 259 & 0.004 \\
\hline $\mathbf{E}_{\text {acetonitrila }}-\mathbf{E}_{\text {agua }}(\mathbf{e V})^{*}$ & \multicolumn{2}{|c|}{$-0.04 \pm 0.01$} & & & & \\
\hline ASEC $\left[5 \mathrm{FU}+254 \mathrm{H}_{2} \mathrm{O}\right.$ (c.p.) $]$ & 6.21 & 200 & 0.415 & 6.80 & 182 & 0.000 \\
\hline$\stackrel{\mathscr{\Omega}}{\mathcal{U}}$ ASEC $\left[5 \mathrm{FU}+254 \mathrm{CH}_{3} \mathrm{CN}\right.$ (c.p.)] & 6.22 & 199 & 0.431 & 6.44 & 193 & 0.000 \\
\hline $\mathbf{E}_{\text {acetonitrila }}-\mathbf{E}_{\text {agua }}(\mathbf{e V})$ & \multicolumn{2}{|l|}{0.01} & & & & \\
\hline$\widehat{\mathrm{e}} \mathrm{ASEC}\left[5 \mathrm{FU}+254 \mathrm{H}_{2} \mathrm{O}\right.$ (c.p.)] & 5.15 & 241 & 0.415 & 5.27 & 235 & 0.000 \\
\hline$\cong \mathrm{ASEC}\left[5 \mathrm{FU}+254 \mathrm{CH}_{3} \mathrm{CN}\right.$ (c.p.)] & 5.20 & 238 & 0.431 & 5.01 & 247 & 0.000 \\
\hline$\cup \overline{\mathbf{E}_{\text {acetonitrila }}-\mathbf{E}_{\text {agua }}(\mathbf{e V})}$ & \multicolumn{2}{|l|}{0.05} & & & & \\
\hline
\end{tabular}

*Pode-se questionar porque 7 moléculas de água explícita ao invés de 16. Ocorre que esses cálculos são deveras dispendiosos e, como os valores obtidos com o solvente sendo aproximado apenas por cargas pontuais já apresentavam a tendência incorreta, nós resolvemos usar apenas 7 águas que, como vimos na tabela 3.5, apresenta um valor de aproximadamente $0.03 \mathrm{eV}$ acima do valor obtido com 16 moléculas explícitas, o que nos leva a estimar uma diferença de $-0.01 \mathrm{eV}$, exatamente igual ao obtido anteriormente.

Após testar todas essas hipóteses, nós fizemos ainda uma última consideração: a convolução do espectro. A média não necessariamente é o valor mais representativo para uma grandeza, como vemos por exemplo no átomo de hidrogênio, onde a distância média do elétron ao núcleo é diferente da distância mais provável de se encontrar o elétron. De fato, o que é medido experimentalmente é o valor mais provável, e não o 
valor médio. Observando isso, nós convoluimos o espectro ajustando uma Lorentziana (equação 3.2) sobre os valores calculados e tomamos como energia de absorção o máximo da curva obtida.

$$
\mathfrak{I}=\frac{1}{\pi}\left(\frac{\gamma}{\left(x-x_{0}\right)^{2}+\gamma^{2}}\right)
$$

Para realizar o ajuste, é necessário fornecer uma largura de linha $\gamma$ já que, como dissemos na Introdução, ela reflete a mesma transição eletrônica entre diferentes níveis vibracionais, além de haver o alargamento inomogêneo devido à temperatura e as limitações do aparato experimental, e não pode ser calculada. Para esse alargamento nós usamos o valor de $0.25 \mathrm{eV}$, que é aproximadamente a largura a meia altura do espectro experimental (figura 3.9). Os espectros convoluídos obtidos a partir dos cálculos feitos com moléculas de solvente explícitas das tabelas 3.5 e 3.6 são apresentados na figura 3.13. A tabela 3.13 apresenta o deslocamento obtido a partir dos espectros convoluidos.

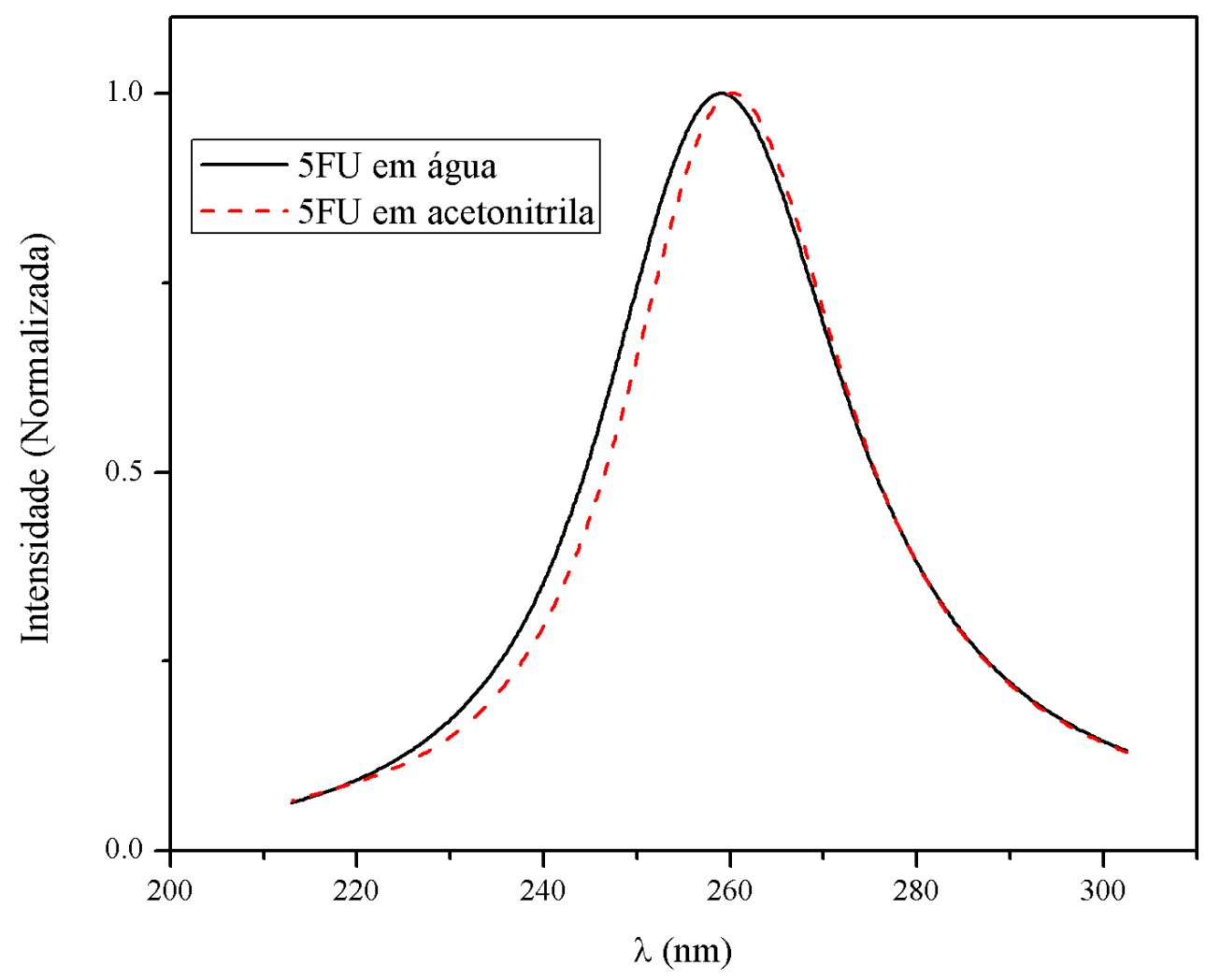

Figura 3.13: Espectro obtido a partir dos resultados teóricos com nível B3LYP/6-311++G(d,p) considerando o solvente explicitamente. 
Tabela 3.13: Deslocamento da transição $\pi-\pi^{*}$ obtido da convolução dos resultados teóricos e comparação com os valores obtidos a partir das médias. Exceto quando indicado, a base utilizada foi $6-311++G(d, p)$.

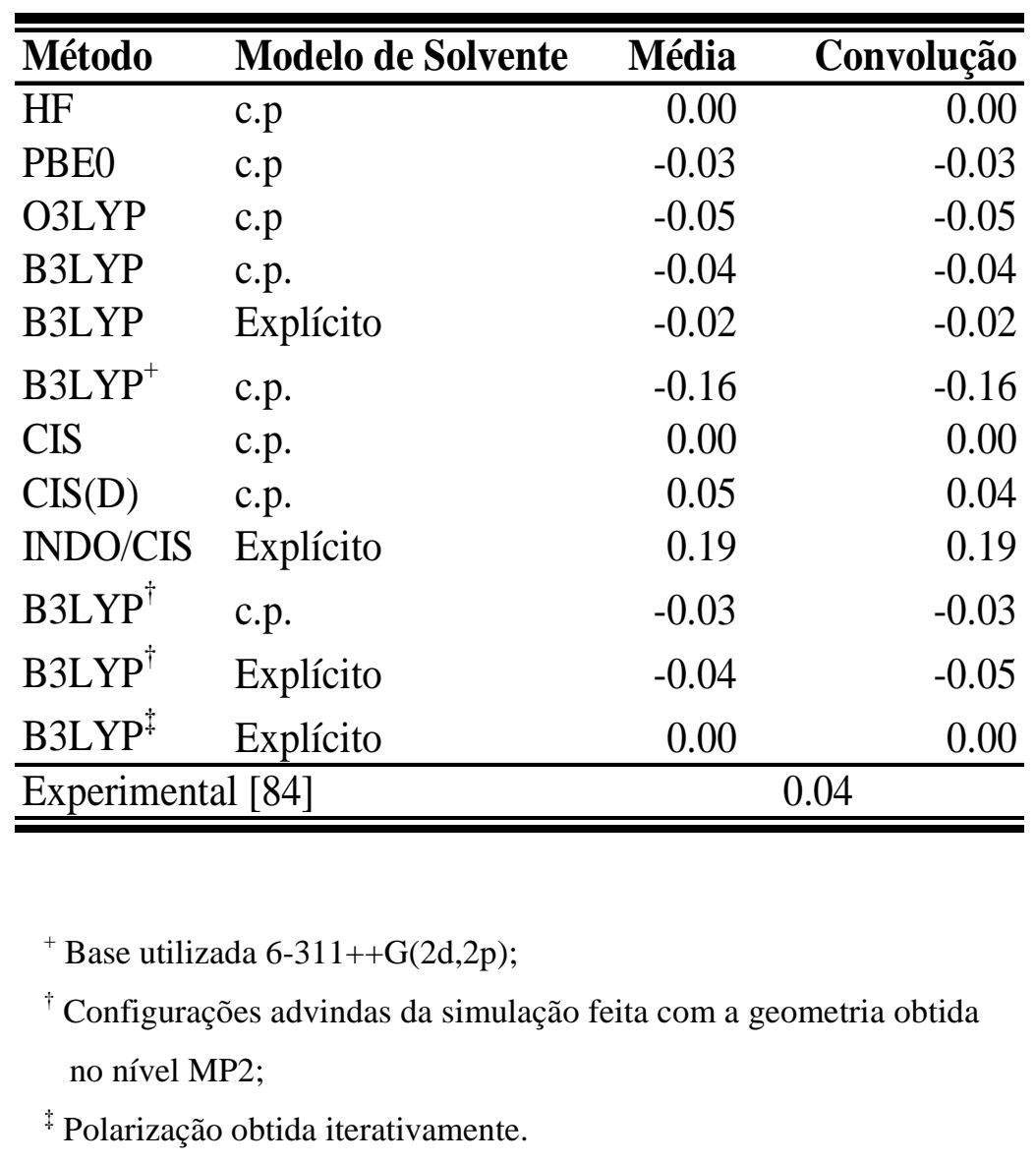

Como vemos, convoluir o espectro não afeta o resultado, mostrando que o valor mais provável e a média são iguais.

Em suma, não é possível obter uma "vitória perfeita": TD-DFT apresentou resultados para a energia de transição muito próximos dos valores experimentais a um custo computacional factível, permitindo a inclusão de algumas moléculas explícitas de solvente, mas ela não é capaz de reproduzir o comportamento observado experimentalmente, no sentido em que erra ao colocar a transição em água como mais energética que a transição em acetonitrila. Essa falha é possivelmente proveniente dos problemas que os funcionais têm em descrever interações de van der Waals. A única exceção foi o funcional BHandHLYP que, quando combinado com o procedimento iterativo, apresentou a variação correta e com um valor que é a metade do obtido experimentalmente e, como o solvente foi representado apenas por cargas pontuais, o 
resultado pode ser ainda mais próximo ao experimental se moléculas de solvente explícitas forem incluídas no cálculo. Ainda contrariando os demais funcionais, BHandHLYP foi um dos métodos utilizados que apresentou os piores valores para as energias de transição, ficando atrás somente de TD-HF e CIS.

O método semiempírico INDO/CIS superestima os valores para a energia, mas apresenta a transição em água como menos energética que em acetonitrila, condizente com o que é medido experimentalmente. Porém, a diferença entre ambas é quase cinco vezes o valor experimental.

O método ab initio CIS(D) foi o único a descrever corretamente a diferença de energia, embora os valores individuais sejam superestimados. Entretanto, esse é um método computacionalmente caro, de modo que ficamos restritos a aproximar o solvente como cargas pontuais. A inclusão de moléculas explícitas tende a melhorar os valores da energia de transição, mas isso ainda é computacionalmente inviável (como veremos na próxima seção). Para a diferença da energia de transição de um solvente para outro, nosso melhor resultado foi obtido quando o método CIS(D) foi combinado com a polarização implícita, via PCM, do soluto pelo solvente, apesar dessa polarização não apresentar valores razoáveis para o momento de dipolo. Usando um método iterativo nós obtivemos valores mais coerentes para o dipolo, entretanto a variação da energia passou a ser o dobro do valor experimental. Atribuímos a isso o fato de que somente as cargas do soluto são atualizadas durante o procedimento, além de que mudanças geométricas também são desprezadas.

\subsubsection{Inversão dos estados $n-\pi *$ e $\pi$ - $\pi^{*}$ quando em meio solvente}

Há uma grande discussão na literatura sobre a inversão dos estados $n-\pi^{*}$ e $\pi$ - $\pi^{*}$ das bases do DNA quando interagindo com um meio solvente [79,87]. Esse é um fenômeno importante do ponto de vista biológico, pois como alguns estudos apontam, essa inversão pode acarretar em um acoplamento desses estados através do efeito pseudo-Jahn-Teller [88] ou no surgimento de interseções cônicas [87], o que contribui para aumentar drasticamente a probabilidade de decaimentos não-radioativos, levando a uma diminuição do tempo de vida do estado excitado e, consequentemente, a uma menor foto-reatividade e degradação fotoquímica [89].

Para analisar a inversão dos níveis, precisamos comparar nossos resultados em meio com o resultado em fase gasosa. Na tabela 3.14 sumarizamos os resultados 
obtidos com os métodos ab initio CIS e CIS(D) e com o funcional da densidade B3LYP, todos com a mesma base usada para os cálculos em meio solvente: 6-311++G(d,p). O cálculo também foi feito com o método semiempírico INDO/CIS. $\mathrm{Na}$ figura 3.14 temos os orbitais envolvidos nessas transições. Eles são muito semelhantes aos orbitais obtidos em meio solvente.

Tabela 3.14: Transições de mais baixa energia da molécula 5FU isolada.

\begin{tabular}{lccccccc}
\hline \hline & \multicolumn{3}{c}{ Transições $\boldsymbol{n}-\boldsymbol{\pi}^{*}$} & & \multicolumn{3}{c}{ Transições $\boldsymbol{\pi}-\boldsymbol{\pi}^{*}$} \\
\cline { 2 - 3 } Método & $\mathbf{E}(\mathbf{e V})$ & $\boldsymbol{\lambda}(\mathbf{n m})$ & $\mathbf{f}$ & & $\mathbf{E}(\mathbf{e V})$ & $\boldsymbol{\lambda}(\mathbf{n m})$ & $\mathbf{f}$ \\
\hline B3LYP & 4.67 & 265 & 0.000 & & 4.88 & 254 & 0.125 \\
O3LYP & 4.33 & 286 & 0.000 & & 4.69 & 265 & 0.096 \\
PBE0 & 4.65 & 267 & 0.000 & & 4.95 & 251 & 0.137 \\
BHandHLYP & 5.16 & 240 & 0.000 & & 5.36 & 231 & 0.219 \\
CIS & 6.12 & 203 & 0.000 & & 6.26 & 198 & 0.448 \\
CIS(D) & 4.82 & 257 & 0.000 & & 5.36 & 231 & 0.448 \\
INDO/CIS & 3.99 & 311 & 0.001 & 5.20 & 239 & 0.438 \\
\hline \hline
\end{tabular}

5FU isolada

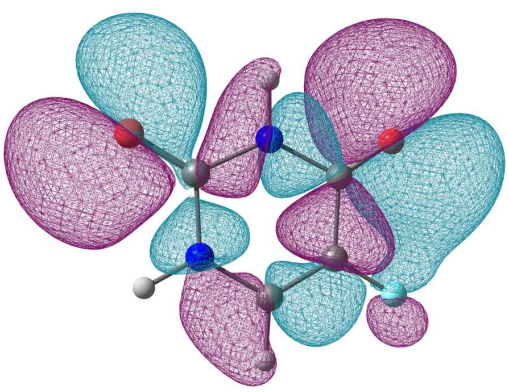

HOMO-1 (n)

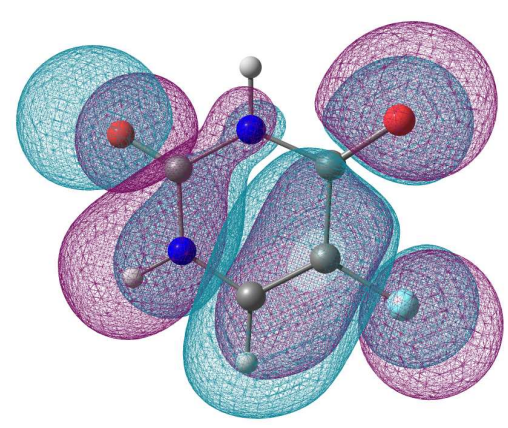

$\operatorname{HOMO}(\pi)$

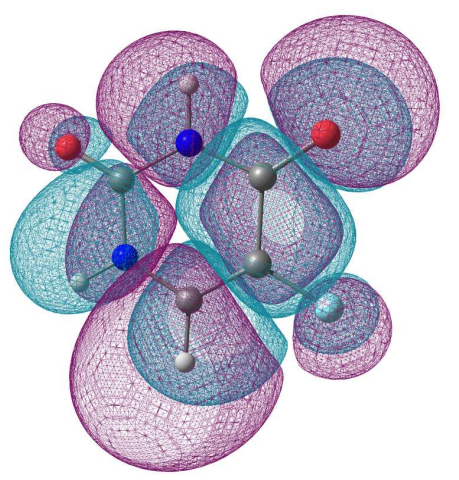

$\operatorname{LUMO}(\pi)$

Figura 3.14: Orbitais moleculares envolvidos na excitação da 5FU isolada, obtidos com B3LYP. São similares ao obtidos em meio.

Uma rápida inspeção na tabela 3.14 nos mostra que, independentemente do método usado, a transição $n-\pi^{*}$ é menos energética que a transição $\pi-\pi^{*}$. Olhando a tabela 3.5 vemos que para a 5FU em água o oposto ocorre: a transição $\pi-\pi^{*}$ é a menos energética. A única exceção é quando o calculo é feito considerando apenas a 5FU e as 7 águas mais próximas: nesse caso as energias são muito próximas mas a transição $n-\pi^{*}$ é ligeiramente 
menos energética. Note porém que os valores obtidos nessa aproximação são muito ruins quando comparados com valor experimental e com os demais valores da tabela. Isso mostra que moléculas de solvente a uma média distância ainda contribuem de maneira muito significativa através de interações eletrostáticas.

Com exceção do método INDO/CIS (tabela 3.10) que será discutido no final dessa seção, todos os outros resultados obtidos para a 5FU em água (tabelas 3.8, 3.9, 3.10, 3.11 e 3.12) apresentam o mesmo comportamento: a transição $\pi-\pi^{*}$ é menos energética que a transição $n-\pi^{*}$, ou seja, tem suas posições invertidas em relação à fase gasosa.

Para a 5FU em acetonitrila ocorre algo um pouco diferente: a tabela 3.6 mostra a transição $\pi-\pi^{*}$ como menos energética que a $n-\pi^{*}$ quando o solvente é tratado nas aproximações contínua e explícita. Quando a acetonitrila é representada discretamente apenas como cargas pontuais ou pela configuração ASEC a transição $n$ - $\pi^{*}$ é mostrada como sendo menos energética. O mesmo acontece em quase todas as situações que estudamos (tabelas 3.8, 3.9, 3.10 e 3.12). As exceções são o método PBE e BHandHLYP (tabela 3.9): o primeiro apresenta ambas as transições com a mesma energia enquanto o segundo as colocas na ordem obtida com as outras aproximações; os métodos TD-HF e CIS (tabela 3.10) também apresentam as transições na mesma ordem em que elas ocorrem nas aproximações contínua e explícita (entretanto a correção para o segundo estado excitado é maior, fazendo com que CIS(D) apresente a transição $n-\pi^{*}$ como sendo menos energética). O método INDO/CIS, com o qual foi utilizado moléculas explícitas, também apresenta a transição $n-\pi^{*}$ como menos energética (tabela 3.10). A tabela 3.11 é outra exceção: nela vemos que B3LYP e CIS também apresentam as transições na mesma ordem em que elas aparecem nas aproximações contínua e explícita, porém novamente a correção para o segundo estado é maior fazendo com que CIS(D) apresente a transições na ordem oposta.

A princípio temos um impasse para a posição das transições em acetonitrila. É de se esperar que o comportamento correto seja aquele descrito pelo maior número de moléculas tratadas quanticamente, levando-nos a afirmar que o modelo discreto não descreve adequadamente essas transições. Parte do problema pode ser atribuído a polarização implícita, já que usando o método iterativo, B3LYP apresentou a transição $\pi$ - $\pi^{*}$ como a menos energética. Porém o problema persiste com o método CIS(D).

Alguns estudos recentes têm mostrado que as transições $\pi-\pi^{*}$ são mais sensíveis as interações não-eletrostáticas [5,90]. Assim, quando consideramos apenas cargas pontuais para representar o solvente, estamos numa aproximação que de um modo geral é razoável para a transição $n-\pi^{*}$ mas que pode ser insuficiente para a transição $\pi-\pi^{*}$, fazendo com que 
sua energia seja superestimada, apresentado inclusive um valor maior do que a transição $n$ $\pi^{*}$. Para a 5FU em água esse efeito também ocorre, mas como a separação entre as transições é maior, a transição $\pi-\pi^{*}$ nunca se mostra mais energética que a $n-\pi^{*}$.

Como a polarização iterativa é uma primeira aproximação para a relaxação solutosolvente, ela ajuda a corrigir este efeito, mas sozinha pode não ser suficiente, como ocorreu com o método CIS(D), evidenciando assim que as interações não-eletrostáticas desempenham papel fundamental na transição $\pi-\pi^{*}$. Com o intuito de ilustrar isso, calculamos as energias de transição da 5FU em acetonitrila com nível CIS(D)/6$311+\mathrm{G}(\mathrm{d}, \mathrm{p})$ aumentado gradativamente o número de moléculas de solvente explícitas (tabela 3.15). Para este cálculo utilizamos somente uma configuração escolhida ao acaso, uma vez que o método CIS(D) requer uma demanda computacional muito elevada.

Tabela 3.15: Dependência das transições $n-\pi^{*}$ e $\pi-\pi^{*}$ com interações não-eletrostáticas; esta última é mais sensível a este tipo de interação. Apenas uma configuração escolhida ao acaso foi utilizada devido à alta demanda computacional para o método CIS(D)*. A base usada foi $6-311++\mathrm{G}(\mathrm{d}, \mathrm{p})$.

\begin{tabular}{lcc}
\hline \hline Modelo de Solvente & $\boldsymbol{n}-\pi^{*}$ & $\boldsymbol{\pi}-\pi^{*}$ \\
\hline $5 \mathrm{FU}+254 \mathrm{CH}_{3} \mathrm{CN}$ (c.p) & 5.10 & 5.22 \\
$5 \mathrm{FU}+01 \mathrm{CH}_{3} \mathrm{CN}+253 \mathrm{CH}_{3} \mathrm{CN}$ (c.p) & 5.08 & 5.23 \\
$5 \mathrm{FU}+02 \mathrm{CH}_{3} \mathrm{CN}+252 \mathrm{CH}_{3} \mathrm{CN}$ (c.p) & 5.10 & 5.17 \\
$5 \mathrm{FU}+03 \mathrm{CH}_{3} \mathrm{CN}+251 \mathrm{CH}_{3} \mathrm{CN}$ (c.p) & 5.12 & 5.14 \\
$5 \mathrm{FU}+04 \mathrm{CH}_{3} \mathrm{CN}+250 \mathrm{CH}_{3} \mathrm{CN}$ (c.p) & 5.13 & 5.11 \\
$5 \mathrm{FU}+05 \mathrm{CH}_{3} \mathrm{CN}+249 \mathrm{CH}_{3} \mathrm{CN}$ (c.p) & 5.11 & 5.13 \\
$5 \mathrm{FU}+06 \mathrm{CH}_{3} \mathrm{CN}+248 \mathrm{CH}_{3} \mathrm{CN}$ (c.p) & 5.12 & 5.11 \\
\hline \hline
\end{tabular}

*Para ilustrar esse custo, com 5 moléculas de acetonitrila foram necessárias 60 horas dedicadas em uma máquina com processador 8-core e 47 GB de memória RAM. Com 6 moléculas, foram necessárias 97 horas na mesma máquina.

Os resultados da tabela 3.15 mostram que a energia para a transição $n$ - $\pi^{*}$ fica em torno de um valor médio conforme aumentamos o número de moléculas explícitas, evidenciando que as interações eletrostáticas são dominantes para descrever seu comportamento; em contrapartida, a transição $\pi-\pi^{*}$ tem um decréscimo na energia de aproximadamente $0.11 \mathrm{eV}$, ressaltando que para descrevê-la corretamente se faz necessário 
considerar interações não-eletrostáticas, mostrando a importância do tratamento explícito do solvente. Aqui cabe uma pequena defesa ao modelo PCM, que apesar de não diferenciar os solventes e de apresentar valores superestimados para as transições, posicionou-as corretamente.

Resumindo: em meio solvente a transição $n-\pi^{*}$ de mais baixa energia da molécula 5FU sofre um deslocamento para o azul, enquanto a transição $\pi-\pi^{*}$ sofre um deslocamento para o vermelho. Esse deslocamento é grande o suficiente para que a posição das transições seja trocada. A figura 3.15 apresenta um diagrama ilustrativo desse processo. Entretanto, para que esse deslocamento seja obtido de maneira correta, faz-se de extrema importância o tratamento explícito das moléculas de solvente, uma vez que a transição $\pi$ - $\pi$ * é fortemente influenciada por interações não-eletrostáticas. Além disso, como vimos na seção anterior, a variação correta desta transição em diferentes solventes só é obtida usando métodos que incluem correlação eletrônica.

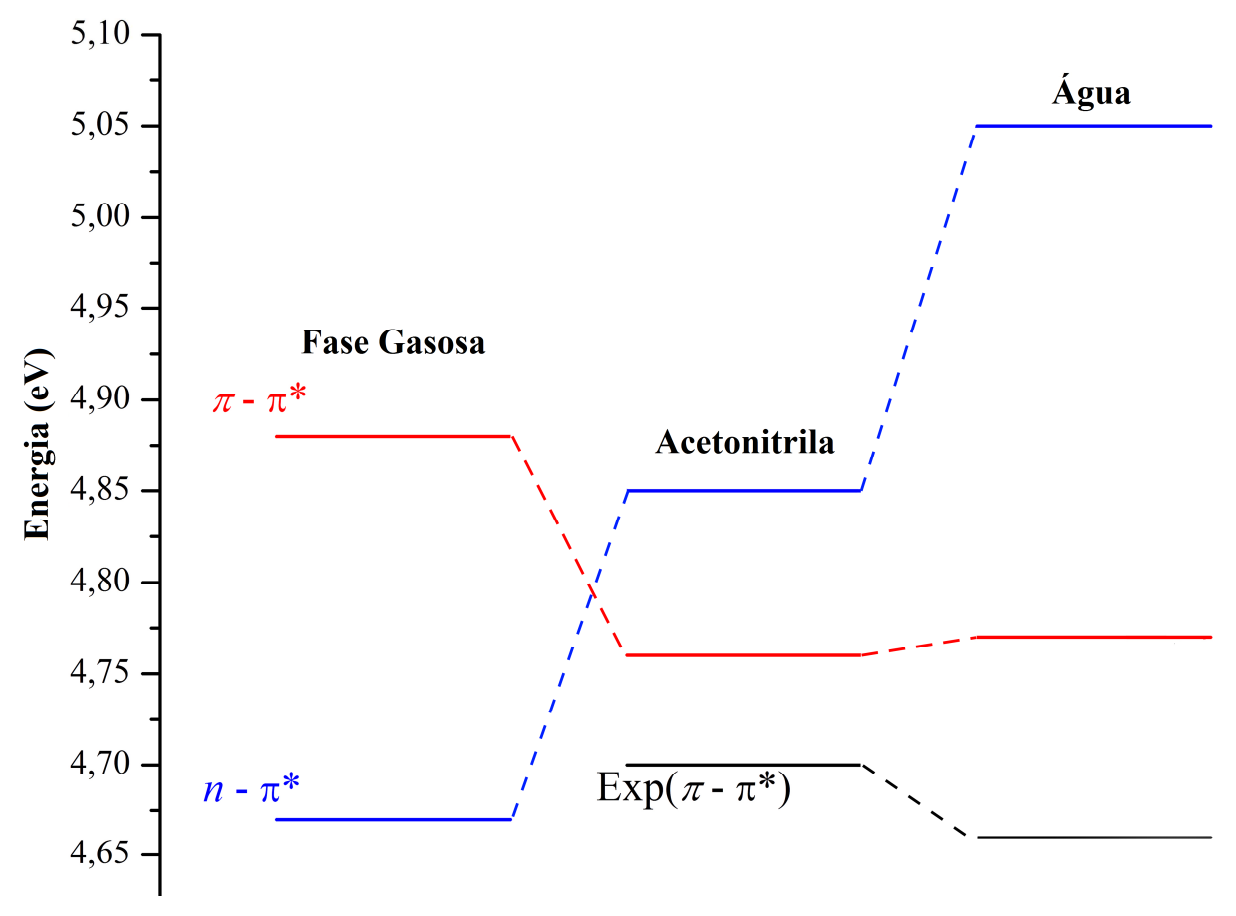

Figura 3.15: Diagrama ilustrando o processo de inversão das transições $n-\pi^{*}$ e $\pi-\pi^{*}$ da molécula 5FU, quando em meio solvente, calculado com nível B3LYP. TD-DFT falha ao calcular a transição $\pi-\pi^{*}$ em água: outros métodos como CIS(D) mostram comportamento similar ao obtido experimentalmente (linha preta), onde a transição em água é menos energética que a transição em acetonitrila. 
Para finalizarmos a discussão dos resultados, vamos comentar o motivo do método INDO/CIS apresentar resultados ruins, mesmo utilizando apenas moléculas explícitas. Na tabela 3.14 vemos que a diferença energética entre as duas transições está entre 0.2 e $0.5 \mathrm{eV}$, mas o método INDO/CIS mostra-a como sendo $1.2 \mathrm{eV}$, evidenciando uma excessiva e irrealista separação entre os níveis na fase gasosa. Quando passamos para o tratamento incluindo o solvente, o efeito deste desloca as transições, mas como elas estão muito separadas, o efeito não é suficiente para que haja a inversão. 



\section{Conclusões e Perspectivas}

Nosso intuito com esse trabalho era o estudo teórico da absorção da molécula 5-fluorouracil (5FU) em dois solvente: água e acetonitrila. Para tal, utilizamos o método Sequential - Quantum Mechanics/Molecular Mechanics (S-QM/MM), um método sofisticado que combina tratamento estatístico através de simulações computacionais, usando o método de Monte Carlo e posteriores cálculos quânticos.

Ambos os solvente foram tratados em mais de uma aproximação: contínua (que não foi capaz de diferenciar os solventes), discreta e explícita. A polarização também foi obtida de duas maneiras: implicitamente com o modelo contínuo e usando um método iterativo.

Os cálculos quânticos foram feitos com mais de um método: TD-HF, TD-DFT, CI e INDO. Como o deslocamento espectral nesse caso é muito pequeno, nós o utilizamos como um parâmetro para avaliar esses métodos.

Usando TD-DFT, mais especificamente o funcional B3LYP, o valor da transição $\pi-\pi^{*}$ de mais baixa energia obtido foi muito próximo dos valores experimentais, uma diferença de cerca de $0.1 \mathrm{eV}$. Entretanto, o método erra ao colocar a transição em água como sendo mais energética que em acetonitrila, quando o oposto é medido experimentalmente. Esse erro ocorre em ambas as aproximações de solvente e persiste mesmo trocando o funcional ou mudando a forma como a polarização é obtida, levandonos a conclusão que ele advém da própria TD-DFT, e deve ser proveniente do conhecido fato que os funcionais não contemplam as interações de van der Waals. A única exceção foi o método BHandHLYP que, ao ser combinado com a polarização iterativa, apresentou a transição da 5FU em água como sendo menos energética, com uma diferença para a acetonitrila que é a metade do valor medido experimentalmente. Como o cálculo foi realizado aproximando as moléculas do solvente apenas como cargas pontuais, é de se esperar que o resultado melhore se moléculas explícitas forem 
consideradas. Porém, BHandHLYP foi um dos métodos que apresentou os piores valores para a energia de excitação, ficando atrás somente de HF e CIS.

O método ab initio CIS(D) superestimou a energia de transição, mas apresentou o valor correto para o deslocamento. Por ser um método muito custoso, só foi possível aproximar o solvente por cargas pontuais. A inclusão de moléculas explícitas para representá-lo tende a aproximar os valores teóricos dos experimentais. Interessante notar que ao incluir a polarização iterativamente, o deslocamento mais que dobrou. Creditamos a isso o fato da aproximação ter se tornado desequilibrada: o método usado polariza apenas cargas do soluto. Relaxação de geometria também não foi considerada.

O método semiempírico INDO/CIS também apresentou a tendência correta para o deslocamento, mas um valor 5 vezes maior que o medido experimentalmente. Isso ocorre porque o método separa muito o valor das transições da 5FU isolada, e o efeito de solvente não é grande ao ponto de compensar tal falha.

Assim, para descrever apenas a energia de excitação de uma molécula em meio, TD-DFT é uma boa alternativa, pois apresenta resultados próximos aos valores obtidos experimentalmente e seu baixo custo computacional permite a inclusão de algumas moléculas explícitas de solvente nos cálculos. Porém, para uma descrição satisfatória do deslocamento em diferentes solventes, é preferível o uso de métodos que incluam a correlação eletrônica de forma sistemática.

Quando calculamos as energias de transição para a 5FU isolada, observamos que a transição de mais baixa energia tem caráter $n-\pi^{*}$ e uma força de oscilador quase nula enquanto a segunda é uma transição $\pi-\pi^{*}$ muito intensa.

Em água, a transição $\pi-\pi^{*}$ tem sua energia diminuída (é deslocada para o vermelho) enquanto a transição $n-\pi^{*}$ tem sua energia aumentada (deslocamento para o azul), como é esperado. Mais que isso, o deslocamento é grande o suficiente não só para aproximá-las, mas para inverter as posições, fazendo com que a transição $\pi$ - $\pi *$ seja a de menor energia. Esse efeito foi observado em todos os níveis de cálculo realizados e em todas as aproximações por nós utilizadas.

Já para as transições em acetonitrila houve um impasse inicial: enquanto as aproximações contínua e explícita mostravam o mesmo comportamento apresentado em água, invertendo a posição das transições, a aproximação discreta, na maioria dos casos estudados, mantinha o ordem. Esse efeito corrobora resultados recentes de que transições $\pi$ - $\pi^{*}$ são mais sensíveis as interações não-eletrostáticas. Dessa forma, a aproximação discreta descreve bem as transições $n-\pi^{*}$ mas é insuficiente para a 
transição $\pi-\pi^{*}$. Parte do problema foi solucionada considerando a polarização iterativamente, como podemos observar com o método B3LYP, mas ela não foi suficiente em todos os casos. Para o método CIS(D), apenas a inclusão de moléculas explícitas foi capaz de elucidar a questão, mostrando que conforme aumentamos a quantidade de moléculas de solvente tratadas explicitamente, o valor da transição $n-\pi *$ flutua em torno de uma média enquanto a transição $\pi-\pi^{*}$ tem seu valor diminuído até se tornar a transição menos energética. Essa sensibilidade também é verdade para as transições em água, mas nesse caso a separação dos níveis é maior, fazendo com que a transição $n-\pi^{*}$ sempre seja mais energética.

O estudo do comportamento dessas transições é o primeiro passo para se entender a fotofísica e a dinâmica dos estados excitados.

Emissão e dinâmica do estado excitado são temas de enorme interesse atual. A grande motivação é biológica e vai desde a elaboração de sondas até a compreensão dos mecanismos fundamentais das bases nitrogenadas que compõem o DNA. Curiosamente as bases nitrogenadas, apesar da grande absorção, apresentam um baixo rendimento quântico. Os estudos atuais apontam que isso ocorre principalmente devido ao acoplamento de estados excitados próximos através de efeito pseudo-Jahn-Teller e a existência de interseções cônicas, que permitem decaimentos não-radioativos. Biologicamente isso é muito desejável, pois o tempo de vida do estado excitado diminui, passando a ser da ordem de poucas dezenas ou centenas de femtosegundos, reduzindo drasticamente a possibilidade de que reações fotoquímicas potencialmente perigosas ocorram.

Nossas perspectivas se abrem então para o estudo do efeito de solvente na dinâmica do estado excitado e na emissão de bases nitrogenadas e seus derivados, como a 5 FU.

Apesar de essas moléculas apresentarem sua plena fenomenologia em meio, a grande maioria dos estudos atuais é feita com moléculas isoladas. Isso advém do fato que um enorme esforço computacional é necessário para obtenção da geometria de uma molécula no estado excitado, pois geralmente são utilizados métodos multiconfiguracionais. A justificativa para tal aproximação é justamente o curto tempo de vida do estado excitado apresentado por essas moléculas que, em tese, seria escasso demais para que interações com o meio sejam significativas.

Os resultados advindos deste tratamento muitas vezes apresentam razoável concordância com valores experimentais. Observe, porém, que essa aproximação é 
limitante: quanto maior o tempo de vida do estado excitado, piores tendem a ser os resultados. Além disso, o caminho de reação pode ser bem diferente na presença de solvente.

A tentativa inicial de resolver esses problemas é a utilização de modelos contínuos, como PCM, devido a sua baixa exigência computacional. Entretanto, como vimos, esses modelos se mostram insuficientes para a descrição correta de sistemas moleculares onde a interação dominante não é eletrostática.

Para uma melhor descrição, a microsolvatação dos resultados obtidos em fase gasosa tem se tornado uma opção crescente. Contudo, novamente surgem dificuldades: como devem ser distribuídas essas poucas moléculas de solvente em torno do soluto? O caminho de reação calculado desta maneira é o mesmo que seria obtido caso o solvente fosse incluído desde o início? A discrepância e/ou inconclusibilidade de alguns resultados mostra que essa aproximação ainda não é o suficiente.

Nós acreditamos que o tratamento híbrido sequencial pode ser uma das chaves para a inclusão de efeito de solvente no estado excitado de maneira concisa e eficiente. Esse será o foco de um projeto de Doutorado que iniciaremos em breve. 


\section{Referências Bibliográficas}

[1] "GLOBOCAN project", http://globocan.iarc.fr/.

[2] D.B. Longley, D.P. Harkin, \& P.G. Johnston, "5-Fluorouracil: Mechanisms of Action and Clinical Strategies", Nature Reviews Cancer, vol. 3, May. 2003, pp. 330-338.

[3] G. Alagona, C. Ghio, \& S. Monti, "5-Fluorouracil Dimers in Aqueous Solution: Molecular Dynamics in Water and Continuum Solvation", International Journal of Quantum Chemistry, vol. 88, 2002, pp. 133-146.

[4] T. Gustavsson, E. Lazzarotto, D. Markovitsi, G. Scalmani, M.J. Frisch, V. Barone, \& R. Improta, "Singlet Excited-State Behavior of Uracil and Thymine in Aqueous Solution: A Combined Experimental and Computational Study of 11 Uracil Derivatives", Journal of the American Chemical Society, vol. 128, 2006, pp. 607-619.

[5] J.M. Olsen, K. Aidas, K.V. Mikkelsen, \& J. Kongsted, "Solvatochromic Shifts in Uracil: A Combined MD-QM/MM Study", Journal of Chemical Theory and Computation, vol. 6, 2009, pp. 249-256.

[6] O. Tapia \& O. Goscinski, "Self-Consistent reaction field theory of solvent effects", Molecular Physics, vol. 29, 1975, pp. 1653-1661.

[7] L. Onsager, "Electric Moments of Molecules in Liquids", Journal of the American Chemical Society, vol. 58, 1936, p. 1486.

[8] J.G. Kirkwood \& F.H. Westheimer, "The Electrostatic Influence of Substituents on the Dissociation Constants of Organic Acids.", Journal of Chemical Physics, vol. 6, 1938, p. 506. 
[9] J. Tomasi, "Thirty years of continuum solvation chemistry: a review, and prospects for the near future", Theoretical Chemistry Accounts, vol. 112, 2004, pp. 184-203.

[10] S. Canuto \& K. Coutinho, "From Hydrogen Bond to Bulk: Solvation Analysis of the $\mathrm{n}-\pi^{*}$ Transition of Formaldehyde in Water", International Journal of Quantum Chemistry, vol. 77, 2000, pp. 192-198.

[11] K. Coutinho \& S. Canuto, "Solvent effects in emission spectroscopy: A Monte Carlo quantum mechanics study of the $n-\pi^{*}$ shift of formaldehyde in water", Journal of Chemical Physics, vol. 113, 2000, pp. 9132-9139.

[12] W.R. Rocha, K.J.D. Almeida, K. Coutinho, \& S. Canuto, "The electronic spectrum of $\mathrm{N}$-methylacetamide in aqueous solution: a sequential Monte Carlo/quantum mechanical study", Chemical Physics Letters, vol. 345, Sep. 2001, pp. 171-178.

[13] K. Coutinho, N. Saavedra, A. Serrano, \& S. Canuto, "A Monte Carlo-quantum mechanics study of the spectroscopic properties of molecules in solution", Journal of Molecular Structure (Theochem), vol. 539, Apr. 2001, pp. 171-179.

[14] K.J. de Almeida, K. Coutinho, W.B. de Almeida, W.R. Rocha, \& S. Canuto, “A Monte Carlo-quantum mechanical study of the solvatochromism of pyrimidine in water and in carbon tetrachloride", Physical Chemistry Chemical Physics, vol. 3, 2001, pp. 1583-1587.

[15] R. Rivelino, K. Coutinho, \& S. Canuto, “A Monte Carlo-Quantum Mechanics Study of the Solvent-Induced Spectral Shift and the Specific Role of Hydrogen Bonds in the Conformational Equilibrium of Furfural in Water", The Journal of Physical Chemistry B, vol. 106, Nov. 2002, pp. 12317-12322.

[16] W.R. Rocha, V.M. Martins, K. Coutinho, \& S. Canuto, "Solvent effects on the electronic absorption spectrum of formamide studied by a sequential Monte Carlo/quantum mechanical approach”, Theoretical Chemistry Accounts, vol. 108, Jul. 2002, pp. 31-37.

[17] H.C. Georg, K. Coutinho, \& S. Canuto, "Solvent effects on the UV-visible absorption spectrum of benzophenone in water: a combined Monte Carlo quantum mechanics study including solute polarization", The Journal of Chemical Physics, vol. 126, Jan. 2007, p. 034507. 
[18] S. Canuto (ed.), Solvation Effects on Molecules and Biomolecules: Computational Methods and Applications, Springer, 2008.

[19] V. Manzoni, "Estudo das Propriedades Espectroscópicas de Moléculas Orgânicas em Soluçãoo Utilizando a Combinação do Modelo Contínuo PCM e o Método Sequencial QM/MM", Tese de Doutorado - UFAL, 2010.

[20] D.C. Harris \& M.D. Bertolucci, Symetry and Spectroscopy: An Introduction to Vibrational and Electronic Spectrocopy, Dover Publications, 1989.

[21] M. Cossi, G. Scalmani, N. Rega, \& V. Barone, "New developments in the polarizable continuum model for quantum mechanical and classical calculations on molecules in solution", The Journal of Chemical Physics, vol. 117, 2002, p. 43.

[22] K. Coutinho \& S. Canuto, "DICE, A Monte Carlo program for molecular liquid simulation", USP, 2003.

[23] “ISAACS”, http://isaacs.sourceforge.net/phys/pbc.html.

[24] M.P. Allen \& D.J. Tildesley, Computer Simulation of Liquids, Oxford University Press, 1987.

[25] H.J.C. Berendsen, J.P.M. Postma, W.F.V. Gunsteren, \& J. Hermans, "Interaction Models for Water in Relation To Protein Hydration", Intermolecular Forces, B. Pullman, ed., D. Reidel Publishing Company, 1981, pp. 331-338.

[26] W.L. Jorgensen, J. Chandrasekhar, J.D. Madura, R.W. Impey, \& M.L. Klein, "Comparison of simple potential functions for simulating liquid water", Journal of Chemical Physics, vol. 79, 1983, pp. 926-935.

[27] M.W. Mahoney \& W.L. Jorgensen, "A five-site model for liquid water and the reproduction of the density anomaly by rigid, nonpolarizable potential functions", The Journal of Chemical Physics, vol. 112, 2000, pp. 8910-8922.

[28] K. Coutinho, "Modelo Discreto de Solvente. Solvatocromismo no Espectro de Absorção Molecular", Tese de Doutorado - USP, 1997.

[29] J. Pranata, S.G. Wierschke, \& W.L. Jorgensen, "OPLS Potential Functions for Nucleotide Bases. Relative Association Constants of Hydrogen-Bonded Base Pairs in Chloroform", Journal of the American Chemical Society, vol. 113, Apr. 1991, pp. 2810-2819. 
[30] W.L. Jorgensen, D.S. Maxwell, \& J. Tirado-Rives, "Development and Testing of the OPLS All-Atom Force Field on Conformational Energetics and Properties of Organic Liquids", Journal of the American Chemical Society, vol. 118, 1990, pp. $112251-12$.

[31] H.C. Georg, "Efeitos do Meio em Propriedades Conformacionais e Eletrônicas de Moléculas", Tese de Doutorado - USP, 2006.

[32] S. Canuto, K. Coutinho, \& D. Trzesniak, "New Developments in Monte Carlo/ Quantum Mechanics Methodology . The Solvatochromism of Beta-Carotene in Different Solvents", Advances in Quantum Chemistry, vol. 41, 2002, p. 161.

[33] C. Chatfield, The Analysis of Time Series. An Introduction, London: Chapman \& Hall, 1984.

[34] H.C. Georg, K. Coutinho, \& S. Canuto, "Converged electronic polarization of acetone in liquid water and the role in the $n-\pi^{*}$ transition", Chemical Physics Letters, vol. 429, Sep. 2006, pp. 119-123.

[35] K. Coutinho, H.C. Georg, T.L. Fonseca, V. Ludwig, \& S. Canuto, "An efficient statistically converged average configuration for solvent effects", Chemical Physics Letters, vol. 437, 2007, pp. 148-152.

[36] M.L. Sanchez, M.A. Aguilar, \& F.J. Olivares del Valle, "Study of Solvent Effects by Means of Averaged Solvent Electrostatic Dynamics Data", Journal of Computational Chemistry, vol. 18, 1997, pp. 313-322.

[37] R.M. Gester, H.C. Georg, S. Canuto, M.C. Caputo, \& P.F. Provasi, "NMR Chemical Shielding \& Spin-Spin Coupling Constants of Liquid $\mathrm{NH}_{3}$. A Systematic Investigation using the Sequential QM/MM Method", The Journal of Physical Chemistry A, vol. 113, 2009, pp. 14936-14942.

[38] H. Hirao, Y. Nagae, \& M. Nagaoka, "Transition-state optimization by the free energy gradient method: Application to aqueous-phase Menshutkin reaction between ammonia and methyl chloride", Chemical Physics Letters, vol. 348, Nov. 2001, pp. 350-356.

[39] N. Okuyama-Yoshida, K. Kataoka, M. Nagaoka, \& T. Yamabe, "Structure optimization via free energy gradient method: Application to glycine zwitterion in aqueous solution", The Journal of Chemical Physics, vol. 113, 2000, p. 3519. 
[40] N. Okuyama-Yoshida, M. Nagaoka, \& T. Yamabe, “Transition-State Optimization on Free Energy Surface: Toward Solution Chemical Reaction Ergodography", International Journal of Quantum Chemistry, vol. 70, 1998, pp. 95-103.

[41] H.C. Georg \& S. Canuto, "Diceplayer”, USP, 2008.

[42] A. Szabo \& N.S. Ostlund, Modern Quantum Chemistry, New York: Dover Publications, 1982.

[43] J.D.M. Vianna, A. Fazzio, \& S. Canuto, Teoria Quântica de Moléculas e Sólidos, São Paulo: Editora Livraria da Física, 2004.

[44] N.H. Morgon \& K. Coutinho, eds., Métodos de Química Teórica e Modelagem Molecular, São Paulo: Editora Livraria da Física, 2007.

[45] M. Born \& K. Huang, Dynamical Theory of Cristal Lattice (Apêndice VII), New York: Oxford University Press, 1954.

[46] R.E. Stratmann, G.E. Scuseria, \& M.J. Frisch, “An efficient implementation of time-dependent density-functional theory for the calculation of excitation energies of large molecules", Journal of Chemical Physics, vol. 109, 1998, pp. $8218-8224$.

[47] D.C. Young, Computational Chemistry, New York: John Wiley \& Sons, 2001.

[48] P.-O. Löwdin, "Quantum Theory of Many-Particle Systems. III. Extension of the Hartree-Fock Scheme to Include Degenerate Systems and Correlation Effects", Physical Review, vol. 97, 1955, pp. 1509-1520.

[49] T. Helgaker, P. Jørgensen, \& J. Olsen, Molecular Electronic Structure Theory, John Wiley \& Sons, 2000.

[50] M. Head-Gordon, R.J. Rico, M. Oumi, \& T.J. Lee, "A doubles correction to electronic excited states from configuration interaction in the space of single substitutions", Chemical Physics Letters, vol. 219, 1994, pp. 21-29.

[51] D.J. Griffiths, Introduction to Quantum Mechanics, London: Pearson Prentice Hall, 2005.

[52] J.J. Sakurai, Modern Quantum Mechanics, Massachusetts: Addison-Wesley Publishing Company, 1994. 
[53] M.J. Frisch, G.W. Trucks, H.B. Schlegel, G.E. Scuseria, M.A. Robb, J.R. Cheeseman, J.A. Montgomery Jr., T. Vreven, K.N. Kudin, J.C. Burant, J.M. Millam, S.S. Iyengar, J. Tomasi, V. Barone, B. Mennucci, M. Cossi, G. Scalmani, N. Rega, G.A. Petersson, H. Nakatsuji, M. Hada, M. Ehara, K. Toyota, R. Fukuda, J. Hasegawa, M. Ishida, T. Nakajima, Y. Honda, O. Kitao, H. Nakai, M. Klene, X. Li, J.E. Knox, H.P. Hratchian, J.B. Cross, V. Bakken, C. Adamo, J. Jaramillo, R. Gomperts, R.E. Stratmann, O. Yazyev, A.J. Austin, R. Cammi, C. Pomelli, J.W. Ochterski, P.Y. Ayala, K. Morokuma, G.A. Voth, P. Salvador, J.J. Dannenberg, V.G. Zakrzewski, S. Dapprich, A.D. Daniels, M.C. Strain, O. Farkas, D.K. Malick, A.D. Rabuck, K. Raghavachari, J.B. Foresman, J.V. Ortiz, Q. Cui, A.G. Baboul, S. Clifford, J. Cioslowski, B.B. Stefanov, G. Liu, A. Liashenko, P. Piskorz, I. Komaromi, R.L. Martin, D.J. Fox, T. Keith, M.A. AlLaham, C.Y. Peng, A. Nanayakkara, M. Challacombe, P.M.W. Gill, B. Johnson, W. Chen, M.W. Wong, C. Gonzalez, \& J.A. Pople, "Gaussian 03”, 2004.

[54] O. Christiansen, J. Olsen, P. Jørgensen, H. Koch, \& P.-Å. Malmqvist, "On the inherent divergence in the Møller-Plesset series. The neon atom - a test case", Chemical Physics Letters, vol. 261, 1996, pp. 369-378.

[55] R.G. Parr \& W. Yang, Density-Functional Theory of Atoms and Molecules, New York: Oxford Science Publications, 1989.

[56] M.A.L. Marques \& E.K.U. Gross, "Time-dependent density functional theory", Annual Review of Physical Chemistry, vol. 55, 2004, pp. 427-455.

[57] N.H. Morgon \& R. Custodio, "Teoria do Funcional de Densidade", Química Nova, vol. 18, 1995, pp. 44-55.

[58] A.D. Becke, "Density-Functional exchange-energy approximation with correct asymptotic behavior", Physical Review A, vol. 38, 1988, pp. 3098-3100.

[59] C. Lee, W. Yang, \& R.G. Parr, "Development of the Colle-Salvetti correlationenergy formula into a functional of the electron density", Physical Review B, vol. 37, 1988, pp. 785-789.

[60] J.P. Perdew, K. Burke, \& M. Ernzerhof, "Generalized Gradient Approximation Made Simple”, Physical Review Letters, vol. 77, Oct. 1996, pp. 3865-3868.

[61] A.D. Becke, "A new mixing of Hartree-Fock and local density-functional theories", Journal of Chemical Physics, vol. 98, 1993, pp. 1372-1377. 
[62] S.H. Vosko, L. Wilk, \& M. Nusai, "Accurate spin-dependent electron liquid correlation energies for local spin density calculations: a critical analysis", Canadian Journal of Physics, vol. 58, 1980, pp. 1200-1211.

[63] W.-M. Hoe, A.J. Cohen \& N.C. Handy, "Assessment of a new local exchange functional OPTX”, Chemical Physics Letters, vol. 341, Jun. 2001, pp. 319-328.

[64] N.C. Handy \& A.J. Cohen, "Left-Right Correlation Energy", Molecular Physics, vol. 99, 2001, pp. 403-412.

[65] C. Adamo \& V. Barone, "Toward reliable density functional methods without adjustable parameters: The PBE0 model", The Journal of Chemical Physics, vol. 110, 1999, pp. 6158-6170.

[66] A.D. Becke, "A new mixing of Hartree-Fock and local density-functional theories", The Journal of Chemical Physics, vol. 98, 1993, pp. 1372-1377.

[67] F. Jensen, Introduction to Computational Chemistry, Chichester, UK: John Wiley \& Sons, 1999.

[68] M.C. Zerner, "ZINDO, A semi-empirical program package", University of Florida, 2000.

[69] J.E. Ridley \& M.C. Zerner, "An intermediate neglect of differential overlap technique for spectroscopy: Pyrrole and the azines", Theoretica Chimica Acta, vol. 32, 1973, pp. 111-134.

[70] U.C. Singh \& P.A. Kollman, "An approach to computing electrostatic charges for molecules", Journal of Computational Chemistry, vol. 5, 1984, pp. 129-145.

[71] L.E. Chirlian \& M.M. Francl, "Atomic charges derived from electrostatic potentials: A detailed study", Journal of Computational Chemistry, vol. 8, 1987, pp. 894-905.

[72] F. Martin \& H. Zipse, "Charge Distribution in the Water Molecule - A Comparison of Methods.”, Journal of Computational Chemistry, vol. 26, Jan. 2005, pp. 97-105.

[73] “LMU München”, http://www.cup.uni-muenchen.de/ch/compchem/pop/chelpg.html

[74] "LMU München”, http://www.cup.uni-muenchen.de/ch/compchem/pop/mk.html 
[75] L. Chinsky, A. Laigle, W.L. Peticolas, \& P.-Y. Turpin, "Excited state geometry of uracil from the resonant Raman overtone spectrum using a Kramers-Kronig technique", Journal of Chemical Physics, vol. 76, 1982.

[76] M. Fujii, T. Tamura, N. Mikami, \& M. Ito, "Electronic Spectra of Uracil in a Supersonic Jet", Chemical Physics Letters, vol. 126, 1986, pp. 583-587.

[77] N. Markova, V. Enchev, \& I. Timtcheva, "Oxo-Hydroxy Tautomerism of 5Fluorouracil: Water-Assisted Proton Transfer", Journal of Physical Chemistry A, vol. 109, 2005, pp. 1981-1988.

[78] R.D. Brown, P.D. Godfrey, D. McNaughton, \& A.P. Pierlot, "Microwave Spectrum of Uracil”, Journal of the American Chemical Society, vol. 110, 1988, pp. 2329-2330.

[79] V. Ludwig, K. Coutinho, \& S. Canuto, "A Monte Carlo-quantum mechanics study of the lowest $\mathrm{n}-\pi^{*}$ and $\pi-\pi^{*}$ states of uracil in water", Physical Chemistry Chemical Physics, vol. 9, 2007, pp. 4907-4912.

[80] V. Manzoni, M.L. Lyra, R.M. Gester, K. Coutinho, \& S. Canuto, "Study of the optical and magnetic properties of pyrimidine in water combining PCM and QM/MM methodologies”, Physical Chemistry Chemical Physics, vol. 12, 2010, pp. 14023-14033.

[81] V. Ludwig, Z.M. da Costa, M.S. do Amaral, A.C. Borin, S. Canuto, \& L. Serrano-Andrés, "Photophysics and photostability of adenine in aqueous solution: A theoretical study", Chemical Physics Letters, vol. 492, 2010, pp. 164169.

[82] B. Guillat, "A reappraisal of what we have learnt during three decades of computer simulations on water", Journal of Molecular Liquids, vol. 101, 2002, pp. 219-260.

[83] H.J. Böhm \& I.R. McDonald, “An effective pair potencial for liquid acetonitrile", Molecular Physics, vol. 49, 1983, pp. 347-360.

[84] T. Gustavsson, N. Sarkar, E. Lazzarotto, D. Markovitsi, V. Barone, \& R. Improta, "Solvent Effect on the Singlet Excited-state Dynamics of 5-Fluorouracil in Acetonitrile as Compared with Water", Journal of Physical Chemistry B, vol. 110, 2006, pp. 12843-12847. 
[85] M.V.A. Damasceno, "Estudo Teórico dos Efeitos de Solvente no Espectro Eletrônico de Absorção da Molécula Óxido Mesitil.”, 2009.

[86] C.A. Sprecher \& W.C. Johnson, "Circular Dichroism of the Nucleic Acid Monomers", Biopolymers, vol. 16, 1977, pp. 2243-2264.

[87] F. Santoro, V. Barone, T. Gustavsson, \& R. Improta, "Solvent Effect on the Singlet Excited-State Lifetimes of Nucleic Acid Bases: A Computational Study of 5-Fluorouracil and Uracil in Acetonitrile and Water", Journal of the American Chemical Society, vol. 128, 2006, pp. 16312-16322.

[88] E.C. Lim, "Proximity Effect in Molecular Photophysics : Dynamical Consequences of Pseudo-Jahn-Teller Interaction", Journal of Physical Chemistry, vol. 90, 1986, pp. 6770-6777.

[89] A.L. Sobolewski \& W. Domcke, "Molecular mechanisms of the photostability of life", Physical Chemistry Chemical Physics, vol. 12, May. 2010, pp. 4897-8.

[90] K. Aidas, A. Møgelhoj, E.J.K. Nilsson, M.S. Johnson, K.V. Mikkelsen, O. Christiansen, P. Söderhjelm, \& J. Kongsted, "On the performance of quantum chemical methods to predict solvatochromic effects: the case of acrolein in aqueous solution.", Journal of Chemical Physics, vol. 128, May. 2008, p. 194503. 